University of Tennessee Health Science Center

UTHSC Digital Commons

\title{
$5-2011$
}

\section{Temporal and Aerodynamic Aspects of Velopharyngeal Coarticulation: Effects of Age, Gender and Vowel Height}

Fadwa Khwaileh

University of Tennessee Health Science Center

Follow this and additional works at: https://dc.uthsc.edu/dissertations

Part of the Speech and Hearing Science Commons, and the Speech Pathology and Audiology Commons

\section{Recommended Citation}

Khwaileh, Fadwa, "Temporal and Aerodynamic Aspects of Velopharyngeal Coarticulation: Effects of Age, Gender and Vowel Height" (2011). Theses and Dissertations (ETD). Paper 132. http://dx.doi.org/ 10.21007/etd.cghs.2011.0162.

This Dissertation is brought to you for free and open access by the College of Graduate Health Sciences at UTHSC Digital Commons. It has been accepted for inclusion in Theses and Dissertations (ETD) by an authorized administrator of UTHSC Digital Commons. For more information, please contact jwelch30@uthsc.edu. 


\title{
Temporal and Aerodynamic Aspects of Velopharyngeal Coarticulation: Effects of Age, Gender and Vowel Height
}

\begin{abstract}
Previous studies on the normal patterns of velopharyngeal coarticulation did not provide a multidimensional description of the phenomenon. The primary objective of this study was to determine the effects of age, gender and vowel height on the temporal and aerodynamic aspects of nasal airflow segments related to velar coarticulation in the normal speech of children and adults. A secondary objective was to determine the within speaker variability of the segments.

Speakers consisted of 20 children between the ages of 5 and 7 years, 20 children between 9 and 11 years and 20 adult speakers 18 years or older. Nasal and oral air flows were collected from the participants using partitioned oro-nasal masks during the production of vowel-nasal-vowel sequences (VNV) including /ini/ and /ana/ embedded in two carrier phrases. Temporal and aerodynamic measurements were obtained for anticipatory and carryover nasal airflow for (VNV) sequences including absolute (in seconds) and proportional duration, as well as the volume of nasal airflow (in milliliters) and the ratio of nasal to oral-plus-nasal airflow volume.
\end{abstract}

A mixed design $3 \times 2 \times 2 \times 2$ ANOVA procedure was used to determine the effects of age group, gender, vowel height and production level (type of carrier phrase) on temporal and aerodynamic aspects of anticipatory and carryover nasal airflow. In addition, coefficient of variation (CV) was computed for both temporal and aerodynamic measures as an index to speaker's variability. Group Analysis of Variance $3 \times 2$ ANOVA procedures were used to determine the effect of age group, gender, or both on within speaker variability for all temporal and aerodynamic measurements.

The results of the analysis suggest a significant age effect $(p<.001)$ on both temporal aspects and on the absolute volume ( $\mathrm{ml}$ ) of anticipatory nasal airflow. Duration, absolutely (sec) and proportionally, and volume of nasal airflow $(\mathrm{ml})$ decreased with increasing age. No significant age effect was found for carryover nasal airflow. However, a significant interaction between gender and vowel height was found. Female speakers produced longer duration than male speakers on high vowel contexts, and women produced greater volume of nasal airflow $(\mathrm{ml})$ and greater ratio of nasal to oral-plus-nasal airflow. A significant production level effect was also found. Generally, all speakers exhibited reduced absolute $(\mathrm{sec})$ and proportional duration as well as reduced nasal airflow volume $(\mathrm{ml})$ when the carrier phrase contained 'say' preceding the VNV sequence compared to the one without 'say'.

Results of the CVs analysis showed main effect of age as well as age and gender interaction. Results indicate a reduction on variability with increasing age. Older boys and men exhibited greater variability than older girls and women particularly on high vowel context.

Results of the study indicate that children and adults produce distinct patterns of temporal and aerodynamic aspect of anticipatory nasal airflow. Findings were consistent with previous studies that reduction in duration of speech segment and reduction in variability is a general pattern of speech development. It is also suggested that subtle gender differences in oral-pharyngeal anatomy as well as vowel-specific production patterns may explain the gender difference on high vowels. Results of the study were discussed in the light of Gestural Phonology view of speech development and velar movement. Clinical implications were suggested for the diagnosis and treatment of patients with velopharyngeal dysfunction.

\section{Document Type}

Dissertation 


\section{Degree Name}

Doctor of Philosophy (PhD)

\section{Program}

Audiology and Speech Pathology

\section{Research Advisor}

Molly Erickson, Ph.D.

\section{Keywords}

velopharyngeal coarticulation, speech aerodynamics, development of speech production, cleft palate speech

\section{Subject Categories}

Communication Sciences and Disorders | Medicine and Health Sciences | Speech and Hearing Science | Speech Pathology and Audiology 
TEMPORAL AND AERODYNAMIC ASPECTS OF VELOPHARYNGEAL COARTICULATION: EFFECTS OF AGE, GENDER AND VOWEL HEIGHT

\author{
A Dissertation \\ Presented for \\ The Graduate Studies Council \\ The University of Tennessee \\ Health Science Center
}

\author{
In Partial Fulfillment \\ Of the Requirements for the Degree \\ Doctor of Philosophy \\ From The University of Tennessee
}

By

Fadwa A. Khwaileh

May 2011 
Copyright (C) 2011 by Fadwa Ahmad Khwaileh. All rights reserved. 


\section{DEDICATION}

To my parents, Ahmad and Tamam Khwaileh, my husband, Ali Al-Nadi, and my two sons, Jawad and Abraham. 


\section{ACKNOWLEDGEMENTS}

I wish to express my gratitude to my advisor, Dr. Molly Erickson for her diligence, assistance, patience and endless support. I am so grateful to her. I also thank my committee members, Dr. David Zajac, Dr.Tim Saltuklaruglu, and Dr. Deborah von Hapsburg for their assistance, valuable comments and willingness to serve. Especially, I would like to extend my deep gratitude to Dr. David Zajac for his help with the study design as well as equipment necessary to conduct data collection for the study. Without his help, this work would have never seen the light. In addition, I like to thank those who helped me during the whole course of my program particularly Dr. Ilsa Schwarz, the previous head of the department of Audiology and Speech Pathology, Dr. Ashley Harkrider, the current head of the department, and all faculty members and all my colleagues. Their kind support is invaluable. Finally, I would like to thank my husband, Ali, for his continuing support for me throughout my doctoral program. His patience and dedication for his doctoral study was a source of inspiration for me. I also owe my two beautiful sons, Jawad and Abraham, for the time that I had to spend away from them. 


\begin{abstract}
Previous studies on the normal patterns of velopharyngeal coarticulation did not provide a multidimensional description of the phenomenon. The primary objective of this study was to determine the effects of age, gender and vowel height on the temporal and aerodynamic aspects of nasal airflow segments related to velar coarticulation in the normal speech of children and adults. A secondary objective was to determine the within speaker variability of the segments.
\end{abstract}

Speakers consisted of 20 children between the ages of 5 and 7 years, 20 children between 9 and 11 years and 20 adult speakers 18 years or older. Nasal and oral air flows were collected from the participants using partitioned oro-nasal masks during the production of vowel-nasal-vowel sequences (VNV) including /ini/ and /ana/ embedded in two carrier phrases. Temporal and aerodynamic measurements were obtained for anticipatory and carryover nasal airflow for (VNV) sequences including absolute (in seconds) and proportional duration, as well as the volume of nasal airflow (in milliliters) and the ratio of nasal to oral-plus-nasal airflow volume.

A mixed design $3 \times 2 \times 2 \times 2$ ANOVA procedure was used to determine the effects of age group, gender, vowel height and production level (type of carrier phrase) on temporal and aerodynamic aspects of anticipatory and carryover nasal airflow. In addition, coefficient of variation (CV) was computed for both temporal and aerodynamic measures as an index to speaker's variability. Group Analysis of Variance 3 x 2 ANOVA procedures were used to determine the effect of age group, gender, or both on within speaker variability for all temporal and aerodynamic measurements.

The results of the analysis suggest a significant age effect $(p<.001)$ on both temporal aspects and on the absolute volume $(\mathrm{ml})$ of anticipatory nasal airflow. Duration, absolutely (sec) and proportionally, and volume of nasal airflow (ml) decreased with increasing age. No significant age effect was found for carryover nasal airflow. However, a significant interaction between gender and vowel height was found. Female speakers produced longer duration than male speakers on high vowel contexts, and women produced greater volume of nasal airflow $(\mathrm{ml})$ and greater ratio of nasal to oral-plus-nasal airflow. A significant production level effect was also found. Generally, all speakers exhibited reduced absolute (sec) and proportional duration as well as reduced nasal airflow volume $(\mathrm{ml})$ when the carrier phrase contained 'say' preceding the VNV sequence compared to the one without 'say'.

Results of the CVs analysis showed main effect of age as well as age and gender interaction. Results indicate a reduction on variability with increasing age. Older boys and men exhibited greater variability than older girls and women particularly on high vowel context.

Results of the study indicate that children and adults produce distinct patterns of temporal and aerodynamic aspect of anticipatory nasal airflow. Findings were consistent 
with previous studies that reduction in duration of speech segment and reduction in variability is a general pattern of speech development. It is also suggested that subtle gender differences in oral-pharyngeal anatomy as well as vowel-specific production patterns may explain the gender difference on high vowels. Results of the study were discussed in the light of Gestural Phonology view of speech development and velar movement. Clinical implications were suggested for the diagnosis and treatment of patients with velopharyngeal dysfunction. 


\section{TABLE OF CONTENTS}

CHAPTER 1. INTRODUCTION ....................................................................................

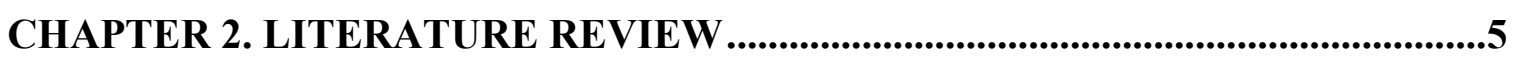

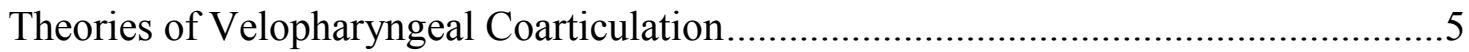

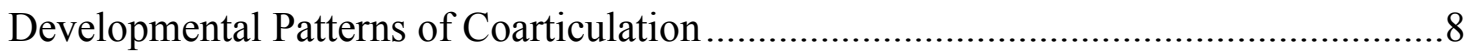

Velopharyngeal Function and Gender Differences ...................................................12

Velopharyngeal Coarticulation and Vowel Height........................................................14

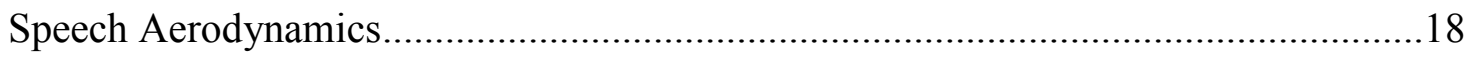

Statement of the Problem.........................................................................................20

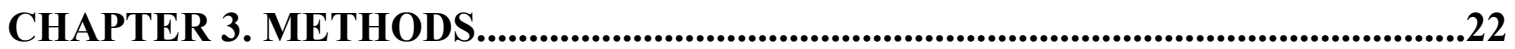

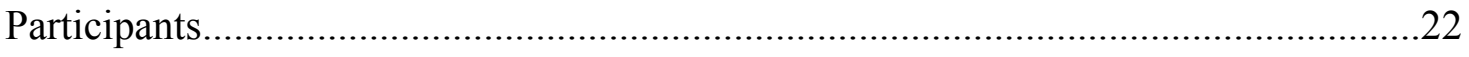

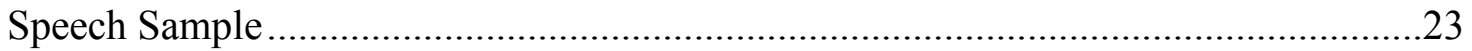

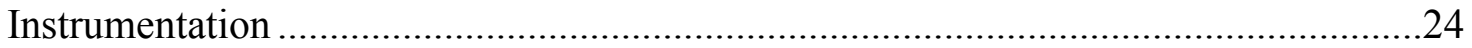

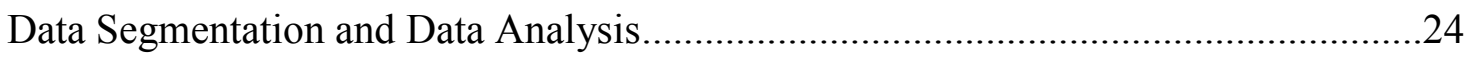

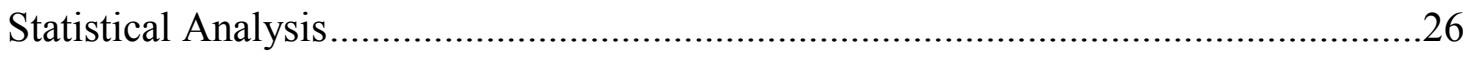

CHAPTER 4. RESULTS......................................................................................................27

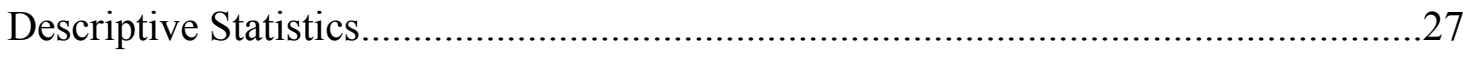

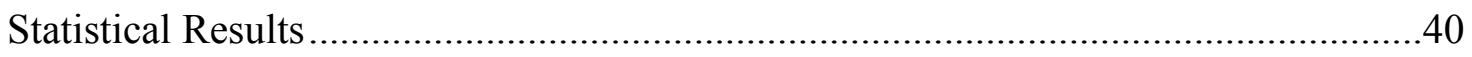

Temporal Measurements ....................................................................................... 40

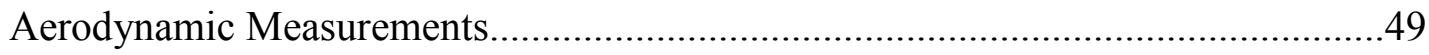

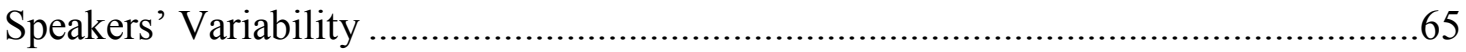

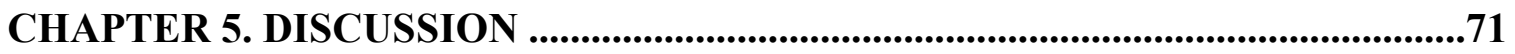

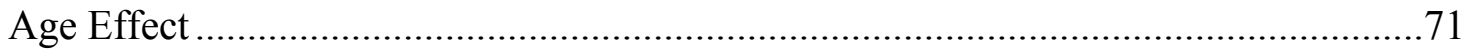

Gender and Vowel Height Effects .........................................................................74

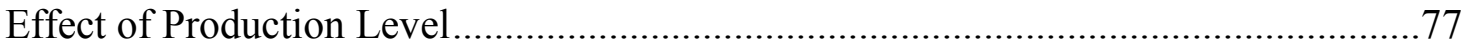


Speakers' Variability

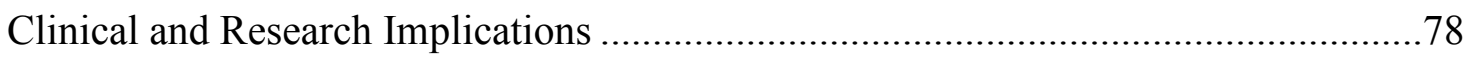

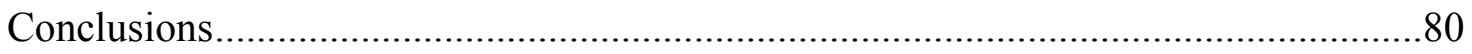

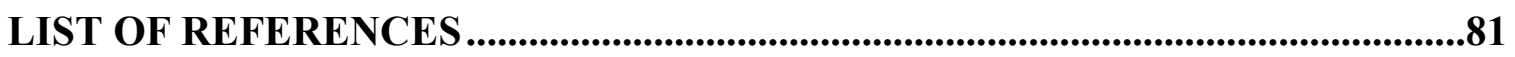

APPENDIX A. CONSENT FORM ....................................................................................90

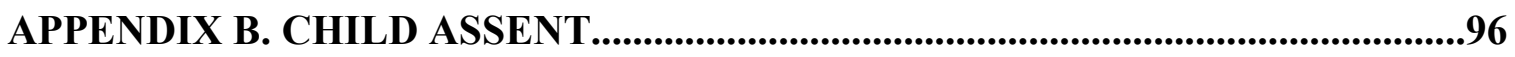

APPENDIX C. SUBJECT BACKGROUND FORM .......................................................97

APPENDIX D. LANGUAGE ITEMS ..............................................................................99

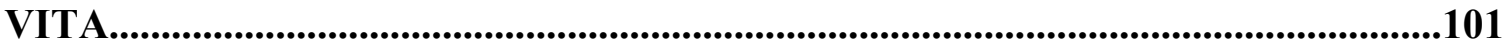




\section{LIST OF TABLES}

Table 1. Age (years;months) and gender distribution of the speakers.

Table 2. Descriptive statistics for the absolute duration of anticipatory nasal airflow in seconds as a function of age group, gender, and vowel height and production level.

Table 3. Descriptive statistics for the absolute duration of carryover nasal airflow in seconds as a function of age group, gender, vowel height and production level.

Table 4. Descriptive statistics for the proportional duration of anticipatory nasal airflow as a function of age group, gender, vowel height and production level.

Table 5. Descriptive statistics for the proportional duration of carryover nasal airflow as a function of age group, gender, vowel height and production level.

Table 6. Descriptive statistics for the absolute volume of anticipatory nasal airflow in milliliters as a function of age group, gender, vowel height and production level.

Table 7. Descriptive statistics for the absolute volume of carryover nasal airflow in milliliters as a function of age group, gender, vowel height and production level.

Table 8. Descriptive statistics for the ratio of nasal to oral-plus-nasal airflow volume related to anticipatory nasal flow segment as a function of age, gender, vowel type and production level.

Table 9. Descriptive statistics for the ratio of nasal to oral-plus-nasal airflow volume related to carryover nasal flow segment as a function of age, gender, vowel type and production level.

Table 10. Results of $2 \times 2 \times 2 \times 3$ ANOVA for the absolute duration of anticipatory nasal airflow.

Table 11. Results of $2 \times 2 \times 2 \times 3$ ANOVA for the absolute duration of carryover nasal airflow. 
Table 12. Results of $2 \times 2 \times 2 \times 3$ ANOVA for the proportional duration of anticipatory nasal airflow.

Table 13. Results of $2 \times 2 \times 2 \times 3$ ANOVA for the proportional duration of carryover nasal airflow.

Table 14. Results of $2 \times 2 \times 2 \times 3$ ANOVA for the absolute volume (ml) of anticipatory nasal airflow.

Table 15. Results of $2 \times 2 \times 2 \times 3$ ANOVA for the absolute volume (ml) of carryover nasal airflow.

Table 16. Results of $2 \times 2 \times 2 \times 3$ ANOVA for the ratio of nasal to oral-plus-nasal airflow related to anticipatory nasal airflow.

Table 17. Results of $2 \times 2 \times 2 \times 3$ ANOVA for the ratio of nasal to oral-plus-nasal airflow related to carryover nasal airflow.

Table 18. CVs of the absolute duration of anticipatory and carryover nasal airflow as a function of age group and gender.

Table 19. CVs of the absolute volume of anticipatory and carryover nasal airflow as a function of age group and gender. 


\section{LIST OF FIGURES}

Figure 1. "Right angle" female and "acute" male velar configuration with broken lines showing the velum at rest and arrows showing direction of movement.

Figure 2. Oral and nasal air flow rates and articulatory positioning for the phrase /se nip/: V-H, velar height; V-P, velopharyngeal distance; and T-C tongue constriction.

Figure 3. Diagrammatic representation of the artificial model of the vocal apparatus used to calculate VP orifice size.

Figure 4. Example of nasal flow, oral flow and voice signal for an adult female production of /ini/.

Figure 5. Absolute duration (sec) of anticipatory nasal airflow during the production of /ana/ as a function of age group and gender of the speakers.

Figure 6. Absolute duration (sec) of anticipatory nasal airflow during the production of /ini/ as a function of age group and gender of the speakers.

Figure 7. Absolute duration (sec) of anticipatory nasal airflow as a function of age group and production level.

Figure 8. Absolute duration (sec) of carryover nasal airflow as a function of age group and vowel type.

Figure 9. Absolute duration (sec) of carryover nasal airflow as a function of age group and production level.

Figure 10. Proportional duration of anticipatory nasal airflow during the production of /ana/ as a function of age group and gender of the speakers.

Figure 11. Proportional duration of anticipatory nasal airflow during the production of /ini/ as a function of age group and gender of the speakers.

Figure 12. Proportional duration of carryover nasal airflow as a function of vowel type and age group of the speakers. 
Figure 13. Proportional duration of carryover nasal airflow as a function of vowel type and production level....................................................................54

Figure 14. Absolute volume (ml) of anticipatory nasal airflow as a function of age group and production level................................................................56

Figure 15. Absolute volume ( $\mathrm{ml})$ of anticipatory nasal airflow as a function of gender and production level..............................................................58

Figure 16. Absolute volume (ml) of carryover nasal flow as a function of vowel type and production level.................................................................60

Figure 17. Ratio of anticipatory nasal to oral-plus-nasal airflow as during the production of /ana/ as a function of age and gender of the speakers.

Figure 18. Ratio of anticipatory nasal to oral-plus-nasal airflow volume during the production of /ini/ as a function of age group and gender of the speakers.

Figure 19. Ratio of carryover nasal to oral-plus-nasal airflow during the production of "say /ini/ again" as a function of age and gender of the speakers............66

Figure 20. Ratio of carryover nasal to oral-plus-nasal airflow during the production of "/ini/ again" as a function of age group and gender of the speakers.......67 


\section{CHAPTER 1. INTRODUCTION}

As soon as technical tools were introduced to study speech production, speech became recognized as a continuum of overlapping articulatory movement (Kent \& Minifie, 1977). This gave rise to the concept of coarticulation which refers to the phenomenon in speech production where the articulatory and the acoustic properties of sounds are affected by other contiguous sounds. Nowadays, there is a general consensus that coarticulation is responsible for the lack of acoustic and articulatory invariants for speech sounds.

Coarticulatory effects are generally described according to the direction in which they occur. Forward or anticipatory coarticulation occurs when the acoustic and articulatory characteristics of a sound are affected by those of a subsequent sound. Benguerel \& Cowan (1974) provided an example of anticipatory lip protrusion in French. They showed that the lip protrusion for the second vowel in VCC ... CV sequence starts as early as the first consonant of a cluster of 4-6 consonants. They even observed the lip rounding gesture to begin, in some cases, during the unrounded vowel preceding the cluster. This observation of anticipatory coarticulation suggests an active neurological strategy in which the system of motor control has information about all of these segments beforehand (MacNeilage \& DeClerk, 1969; Daniloff \& Hammarberg, 1973).

Preservatory or carryover coarticulation occurs when an articulatory adjustment for a segment appears to carryover to a later one. For example, in the word 'boots', lip protrusion associated with the vowel $/ \mathrm{u} /$ is retained in the following segments $/ \mathrm{t} /$ and $/ \mathrm{s} /$ (Kent \& Minifie, 1977). Carryover coarticulation is widely believed to be inevitable and caused by mechano-inertial forces acting upon the articulators in motion (Turnbaugh, Hoffman, \& Daniloff, 1985; Sereno, Baum, Marean, \& Lieberman, 1987; Katz, Kripke, \& Tallal, 1991).

The study of the coarticulatory patterns of speech movements is fundamental to our knowledge of articulatory and acoustic properties of speech. In addition, the study of

the temporal and spatial aspects of coarticulation may provide valuable information about the size of the organizational units of speech production (Bell-Berti, Krakow, Gelfer \& Boyce, 1995). For these purposes, numerous studies have been undertaken to investigate the coarticulatory patterns of several speech sub-systems including lingual, labial and velopharyngeal.

The velopharyngeal port (VP) is a valve located between the oral and nasal portions of the supralaryngeal tract. The primary function of this valve is to control the degree of oral and nasal coupling for normal production of speech. When the VP valve is tightly closed, it allows for sufficient oral air pressure and airflow for the production of hypernasal free obstruents and oral vowels, and when it is open, air will flow through the nasal chamber resulting in the production of nasal consonants and nasalized vowels. Thus, effective control of the degree of oral-nasal coupling is important for the development of intelligible speech. 
Velopharyngeal coarticulation (VPC) refers to the influence of a nasal consonant onto the preceding segment(s) (i.e., anticipatory) or the following segment(s) (i.e., carryover) during continuous speech. Several articulatory studies employing different observation techniques have documented the existence of a contextual effect of the nasal sound on the adjacent vowels (e.g., Moll, 1962; Lubker, 1968; Ushijima \& Swashima, 1972; Kent, Carney \& Severeid, 1974). These studies detected a lower position of the velum during the production of a vowel before and after nasal consonants than for vowels near non-nasal consonants. Specifically, Kent et al. (1974) found that in vowel-nasal-oral consonant (VNC) sequences, lowering the velum began during the tongue movement toward the position of the vowel. This suggests that the velopharyngeal port is already open when the oral tract is constricted by the tongue for $/ \mathrm{n} /$ or lips for $/ \mathrm{m} /$. They also found that in nasal-vowel-oral consonant (NVC) sequences, velum elevation started during or after the constriction of the oral tract for the nasal consonant. This pattern of velar movement causes the vowels before and after the nasal consonant to be nasalized for a certain duration of time.

In addition, studies observed that the velum position is influenced by the tongue height in both oral and nasal contexts. In oral contexts, high vowels are produced with higher velum position and greater VP closure force than are low vowels (Bell-Berti, 1976; Kuehn \& Moon, 1998). In nasal contexts, high vowels are produced with a higher velum position and less VP opening than low vowels (Moll, 1962; Clumeck, 1976; AlBamerni, 1983). Therefore, the degree of nasality is not only related to the degree of oralnasal coupling but it is also highly dependent upon the oral configuration.

Aerodynamic data have attracted a considerable amount of interest in the study of nasalization for many reasons. First, it is a non-invasive technique that allows for the collection of a greater amount of data than other observation methods. Second, variation in pressure and flow patterns can allow inferences about articulatory positions associated with the production of various sounds. For instance, variation in nasal flow was found to be related to the degree of VP opening as well as the tongue position (Lubker \& Moll, 1965; Warren, Dalston, Trier \& Holder, 1985; Warren, Dalston \& Mayo, 1993).

In a clinical setting, understanding the extent of velar coarticulation is critical for distinguishing between normal and abnormal degrees of nasality. Such distinction is necessary if appropriate intervention decisions for velopharyngeal insufficiency (VPI) are to be made. Pressure-flow data have proven useful in the distinction between adequate and inadequate VP function. For instance, estimates of the size of the VP orifice during the production of /p/ in "hamper" have been suggested as a primary aerodynamic diagnostic procedure to describe the adequacy of the VP valve (Dalston \& Warren, 1986). However, temporal aspects of nasal flow events have been shown to more accurately describe varying degrees of hypernasality seen in patients with VPI (Warren, Dalston, Morr, Hairfield \& Smith, 1989; Warren, Dalston \& Mayo, 1993).

Consequently, numerous studies have investigated the temporal and aerodynamic aspects of the VP mechanism during speech production in non-cleft individuals (Zajac \& Mayo, 1996; Zajac, 1997, 2000; Leeper, Tissington \& Munhal, 1998; Zajac \& Hacket, 
2002). The impetus of these studies was to establish normative standards of pressure-flow characteristics that can be useful for the assessment of VP adequacy. However, these studies were only concerned with VP movement and timing patterns in the $/ \mathrm{mp} /$ sequence in "hamper". Studies involving speech samples that allow for the description of aerodynamic and temporal patterns of both anticipatory and carryover VPC are still sparse.

Several acoustic and kinematic studies have investigated the emerging speech patterns of children (e.g., Smith, 1978; Sharkey \& Folkins, 1985; Nittrouer, 1993; Smith, Goffman \& 1998). These studies concluded that children's speech is characterized by less stability, decreased rate of speech production and increased variability. As the child grows, these qualities gradually diminish reflecting the improvement occurring with neuromotor maturation.

Many studies have investigated age-related differences in the extent and degree of coarticulation (e.g., Repp, 1986; Sereno \& Lieberman, 1987; Hodge, 1989; Nittrouer, Studdert-Kennedy \& McGowan, 1989; Katz, Kripke, \& Tallal, 1991). These studies have demonstrated mixed results concerning whether children show greater, less or equal gestural overlap than adults. The conflicting results can be attributed to several factors including use of different measures, analysis of different articulatory subsystems, varied phonetic composition of syllables, and differences in the length and complexity of utterances (Nittrouer, 1993). However, several of these studies reported increased variability in children's coarticulation patterns compared to adults.

Most studies conducted on coariculatorry patterns of children's speech have focused on labial and lingual coarticulation; few studies have investigated the effect of age on the extent of VPC (Thompson \& Hixon, 1979; Flege, 1988; Ha \& Kuehn, 2006). These few studies have not established consistent developmental patterns. For example, Thompson and Hixon (1979) reported an increase of anticipatory nasal airflow with increasing age. In an acoustic study, Flege (1988) reported no differences between adults and children age 5-10 in the duration of the acoustic signal related to anticipatory VP opening; whereas, another acoustic study (Ha \& Keuhn, 2006) showed that children demonstrated longer durations of the nasal acoustic signal associated with anticipatory VPC than did adults during the production of /pamap/,/pimip/, and /pumup/. It seems that it is still premature to have a general agreement about the developmental aspects of VPC; therefore, further investigations employing other experimental techniques and speech tasks are needed.

Relative to gender differences, aerodynamic studies again report inconsistent outcomes regarding the differences in the degree of anticipatory nasal airflow between male and female speakers. For instance, Thompson and Hixon (1979) reported that more female speakers demonstrated nasal airflow at the midpoint of $i_{1}$ in /ini / than did male speakers. On the other hand, no gender differences were reported in the magnitude of anticipatory nasal airflow (Hoit, Watson, Hixon, McMahon, \& Johnson, 1994), or ratios of nasal to oral-plus-nasal flow and sound pressure levels (SPL) (Zajac, Mayo \& Kataoka, 1998) at the midpoint of the $i_{1}$ in /ini/. These studies have only reported 
aerodynamic measurements. It is possible that the gender factor may have an effect on the temporal aspects of nasal airflow segments related to VPC.

Studies examining the extent of VPC have investigated the phenomenon from a single diamention such as the duration of the acoustic signal related to VPC (Flege, 1988; Ha \& Keuhn, 2006) or the aerodynamic aspects of VPC (Thompson \& Hixon, 1979; Zajac, Mayo \& Kataoka, 1998). According to Bell-Berti (1993), a complete description of velopharyngeal motor control requires examination of segmental, intersegmental, and contextual factors associated with speech; therefore, the present study is designed to obtain simultaneous temporal and aerodynamic characteristic of anticipatory and carryover nasal airflow to investigate age and gender as well as vowel height effects on temporal and aerodynamic aspects of nasal airflow segments related to VPC in vowelnasal-vowel (VNV) sequences. Another purpose is to determine the within speaker variability for those temporal and aerodynamic parameters. Such efforts would add to our knowledge of normal range and extent of VPC and would be of great value for the clinical assessment of disordered speech resonance. 


\section{CHAPTER 2. LITERATURE REVIEW}

\section{Theories of Velopharyngeal Coarticulation}

Findings of studies suggesting that coarticulation is not restricted and may extend to several segments in advance (e.g. Benguerel \& Cowan ,1974) indicate it is not merely a result of mechano-inertial forces acting on the articulators but rather involves an active neurological control system that has information about several segments in advance (MacNeilage \& DeClerk, 1969; Daniloff \& Hammarberg, 1973; Kent \& Minifie, 1977); therefore, a large amount of research has been undertaken during the last few decades to develop theories and models to account for the phenomenon of coarticulation.

According to Farnetani and Recasens (1999), the temporal domain of coarticulation refers to how far and to which direction coarticulatory effects can extend in time. It is believed that the temporal and the spatial aspects of coarticulation are cruicial to the testing of coarticulation theories (Farnetani \& Recasens, 1999). It is also believed that the extent of the coarticulatory influence provides information about the size and nature of the organizational units of speech production (Bell-Berti et al., 1995).

Data on the temporal extent of anticipatory velar coarticlation as well as labial coarticulation have been interpreted in light of two theoretical frameworks, the featural phonology model (Moll \& Daniloff, 1971; Daniloff \& Hammarberg, 1973; Hammarberg, 1976) and the gestural phonology or coproduction model (Fowler, 1980, 1992; Fowler, Rubin, Remez \& Turvey, 1980; Bell-Berti and Harris 1981, 1982; Kelso, Tuller, Vatikiotis-Bateson \& Fowler, 1986; Browman and Goldstein, 1989; Saltzman and Munhall, 1989; Fowler \& Saltzman, 1993).

After the introduction of distinctive features (Jakobson, Fant \& Hallé, 1952; Chomsky \& Hallé, 1968), the feature spreading theory was proposed to account for the coarticulatory variability of speech production. This theory proposes discrete features associated with phonemes as input units of speech. These features constitute the properties that specify the identity of each phonological segment. To explain the observation that anticipatory coarticulation is not a result of mechano-inertial constrains of the speech apparatus, proponents of this theory considered coarticulation as a left-toright array of features that occurs between the segments at a higher (phonological) level before the command is issued to the articulators. According to this theory, the essential properties of a segment are altered and modified due to the influence of neighboring segments. These modifications occur to smooth out transitional vocoids between speech segments (Hammarberg, 1976).

Moll and Shriner (1967) and Moll and Daniloff (1971) adopted a binary feature specification model developed by Henke (1966) to account for the timing of anticipatory coarticulation. This model assumed that a "look ahead" procedure allows the "features" or "goals" of upcoming phonemes to influence those of the current phonemes as long as the anticipated goals are not in conflict with articulatory requirements of the more 
immediate goals. According to this model, the phonological feature [nasal] has three specification values, [-] for obstruents (i.e., produced with high velar position), [+] for nasal consonant (i.e., produced with low velar position and [0] for all other segments including vowels (i.e., neutral). Anticipatory VPC occur as vowels preceding a nasal consonant equally assume a low velar position. Based on this model, anticipatory VPC in $\mathrm{CV} n \mathrm{~N}$ would extend as a function of the number and duration of the preceding unspecified segments (Daniloff \& Hammarberg, 1973).

Kent, Carney, and Severeid (1974) tested the prediction of the binary control model of the velar movement. They found that the model failed to account for all patterns of movement and timing of the velum in English. For example, they demonstrated that in a sentence containing vowels and nasals like many a man knew my meaning, the binary model would predict only one velum position; however, speakers actually demonstrated velar elevation gesture during the production of the vowels. They maintain that even though a binary model would seem attractive and parsimonious, it is not sensitive to fine temporal pattern of articulatory movement.

On the other hand, the gestural phonology line of thought proposes gestures as the fundamental invariant units of production and perception. These gestures are articulatory movements with specified dynamic and temporal structures. The dynamic specification of the gestures determines the kinematics of speech movements and the temporal structure allows them to overlap in time when executed. In other words, coarticulation does not arise from articulatory adjustments between neighboring segments, but from the coproduction, or temporal overlap, of invariant neighboring gestures (Fowler, 1980; Fowler \& Saltzman, 1993).

Citing data from anticipatory lip rounding and velar lowering, Bell-Berti and Harris $(1979,1981$, and 1982) proposed a time-locked model or frame model to identify the extent of coarticulation. The model asserts that the articulatory period of a segment is longer than its acoustic period; as a result, the articulatory movements begin before and end after the acoustic period of the segment (Bell-Berti \& Harris, 1981). Anticipatory coarticulation is therefore limited and does not extend very far backward in time before the gesture becomes acoustically dominant. Thus, neither the length of the preceding string of phones nor their conflicting or non-conflicting featural specifications are relevant.

Indeed, Bell-Berti and Krakow (1991) attempted to explain findings of Moll and Danillof (1971). They obtained kinematic and acoustic data for the production of $\mathrm{CV} n \mathrm{~N}$ utterances such as "a ansal" and "say ansal". They observed monophasic and biphasic velum lowering patterns in their test utterances. The monophasic pattern was observed when the vowel sequence was short and the biphasic pattern was observed when the vowel sequence was long. In addition, they included control utterances containing oral consonants $(\mathrm{CV} n \mathrm{C})$. They found that the velum lowers after the oral consonant in a pattern similar to the first stage of the biphasic lowering and the initial portion of the monophasic lowering observed in the test utterances. They concluded that this movement of the velum cannot be ascribed to the nasal consonant. 
The findings of Bell-Berti and Krakow (1991) appear to be in accordance with the earlier articulatory studies on the movement patterns of the velum that showed that in the absence of nasal consonant, vowels and oral consonants are inherently associated with different velum heights (e. g., House \& Stevens, 1956; Moll, 1962; Fritzell, 1969; Ushijima \& Swashima, 1972; Bell-Berti, 1980; Henderson, 1984).

It seems that Moll and Daniloff (1971) considered the low position of the velum during the production of vowel string in $\mathrm{CV} n \mathrm{~N}$ sequence to be part of the gesture of anticipatory velar lowering and failed to capture the observation that this pattern of velum movement is inherently associated with the articulation of the vowel.

In light of the idea that gestures, the articulatory movements specified in space and time, are the input units of speech production, advocates of gestural phonology proposed that these gestural units are, in fact, the basic 'constellations' that constitute the phonological structure of a language (Browman \& Goldstein, 1986, 1989). Specifically, individual gestures are produced according to language-specific spatial and temporal rules, and then are combined in precise and consistent ways that the perceiver can recognize and can use to rebuild the phonological representation intended by the speaker (Nittrouer, 1993). This view represents a departure from the linguistic account that phoneme-sized phonetic segments are the primary units of speech production and perception.

Based on the assumption that the phonological structure is represented by units of actions of the vocal tract, gestural phonology provides an attractive view to the central issue of how children's speech develops into mature adult-like patterns. Browman and Goldstein (1989) established that these gestures are present in the child's repertoire in a primitive way prior to any linguistic development. As such, phonological development is viewed as harnessing these prelinguistic units of actions to be the basic units of phonological structure. Nittrouer (1996) explained that the main task for a child learning to talk involves learning to coproduce gestures in adult fashion, with the precise degree of spatiotemporal overlap that the language requires.

The view of gestural phonology represents an abandoning of the classic assumption that young children first master a repertoire of phonemes and then they establish their lexicon by forming different combinations of these abstract contrasting units (Goodel \& Studdert-Kennedy, 1993). Evidence that articulatory gestures are the basic units of contrast was derived from studies of infants babbling and toddlers producing their first words. Lock (1986) noted a similarity between the toddler's prelinguistic vocal gestures and its first few words. Vihman, Macken, Miller, Simmons \& Miller, 1985) observed that consonants produced with high frequency in the child's babbling are also present in high frequency in his/her first words. Browman and Glodstein (1989) concluded that "The child is recruiting its well-practiced action units for a new task" (p. 204). The idea that pre-linguistic gestures are employed in the service of producing early words was also proposed and supported by other studies (Locke, 1983; Studdert- Kennedy, 1987; Vihman, 1991) where 'gestures' are referred to as 'articulatory routines' or 'word recipes'. 
Browman and Goldstein (1989) explain that for a child's early production to resemble the gestural structure of the adult form, two processes should take place during the course of the child's growth; (1) differentiation and tuning which involve the differentiation of a single prelinguistic constriction gesture into a variety of contrastive gestures each equipped with different degree and location of constriction; (2) coordination, where the child has to master the appropriate organization of the various gestures that represent the atoms of a given word.

\section{Developmental Patterns of Coarticulation}

During recent years, more attention has been focused on children's acquisition of coarticulatory behaviors. The study of developmental coarticulation is fundamental to our knowledge of how speech motor control develops and the nature of its programming units. For example, Kent (1983) suggested that children tend to rely on segments as the main units for speech programming. This tendency seems to decrease as children grow. He explained that the emphasis upon segments reflects a hierarchy in speech acquisition where the temporal ordering of units "sequencing" is acquired first and then the fine details of gestural overlap develop later. On the other hand, evidence from acoustic and auditory perceptual studies (Nittrouer, Studdert-Kennedy \& McGowan, 1989; Nittrouer $\&$ Whalen, 1989) showed that young children may rely upon syllable-based speech planning units to a larger extent than adults do.

Although many studies have examined the patterns and degree of coarticulation in child speech production, findings have not established consistent developmental patterns that appear to depend crucially upon the articulatory subsystems under consideration. Several studies reported that children exhibit a greater degree of anticipatory coarticulation than adults (Repp, 1986; Nittrouer, et al., 1989; Nittrouer \& Whalen, 1989; Ha \& Kuehn, 2006), while other studies indicate that children have less coarticulation than adult speakers (Thompson \& Hixon, 1979; Sereno \& Lieberman, 1987; Hodge, 1989). A third set studies reported that adults and children exhibit approximately the same amount of coarticulation, yet children exhibited increased variability in their coarticulation (Turnbaugh, Hoffman, \& Daniloff, 1985; Sereno, Baum, Marean, \& Lieberman, 1987; Katz, Kripke, \& Tallal, 1991; Goodell \& Studdert-Kennedy, 1993; Katz \& Bharadwja, 2001). Regardless of whether children show equal, greater or less gestural overlap compared to adults' speech, the differences between adults and children may provide valuable information about child's articulatory timing control.

One example of the inconsistency of findings on coarticulation patterns in children is manifested in the study of anticipatory lingual coarticulation. Nittrouer et al. (1989) conducted an acoustic study using fricative-vowel syllables spoken by eight adults and eight children at each of the ages 3, 4, 5 and 7. The authors found that children showed more intrasyllabic coarticulation than adults. The results demonstrated that F2 estimated values showed a gradual, age-related decline of the influence of $/ \mathrm{i} /$ and $/ \mathrm{u} /$ on the preceding $/ \mathrm{s} /$ or $/ \mathrm{J} /$. The authors also obtained the mean frequency distribution of the first spectral noise of both fricatives as an indicator of the precision of fricative 
production. Less difference was observed in the first moments of the $/ \mathrm{s} /$ and $/ \mathrm{J} /$ noises in children's samples compared to those of adults, indicating that children failed to make the precise constrictions characteristics of adults' fricative production. They also reported increased ability to differentiate between $/ \mathrm{s} /$ and $/ \mathrm{f} /$ with increasing age.

Their findings support the idea that children tend to organize their speech segments over a wider temporal domain at least within the size of the syllable, and as children grow, they begin to differentiate the patterns of gestures within the syllable in a way close to their perceived individual segments. Findings of this study along with findings of subsequent studies (Goodell \& Studdert-Kennedy, 1993; Nittrouer, 1993; Nittrouer, Studdert-Kennedy \& Neely, 1996) support the view in speech development that proposes syllables as the initial units of speech organization rather than individual phonetic segments. These studies were also taken as evidence for the view of gestural phonology (Browman \& Goldstein, 1986, 1989) that the process of development of speech production is a lengthy process that involves learning to produce consonant and vowel gestures with the precise spatiotemporal aspects as adults do.

In contrast, an acoustic study by Katz et al. (1991) was designed to test the idea that children exhibited more gestural overlap than adults do. The researchers studied anticipatory lingual coarticulation in a group of 3,5, and 8-year-olds and adults. Results indicated that for an $/ \mathrm{s} /$ followed by a vowel $(/ \mathrm{sV} /)$, acoustic measures did not differ as a function of age. It should be noted that the target segments in the study of Nittrouer et al. (1989) were embedded in a series of nonsense syllables (e.g., / $/ \mathrm{i} \mathrm{j} \mathrm{i} /, / \mathrm{sisi} /, / / \mathrm{Ju} \mathrm{u} /$, and /susu/), whereas, those of Katz et al. (1991) were embedded in meaningful words produced within a carrier phrase.

On the other hand, Kent (1983) reported the effect of the tongue gesture of a final stop on a preceding vowel in a CVC syllable. He observed that in adults, F2 values appears to rise more rapidly during the final portion of the vowel immediately before closure for $/ \mathrm{k} /$ in the word box /baks/, which indicates that adult speakers anticipate the gesture of tongue body elevation required for the stop consonant $/ \mathrm{k} /$. However, children between 3 to 4 years of age showed well-defined steady state phase during the production of vowel. This steady state phase is characterized by the stabilization of the F2 frequency for certain duration of time. He argued that children are more likely to show restricted coarticulatory effect, as their speech appears to be more "segmental" and "synchronous". However, Nittrouer et al. (1989) offered an alternative interpretation for Kent's (1983) finding. They suggested that lack of F2 transition throughout the vowel in children production of $/ \mathrm{baks} /$ is in fact an anticipation of the $/ \mathrm{k} /$ closure, and thus reflects a more rather than less intra-syllabic coarticulation.

Previous studies have relied solely on acoustic data to investigate the effect of age on the degree of coarticulation. Sereno and Lieberman (1987) conducted a perceptualacoustic study examining the influence on a velar stop by a subsequent vowel in $/ \mathrm{ki} /$ and $/ \mathrm{ka} /$ syllables produced by five adults and 14 children between the ages of 3 and 7 . Results from the perceptual and acoustic data indicated that the adults exhibited consistent patterns of anticipatory lingual coarticulation. On the other hand, children's 
speech varied greatly from speaker to speaker, with some of them displaying adult-like patterns while others did not show any traces of lingual coarticulation. The high degree of interspeaker variability in young children's coarticulation was taken as evidence that precise coarticulatory patterns are one form of fine-tuned speech motor patterns that are acquired gradually with maturation. The findings of Sereno and Lieberman (1987) are consistent with acoustic analyses (Eguchi \& Hirsh, 1969; Tingley \& Allen, 1975; Kent \& Forner, 1980, Smith, 1991) and articulatory measurements (Watkins \& Fromm, 1984; Sharkey \& Folkins, 1985, Smith \& Mclean-Muse 1985; Smith \& Goffman, 1998) of children's speech all of which supported the idea that decreased variability is a general trend in speech development reflecting improvement with neuromotor maturation.

Though findings of studies concerning anticipatory lingual coarticulation in children's speech are mixed, those on anticipatory lip-rounding before /u/ (Turnbaugh, Hoffman, \& Daniloff, 1985; Sereno et al., 1987; Nittrouer et al., 1989; Katz et al., 1991) have all suggested that the speech of children is roughly similar to that of adult subjects in terms of anticipatory labial coarticulation.

Most studies of developmental coarticulation have focused on aspects of labial and lingual coarticulation. Literature on the developmental aspects of velopharyngeal coarticulation is still limited and, therefore, it is difficult to define a general pattern. In addition, all studies on anticipatory lingual and labial coarticulation have used acoustic analysis to measure the degree of gestural overlap. Studies on VPC have employed aerodynamic analysis (Thompson \& Hixon, 1979) and timing measurement from acoustic data (Flege, 1988; Ha \& Kuehn, 2006). These studies have yielded inconsistent outcomes.

Thomson and Hixon (1979) calculated the percentage of subjects exhibiting nasal airflow at the midpoint of the initial vowel in /ini/ produces by 111 subjects ranging between 3 and 37 years of age. The study showed that an increasing proportion of subjects produced nasal airflow at the midpoint of $/ i_{1} /$ in /ini/ with increasing age. The authors subdivided the subjects from three to 18 years into subgroups with three year intervals. The data showed the following proportions of subjects that demonstrated nasal airflow at the midpoint of the vowel: $13.6 \%$ at three to six years, $20 \%$ at six to nine years, $42.9 \%$ at nine to twelve years, $78.6 \%$ at twelve to fifteen years, and $71.4 \%$ at fifteen to eighteen year. For the adult group, the proportion was 50\%. They concluded that older subjects tended to show earlier anticipatory coarticulation in preparation for a nasal consonant. These findings support the idea that timing patterns of velopharyngeal port movements are mastered by English-speaking adults. In other words, with increasing experience in using the speech mechanism, subjects tend to take more advantage of the anticipatory gestures of the following sounds as a form of biomechanical economy. However, no timing measurement was obtained in this study. It is possible that the differences between age groups may have been a result of a difference in vowel duration.

In an acoustic study, Flege (1988) investigated the timing of velopharyngeal opening and closing during the vowel in $/ \mathrm{dVn} /$ and $/ \mathrm{nVd} /$ sequences of adults and children age 5 and 10 years. The test syllables included were inserted into the carrier 
phrase "A half_for Sam". The author developed a new technique to acquire the speech samples. He used a pair of small microphones positioned in front of the nares and mouth with an aluminum plate in between to minimize cross talk. He observed that all groups of speakers nasalized most vowels with no difference in the extent and duration of nasalization. He concluded that children's speech is not more segmental than adults' speech and that nasalization of vowels in $/ \mathrm{dVn} /$ contexts is a natural process that needs to be learned by children and can be taken as an evidence supporting the "ease of articulation Hypothesis."

On the other hand, in a similar recent study, Ha and Kuehn (2006) compared the temporal characteristics of nasalization between 28 children between four to seven years and 28 adults. The authors obtained measurements of the absolute and proportional durations of the acoustic energy signal associated with VPC in target utterances /pamap/, /pimip/, and /pumup/. Results indicated that adults demonstrated shorter proportional duration of anticipatory velopharyngeal coarticulation than children; however, carryover coarticualtion was not found to be significantly different between groups. This was consistent with Flege (1988), who reported non-significant difference in the timing of carryover coarticulation between children and adults. Both studies support the idea that anticipatory and carryover coarticulation have different underlying mechanisms. While anticipatory coarticulation involves high neuromotor control, carryover coarticulation is largely attributed to mechanical and inertial forces acting on the articulators (Bell-Berti, 1993).

Considering the results of the previous studies, it appears that it is still too early to arrive at general patterns that describe the developmental process of coarticulation. The results of these studies lead us to a general idea that is best summarized by Repp (1986) "The various patterns of results (...) suggest that phenomena commonly lumped together under the heading of 'coarticulation' may have diverse origins and hence different roles in speech development. Some forms of coarticulation are an indication of advanced speech production skills, whereas others may be a sign of articulatory immaturity, and yet others are neither because they simply cannot be avoided. Therefore, it is probably not wise to draw conclusions about a general process called coarticulation from the study of a single effect. Indeed, such a general process may not exist" (p.1634).

Studies on the development of VPC (Flege, 1988; Ha \& Kuehn, 2006) relied on the duration of acoustic segments to reflect on the extent of gestural overlap. Katz and Bharadwaj (2001) state that there are many problems associated with measuring articulatory movement patterns using solely acoustic data. Only Thompson and Hixon (1979) have used aerodynamic measurements. However, they only measured the number of speakers demonstrating anticipatory nasal airflow at the mid portion of the first vowel in /ini/ and did not obtain temporal measurements. It is assumed that this may not be sufficient to reflect the entire range of anticipatory VPC.

Very recently, Khwaileh \& Ha (2008) investigated the effect of age on the temporal domain of VPC. The authors attempted to measure the duration of anticipatory and carryover nasal airflow segments in /imi/ and /ama/ produced by 10 children between 
4 and 8 years of age, 10 children between 9 and 11 years of age, and 10 adult speakers. Results revealed that younger children exhibited longer anticipatory nasal airflow than both older children and adults. No difference was found between older children and adults. They concluded that children show longer interarticulatory timing. These findings support the idea that children tend to plan their articulatory movements over a longer temporal domain which tends to decrease as they mature (Nitrouer et al., 1989).

\section{Velopharyngeal Function and Gender Differences}

Several studies have examined the effect of gender on various aspects of VP function. While some studies reported significant effect of gender (e.g., McKerns \& Bzoch, 1970; Kuehn, 1976; Thompson \& Hixon, 1979; Seaver, Dalston, Leeper, \& Adams, 1991; Sussman, 1995; Zajac, 1997), other studies reported no differences between men and women relative to certain aspects VP function (Hoit et al., 1994; Zajac \& Mayo, 1996; Zajac, Mayo \& Kataoka, 1998; Young, Zajac, Mayo \& Hooper, 2001).

McKerns and Bzock (1970) used lateral view x-ray to study velar configuration during speech of 20 men and 20 women. They noted gender differences in the patterns of velum orientation and movement toward closure. In women, the configuration of velum appears like a right angle during VP closure, whereas men exhibited an acute angle of velum relative to posterior VP walls as shown in Figure 1. The authors also observed that male speakers demonstrated smaller contact area between the velum and the VP walls, greater velar elevation, higher place of closure, greater velar length and greater distance between the tip of the uvula and the posterior pharyngeal walls than did women. They attributed these findings to structural differences between males and females such as different sites of muscle insertion. In support of McKerns and Bzoch (1970), Kuehn (1976) provided evidence from a cineradiographic study that a female speaker exhibited longer durations of velar movement compared to a male speaker.

In another articulatory study, Kuehn and Moon (1998) used a force bulb inserted transnasally and electromyography to investigate VP closure force and the activation levels of the levator veli palatine muscle, respectively, in seven men and seven women during the production of several phonetic contexts. They reported no sex effect between levels of VP closure; however, when men and women are separated, the authors found that men demonstrated greater variability across various consonant categories in terms of VP closure force than women did. The authors attribute this finding to a reduced upward movement of the velum in female speakers as found by McKerns and Bzoch (1970), which resulted in a limited range of changes in VP closure force.

With regard to acoustic studies, Seaver et al. (1991) used the Nasometer to measure the nasalance score of 148 men and women to study dialectical differences. The amount of nasal acoustic energy was obtained from speakers during the production of three passages; one passage was loaded with nasal consonant, the second contained a combination of nasal and oral consonants (i.e., the Rainbow passage), and the last one contained only oral consonants (i.e., the Zoo passage). Results indicated that female 

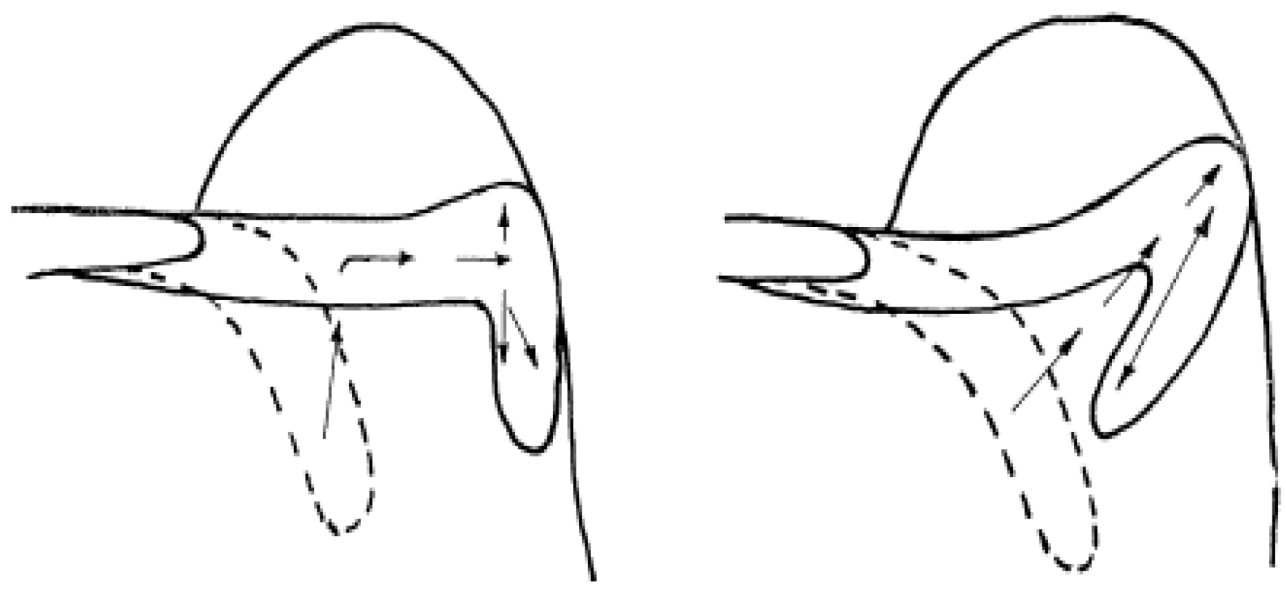

Figure 1. "Right angle" female and "acute" male velar configuration with broken lines showing the velum at rest and arrows showing direction of movement.

Source: Reprinted with permission. McKerns, D., \& Bzoch, K. R. (1970) Variation in velopharyngeal valving: The factor of sex, Cleft Palate Journal, 7, 652-662.

speakers exhibited higher nasalance scores than male speakers in the passages containing nasal consonants. The authors explained that different variables may influence the nasalance score, such as: amount of nasal airflow rate, anatomic and physiologic gender differences of VP mechanism, and filtering characteristics of the Nasometer.

Thompson and Hixon (1979) investigated the effect of gender on the magnitude of nasal airflow at the midpoints of the vowels in /ini/. They reported that more females than males (32 of the 47 speakers) exhibited anticipatory nasal airflow during the initial /i/ of /ini /, but no gender differences on the magnitude of carryover nasal flow associated with the second vowel. The authors concluded that female speakers showed earlier anticipatory nasal coarticulation than males. They attributed these findings to biomechanical differences between sexes. Unfortunately, the authors initially examined 111 subjects, then, 64 of them were excluded because their flow was zero at the midpoint of the first vowel in /ini/. The authors did not specify the gender distribution of the excluded subjects.

In a replicated study, Zajac et al. (1998) used a partitioned oro-nasal mask to examine the effect of gender on aerodynamic aspects of VPC in 10 men and 10 women during the production of /ini/ in two conditions; (1) with equal stress on both syllables, and (2) with contrastive stress on the second one. In addition to the magnitude of nasal airflow at the midpoints of both vowels in /ini/, the authors measured ratio of nasal to oral-plus-nasal airflow and sound pressure level (SPL). In contrast with Thompson and Hixon's study, the findings revealed no significant effect of gender across all measurement variables regardless of stress conditions. The authors concluded that both men and women demonstrate similar patterns of anticipatory and carryover VPC. The 
different findings between Thompson and Hixon (1979) and Zajac et al. (1998) may be attributed to the method of data segmentation. While Thompson and Hixon (1979) used the acoustic signal to determine onsets and offsets of the phonetic segments, Zajac et al. (1998) used aerodynamic criteria.

The findings of Zajac et al. (1998) were consistent with those of Hoit et al. (1994) who reported no significant gender effect on the magnitude of nasal airflow in $/ i_{1} /$. However, Hoit et al. (1994) did report that women exhibited lower rates of nasal flow than men during the production of $/ \mathrm{n} / \mathrm{in} / \mathrm{ni} /$. Zajac et al. (1998) attributed this to syllable stress and/or idiosyncratic intensity levels of the speakers.

In addition to anticipatory and carryover nasal airflow, Zajac and Mayo (1996) investigated the effect of gender on the temporal and aerodynamic characteristics of VP function in $/ \mathrm{mp} /$ sequence in /hamper/ produced by 21 men and 21 women. Findings revealed that men exhibited higher intraoral air pressure associated with $/ \mathrm{p} /$ and shorter interval of the rise of pressure in $/ \mathrm{p} /$. The authors attributed these findings to the increased force of the lungs' elastic recoil in men (Stathopoulos \& Weismer, 1985) allowing them to achieve greater intraoral air pressure for voiceless plosives over a shorter time interval. Nonetheless, no significant gender effect was found in the ratio of nasal air volume emitted during the segments preceding $/ \mathrm{m} /$ to the total nasal air volume emitted during the entire word. The author, however, did not include temporal measurements of anticipatory nasal flow, thus, the effect of gender on the temporal domain of anticipatory VPC may not be ruled out. Warren et al. (1993) suggested that the duration of the nasal airflow pulse may contribute more to perceived nasality than the actual volume of air passing through the nose.

\section{Velopharyngeal Coarticulation and Vowel Height}

The relationship between tongue height and velum height is one of the most documented phonetic factors influencing VP function (Moll, 1962; Moll \& Shriner, 1967; Lubker, 1968; Fritzell, 1969; Ohala, 1971; Bell-Berti, 1976; Clumeck, 1976; Bell-Berti, Baer, Harris \& Niimi, 1979; Al-Bamerni, 1983; Henderson, 1984; Bell-Berti \& Krakow, 1991; Kuehn \& Moon, 1998). Bell-Berti (1993) reported that the velum position varies systematically as a function of the phonetic contexts; she explains that "velic position is lowest for nasal consonant, somewhat higher for low vowels, higher still for high vowels, and highest for obstruent consonant" (p.69).

Studies also found that velar position varies depending on tongue height in a similar pattern for nasalized vowels as well as vowels produced in oral context (BellBerti et al., 1979; Henderson, 1984). Specifically, vowels produced with high tongue position are accompanied with a higher velum and greater VP closure force than vowels produced with lower tongue position (Bell-Berti, 1976; Bell-Berti \& Krakow, 1991; Moon, Kuehn \& Huisman, 1994; Kuehn \& Moon, 1998). In a cineflorographic study, Moll (1962) investigated the variation of VP closure as a function of the vowel produced as well as the consonant environment of the vowel in 10 normal adult speakers during 
their production of CVC syllables containing the vowels /i/, /æ/, /a/ and /u/. He observed the following: (a) high vowels were produced with greater velar height than low vowels, (b) VP closure was not achieved during vowels adjacent to a nasal segment, and (c) in a nasal context, VP gaps associated with low vowels were greater than those in high vowels.

The variation of velic position between high and low vowels is attributed to the activity of two muscles (Bell-Berti, 1993). First is the variation in the strength of the levator veli palatine contractions, the primary muscle of velar elevation, which exerts an upward and posterior pull on the velum as documented in electromyography of the levator veli palatine potentials (Moll \& Shriner. 1967; Lubker, 1968; Fritzell, 1969; BellBerti, 1973, 1976). The second muscle is the palatoglossus which pulls the velum downward to narrow the faucial isthmus (Bell-Berti, 1973, 1976) and resist being stretched during the articulation of low vowels (Moll \& Shriner, 1967).

Moon et al. (1994) used a sensing device (bulb) inserted via the nasal cavity to measure the variations of VP closure force associated with different vowels in normal adult speakers. The bulb was designed to conform to the top of the pharyngeal wall and the velum during VP closure. After the device was positioned, each speaker ( 2 men and 5 women) was asked to produce sustained vowels /a/, /i/, /u/ and /æ/ for five seconds each. Subjects were also asked to produce 10 repetition of the phrase "say s_t again" using each of the vowels listed above. The values of the VP closure force associated with each vowel were collected. The readings of the sensing device indicated vowel-specific closure force during production in isolation and in carrier phrase context. Generally, high vowels were associated with greater VP closure force than low vowels. The authors concluded that articulatiry goals are specified for vowels.

In addition to physiologic studies, the effect of the amount of coupling on the characteristics of the resulting acoustic signal has been extensively studied. Ohala (1975) proposed that the small levels of velopharyngeal opening have a substantial effect on high vowel spectra; therefore, nasalization is likely to be perceptually more salient. This explanation is supported by acoustic studies (House \& Stevens, 1956; Fant, 1960; Lubker, 1968; Maeda, 1993; Stevens, 1998) which showed that a similar level of velopharyngeal opening causes stronger acoustic effects on high than on non-high vowels. Using the Key Elementrix Nasometer, Rochet and Rochet (1991) compared assimilation patterns in French and English as a function of vowel height. In both languages, high vowels exhibited more assimilating nasality than low vowels characterized by longer duration of nasalization in high vowels (both proportionally and absolutely) than in low vowels. Consistent with Rochet and Rochet (1991) similar acoustic studies (Ha, Sim, Zhi \& Kuehn, 2004; Ha \& Kuehn, 2006) investigated the relationship between vowel height and the duration of nasalized portion of the resulting acoustic segment in the utterances of /pamap/, /pimip/, and /pumup/. Both studies reported longer duration for the nasal coarticulatory effect on high vowels compared to low vowels. 
Based on manipulation of both synthetic and natural speech, perceptual studies provided evidence that low vowels need a lower velum and greater amount of coupling to be perceived as nasalized, whereas, high vowels need a small velic aperture to be perceived as nasalized (Benguerel \& Lafargue, 1981; Bell-Berti \& Baer, 1983; Stevens, Fant, \& Hawkins, 1987; Beddor, 1993; Maeda, 1993). For example, Maeda (1993) investigate the difference in degrees of nasal coupling on degree of perceived nasality of three vowels $/ \mathrm{i} /, \mathrm{a} / \mathrm{and} / \mathrm{u} /$. The author used a simulation method to synthesize each of three the vowels with six degrees of VP orifice sizes ranging from 0 to $2.5 \mathrm{~cm}^{2}$.

Five repetitions of the 18 stimuli (3 vowels x 6 degrees of coupling) were then presented randomly to 8 listeners who judged the degree of nasality using a five interval scale from 0 (not nasalized) to 4 (heavily nasalized). Results revealed that for the high vowel $/ \mathrm{i} /$, perceived nasalization increases and saturates when the coupling is as small as $0.4 \mathrm{~cm}^{2}$. A similar pattern was observed for the other high vowel /u/. The low vowel, though, showed a completely different pattern; the perception of nasalization was only evident when the degree of coupling was greater than $1.6 \mathrm{~cm}^{2}$. These studies suggest that the differences in the size of VP gap reflect the speaker's intention to use the appropriate size of the VP depending on the vowel height and thus avoid deviant nasal coupling (Bell-Berti, 1993).

In addition, aerodynamic studies (e.g., Lubker \& Moll, 1965; Young, Zajac, Mayo $\&$ Hooper, 2001) reported a direct association between nasal airflow levels and vowel height in normal speakers. In a review of research findings, Hajek (1997) noted that nasal airflow was greater in high versus low vowels in a VN context (e.g., Al-Bamerni, 1983). Hajek explained this relationship as resulting from increased oral impedance of high vowels that redirects more airflow into the nasal cavity. For example, Lubker and Moll (1965) measured simultaneous oral and nasal airflows in conjunction with the cineflourographic measurement of the articulatory positions of the tongue and velum in a single normal speaker. Speech samples consisted of nonsense syllables (CVC) embedded in a carries phrase. The syllables were constructed to include vowels [i, a, æ, u] and the consonants $[\mathrm{p}, \mathrm{t}, \mathrm{n}]$. They reported that when the vowels /e/ and /i/ preceded the nasal consonant, there was an increase in nasal airflow while the VP orifice size remained constant.

Lubker and Moll attributed this finding to an increase in oral cavity constriction resulting from the high position of the tongue as observed by cineflourography. During production of the phrase "say nip" for example, velar height and VP opening were relatively constant during the vowel /e/, whereas nasal airflow increased, oral airflow decreased, and tongue-to-palate distance decreased (see Figure 2. From Lubker \& Moll, 1965). In other words, the increase in nasal airflow during /e/ was due to an increased tongue constriction rather than to an increase in VP orifice area. Indeed, Lubker and Moll (1965) stated that "nasal pressure and flows undoubtedly are related to various oral phenomena as well as to the activities of the velopharyngeal mechanism" (p. 257).

In another aerodynamic study, Young et al. (2001) attempted to measure the magnitude of anticipatory nasal airflow at the midpoint of the initial vowels in /ini/ and 

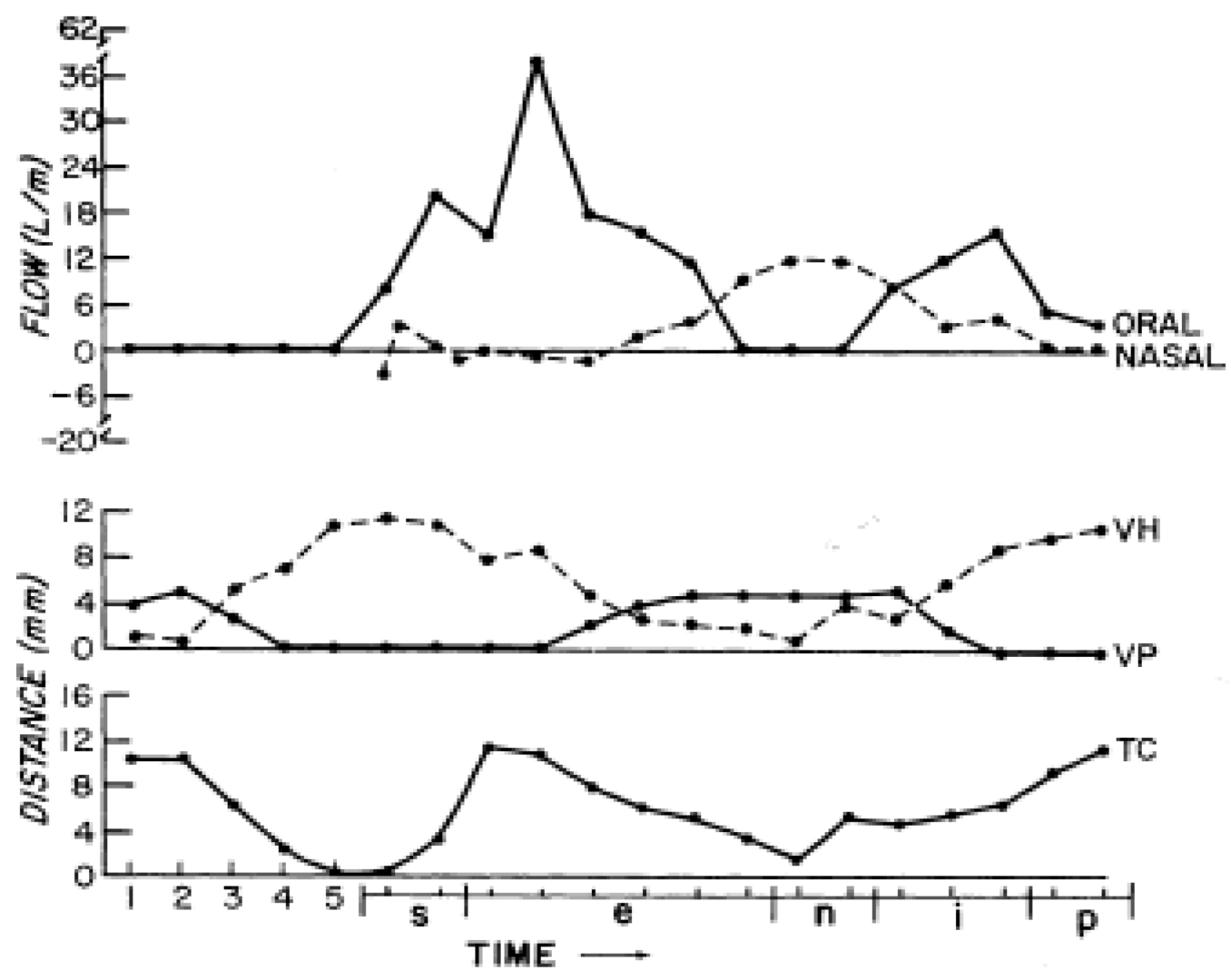

Figure 2. Oral and nasal air flow rates and articulatory positioning for the phrase /se nip/: V-H, velar height; V-P, velopharyngeal distance; and T-C tongue constriction.

Source: Reprinted with permission. Lubker, J. F., \& Moll, K. L. (1965) Simultaneous oral-nasal air flow measurements and cinefluorographic observations during speech production. Cleft Palate Journal, 2, 257-272. 
/ana/ produced by normal speakers. Findings indicated that women exhibited an increase in nasal flow, an increase in the ratio of nasal to oral-plus-nasal flow and a decrease in oral flow during the production of $/ \mathrm{i} /$ as compared to $/ \mathrm{a} /$.

Recently, Khwaileh and Ha (2008) measured the duration of anticipatory and carryover nasal airflow in /imi/ and /ama/ produced by normal children and adults. Findings indicated longer duration of anticipatory nasal flow on low vowels context than high vowel context for all speakers regardless of age. However, the duration of carryover nasal flow was longer for /imi/ as compared to /ama/. A ready explanation for these findings was not available. The authors suggested that the increased perception of nasality in high vowels may be more associated with nasal airflow volume rather than the time during which VP port is open.

\section{Speech Aerodynamics}

The need for reliable, objective, and noninvasive techniques for the assessment of VP function has led to the developmental of the aerodynamic method of evaluation or what is generally referred to as "pressure flow technique". Because it involves observing the aerodynamic events resulting from various vocal tract behaviors, this technique involves indirect assessment of VP activity as it provides inferential information about VP function (Dalston \& Warren, 1986). According to Warren et al. (1989), the common goal for the respiratory and articulatory subsystems is to provide adequate air pressure for the production of consonant rather than maintaining acoustic accuracy.

The pressure-flow technique was first developed by Warren and Dubois (1964) based on hydraulic principals. It proposes that the area of constriction can be calculated if the differential pressure across the constriction and the rate of flow through the constriction can be measures simultaneously. Warren and Dubois developed a human model of the respiratory and vocal tracts. The model was made of plastic tubing. It contained a velopharyngeal orifice and a mouth that can be constricted (see Figure 3). This model was used to estimate the two constrictions found in the normal human anatomy. These constrictions were VP orifice size and the cross sectional area of the nasal cavity. Warren and Dubois (1964) provided the following equation known as the "orifice equation" to indirectly calculate the orifice area:

$$
\mathrm{A}=\mathrm{V} / \mathrm{k}[2 \Delta \mathrm{P} / \mathrm{d}]^{1 / 2}
$$

where $\mathrm{A}=$ area of orifice, $\mathrm{V}=$ nasal airflow through the orifice, $\mathrm{K}=$ a correction factor $(0.65), \Delta \mathrm{P}=$ differential oral-nasal pressure across the constriction, $\mathrm{d}=$ density of air.

Later, Warren (1979) developed PERCI (Palatal Efficiency Ratings Computed Instantaneously). The goal of this device was to provide a simple and efficient way to record nasal and oral pressures to reliably evaluate VP incompetency. This system provides information on the pressure difference between the nose and the mouth associated with the extent of VP opening. Warren (1979) recommended the use of the 


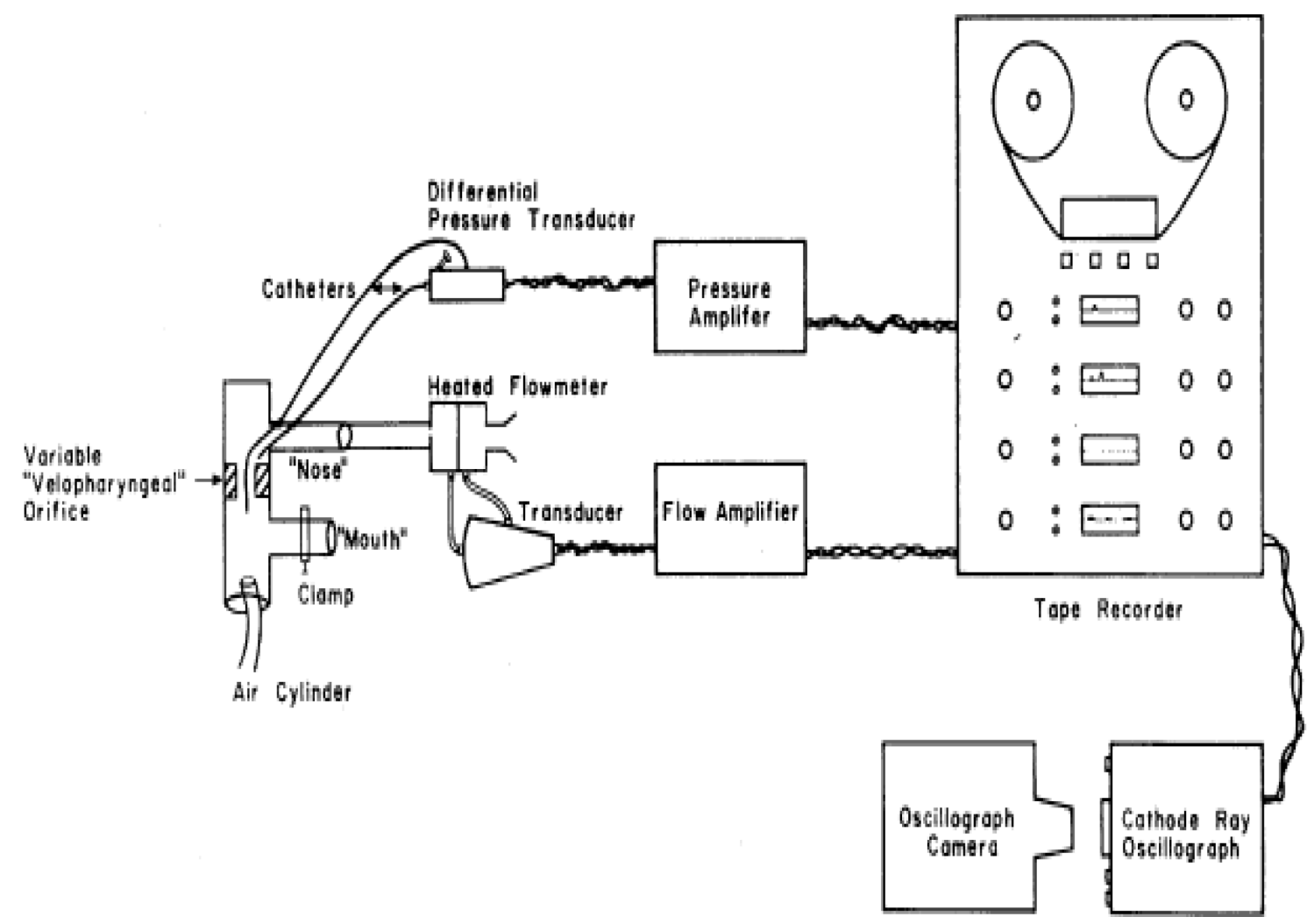

Figure 3. Diagrammatic representation of the artificial model of the vocal apparatus used to calculate VP orifice size.

Source: Reprinted with permission. Warren, D. W., \& Dubois, A. B. (1964) A pressureflow technique for measuring velopharyngeal orifice area during continuous speech. Cleft Palate Journal, 1, 52-71. 
to assure greater accuracy of VP orifice estimates. He explains that when complete closure occurs during the pressure consonant $/ \mathrm{p} /$, pressure in the mouth will vary from about $3 \mathrm{~cm} \mathrm{H}_{2} \mathrm{O}$ to $7 \mathrm{~cm} \mathrm{H}_{2} \mathrm{O}$. The tightly closed $\mathrm{VP}$ valve will prevent air from leaking into the nasal passages, thus air pressure in the nose will not be different from the atmospheric air. An opening in the VP orifice will result in a difference in pressure; therefore, calculation of the size of the VP orifice will depend on the amount of air that leaks into the nose.

As a result of this effort, estimates of the size of VP orifice during the production of /p/ in "hamper" have been suggested as a primary aerodynamic diagnostic procedure to describe adequacy of the VP valve upon which clinical and management decisions are based on in the population of VPI (Dalston \& Warren, 1986). The authors reported that individuals with estimated orifice areas under $5 \mathrm{~mm}^{2}$ during production of $/ \mathrm{p} / \mathrm{in}$. "hamper" were considered to have adequate velopharyngeal function whereas those with areas greater than $20 \mathrm{~mm}^{2}$ were considered to have inadequate function. However, Dalston and Warren (1986) reminded that aerodynamic measures are intended to supplement rather replace impressionistic perceptual estimate of VP function.

Recently, temporal aspects of pressure-flow events have been suggested to differ between cleft and noncleft speakers. Warren et al. (1989) observed that the duration of the nasal airflow pulse associated with the $/ \mathrm{mp} /$ sequence in the word "hamper" was longer in speakers with velopharyngeal inadequacy. Warren, Dalston, and Mayo (1993) indicated that the duration of this interval was increased by approximately $50 \mathrm{~ms}$ in speakers with cleft palate and hypernasality as compared to noncleft speakers and speakers with cleft palate but normal resonance. Warren et al. (1993) speculated that perceived hypernasality of speech is associated with the actual time that the velopharyngeal valve is open rather than the amount of air escaping through the nose. Temporal aspects of velopharyngeal function, therefore, may be important diagnostic indicators for speakers not only with cleft palate but also with individual with congenital or acquired neuromuscular deficits (Zajac \& Mayo, 1996).

In addition to estimation of VP orifice size and temporal characteristics of VP closure, the pressure-flow technique can also be used to detect obstruction of the airflow by the nasal passages (anterior rhinomanometry) and obstruction of airflow by the velopharynx (posterior rhinomamometry). Moreover, the "orifice equation" of pressureflow measurement can be used to estimate the nasal cross-sectional area during rhinomanometry (Warren, 1984).

\section{Statement of the Problem}

Considering the results of the previous studies, it is still too early to arrive at an agreement concerning the effect of age and gender on the temporal and aerodynamic patterns of VPC. Few studies have investigated the developmental patterns of VPC, and those studies have yielded inconsistent results regarding the differences between children and adult in the extent of anticipatory VPC. Inconsistent results may be due to the 
differences in observation methods or the composition of speech samples; thus, a further investigation that uses another observation method is needed.

As for gender effects on the degree of VPC, aerodynamic studies (Thompson \& Hixon, 1979; Hoit et al., 1994; Zajac et al., 1998) have only investigated the nasal airflow magnitude at the midpoint of the initial vowel in /ini/. No studies have attempted to measure the actual duration of nasal flow. Warren et al. (1993) suggested that the duration of the nasal airflow pulse may contribute more to perceived nasality than the actual volume of air passing through the nose.

With regard to vowel height, it seems that further investigation that employs simultaneous measurements of both duration and rate of anticipatory and carryover nasal flow is needed to determine the factors contributing to the degree of perceived nasality associated with high vs. low vowels. Therefore, the present study is expected to answer the following questions:

1. What is the effect of age, gender, and vowel height on the absolute and proportional duration of nasal flow in VNV sequences?

2. What is the effect of age, gender, and vowel height on the volume of nasal airflow in milliliters and ratio of nasal to oral-plus-nasal airflow volume related to anticipatory and carryover velar coarticulation in VNV sequences?

3. What are the effects of age and gender on speakers' variability in all temporal as well as aerodynamic characteristics on anticipatory and carryover nasal airflow in VNV sequences?

In addition, the projected findings from the aerodynamic data will allow for examining the prediction of the coproduction model in coarticulation (Fowler, 1980; Fowler \& Saltzman, 1993) which proposes that articulatory gestures are stable and constrained by their inherent spatiotemporal structure. Based on the time-locked model (Bell-Berti \& Harris, 1979, 1981, 1982), we assume that the extent of anticipatory nasal airflow which corresponds to the gesture of velar lowering will be restricted and limited regardless of the number of vowels before the nasal consonant.

The comparison between children and adults will also assess the view of gestural phonology on speech development (Browman \& Goldstein, 1986, 1989; Nittrouer et al., 1989). This view entails that as children grow, they learn to organize their articulatory gestures with the same time and space relations as adult do, thus we assume that all age groups will demonstrate anticipatory nasal flow; however, the duration and/or the volume of nasal flow related to velic lowering gesture will be different between children and adults. 


\section{CHAPTER 3. METHODS}

\section{Participants}

Participants of the study consisted of 60 adult and children speakers with normal speech, language and hearing. All participants were native speakers of English. These participants were divided into three age groups as the following: twenty adults above 18 years of age (10 men and 10 women), twenty older children between the ages of 9 and 11 years (10 boys and 10 girls), and twenty younger children between the ages of 5 and 7 years (10 boys and 10 girls). We assume that the speech production patterns of the age groups 5-7 years and 9-11 years are different since the speech sounds acquisition in children is almost complete around the age of seven (Smit, Hand, Frelinger, Bernthal \& Bird, 1990; Bauman-Waengler, 2000). Table 1 shows mean and age range for the participants as a function of age and gender.

For the adult group, students at the University of Tennessee, Knoxville were recruited from the Department of Psychology, which offers credit to undergraduate students who participate in research projects at the University. Participants were also recruited from the Department of Audiology and Speech Pathology at the University of Tennessee due to their interest and willingness to participate in the research of their selected field. Children were obtained through preschools, kindergartens, elementary schools in Knox County, and the use of research flyers.

An informed consent statement was reviewed and signed by each participant. Parents or primary caregivers of children were also given a letter of consent to read and sign before initiation of the study. Participants were given written instructions so they understand the procedures. Children between 7 to 11 years old were presented with an oral assent. Sample consent form and oral assent are included (Appendix A and B). Each participant/parent or caregiver was asked to complete a background information form (Appendix C). This form contains identifying information, general health, racial/ethnic background, and speech, language and hearing history.

All participants had no history of speech, language, hearing impairments or craniofacial anomalies. Participants did not show signs of allergies, sinus problems, or

Table 1. Age (years; months) and gender distribution of the speakers.

\begin{tabular}{|c|c|c|c|c|c|c|}
\hline \multirow[b]{2}{*}{ Speakers } & \multicolumn{2}{|c|}{ Younger children } & \multicolumn{2}{|c|}{ Older children } & \multicolumn{2}{|c|}{ Adult speakers } \\
\hline & $\begin{array}{c}\text { Male } \\
(n=10)\end{array}$ & $\begin{array}{l}\text { Female } \\
(n=10)\end{array}$ & $\begin{array}{l}\text { Male } \\
(n=10)\end{array}$ & $\begin{array}{l}\text { Female } \\
(n=10)\end{array}$ & $\begin{array}{c}\text { Male } \\
(n=10)\end{array}$ & $\begin{array}{l}\text { Female } \\
(\mathrm{n}=10)\end{array}$ \\
\hline Age range & $5-7 ; 6$ & $5 ; 3-7 ; 6$ & $9-11 ; 6$ & $9 ; 2-11 ; 4$ & $18 ; 3-23 ; 6$ & $18-28 ; 1$ \\
\hline Mean & $6 ; 2$ & $6 ; 4$ & $10 ; 4$ & $10 ; 1$ & $19 ; 9$ & $19 ; 5$ \\
\hline
\end{tabular}


upper respiratory infections at the time of data collection. None of the participants of the current study reported having a tonsillectomy or an adenoidectomy.

Participants underwent a velopharyngeal function screening by the primary investigator. Each participant was screened for normal nasal emission by means of a mirror placed under the nostrils. In addition, a visual examination of the oral cavity was performed for all the children by the primary investigator to rule out undetected submucous cleft palate (i.e., bifid uvula or midline palatal translucence).

\section{Speech Sample}

During the data collecting session, participants were instructed to produce utterances containing the nonsense syllables /ana/, and /ini/ embedded within two carrier phrases as the following:
1. "Say/ana/ again".
2. “/ana/ again".
3. "Say /ini/ again".
4. “/ini/ again".

Because each nonsense syllable contains a vowel preceding and another one following the nasal consonant, they are appropriate to investigate both anticipatory and carryover VPC, also the choice of the vowels (high and low) is appropriate to detect possible vowel height effect on the duration and the volume of anticipatory and carryover nasal airflow. The chosen carrier phrase would provide a vowel sequence before the nasal sound, which would be useful to test the predictions of the coproduction model of the timing of velar movement. For the purpose of the current study, the two carrier phrases will be referred as two production levels. Level I will refer to the phrase with "say" and level II will refer to the one without "say" preceding the VNV sequence.

All participants practiced the speech tasks before their speech sample was collected. They were instructed to produce each trial on a single exhalation. Participants were asked to produce the speech tasks using self-determined rate, pitch, and loudness. Participants produced ten trials for one speech task consecutively then moved to the next speech task. The speech tasks were presented to the participants in the same order shown above. It was found easier for participants, particularly younger children, to produce the carrier phrase with "say' before the one without "say". All of the ten trials for each utterance were considered for the purpose of temporal and aerodynamic analysis. This is particularly important for calculation of within subject variability of the temporal and aerodynamic characteristics of nasal airflow.

To rule out a possible learning effect on the productions of speech tasks, paired sample t-tests were performed on the durations of anticipatory and carryover nasal airflow intervals between $\mathrm{v}$ the first and last attempts for each speech task. No significant 
difference was found between the first and last attempts concerning the durations of nasal airflow intervals (all $p \mathrm{~s}>.05$ ).

\section{Instrumentation}

Aerodynamic speech data including nasal and oral airflow were collected. Partitioned, circumferentially-vented pneumotachograph face masks (Glottal Enterprises, Syracuse, NY) and two air pressure transducers (Setra, Model 239, Acton, MA) were used to detect nasal and oral airflow. The masks and transducers were calibrated on a daily basis with a compressed air supply and rotameter. In addition to the aerodynamic signals, the voice signal was obtained through a calibrated microphone (PERCI-SARS model; Microtronics, Inc., Chapel Hill, NC) placed 5" from the oral portion of the mask. Airflow data were low-pass filtered at $50 \mathrm{~Hz}$ and digitized to a computer at a rate of 1000 samples/s with 12 bit resolution. Acoustic data were low-pass filtered at $10 \mathrm{kHz}$ and digitized at a sampling rate of $20 \mathrm{kHz}$ with 12 bit resolution. PERCI-SARS (Version 3.43; Microtronics, Inc., Chapel Hill, NC) hardware and software were used to acquire all data. The partitioned masks were disinfected after each use. Two masks, adult and child sizes were used to obtain nasal and oral airflow from children and adults.

\section{Data Segmentation and Data Analysis}

Data segmentation for temporal and aerodynamic measurements was based on information provided by the nasal and oral airflow as well as the oral acoustic signal. Four measurement features were identified (see Figure 4).

1. Total syllable which was identified between the onset and offset of the oral acoustic signal (points $1 \& 6$ ).

2. Anticipatory nasal flow determined to be between the point when nasal airflow crosses the zero level plus $10 \%$ of the maximum level of nasal airflow (point 2) and the first peak oral airflow (point 3).

3. Nasal consonant interval was identified between the first peak oral airflow (point 3 ) and the second peak oral airflow (point 4). This interval also contains peak nasal airflow associated with $/ \mathrm{n} /$.

4. Carryover nasal flow was identified between the second peak oral airflow (point 4 ) and the point where nasal airflow exceeds the $10 \%$ of maximum nasal airflow (point 5).

The $10 \%$ of maximum nasal flow was calculated for each speaker in each segment. This percentage was arbitrarily chosen as the minimum level of nasal airflow that would be considered part of the VPC effects. In their study, Bell-Berti \& Harris (1981) noticed a suppression of the velum during oral vowels in oral contexts. We assume that this may cause a small amount of air to escape through the nasal cavity which is not related to the gesture of velar lowering in anticipation of a nasal consonant. Therefore, for the proposed study, any amount of nasal airflow below $10 \%$ of the peak 


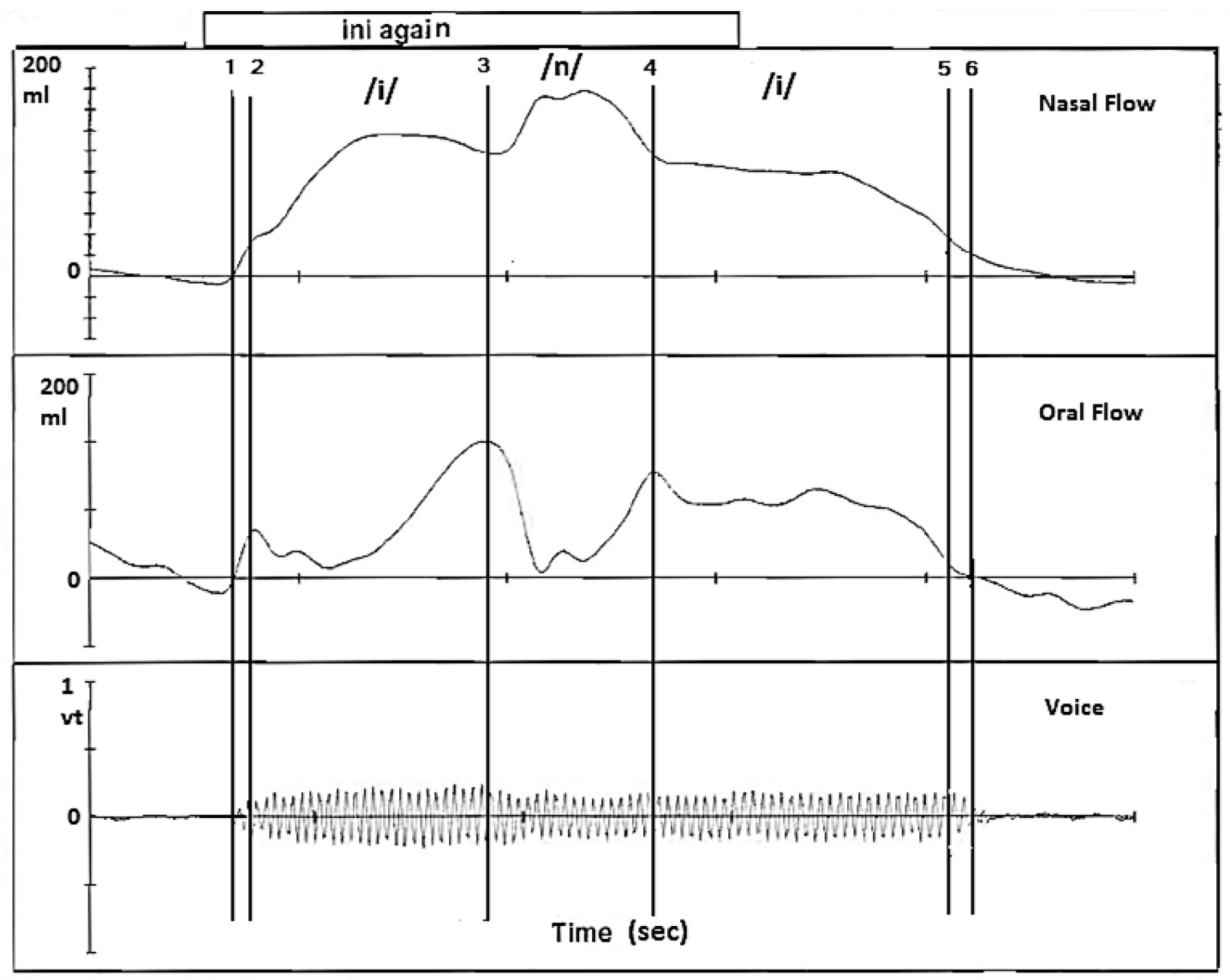

Figure 4. Example of nasal flow, oral flow and voice signal for an adult female production of /ini/.

1-6: whole utterance duration.

2-3: duration of anticipatory nasal flow.

3-4: duration of nasal consonant.

4-5: duration of carryover nasal flow. 
nasal airflow will be excluded from the temporal and aerodynamic measurement related to VPC.

In order to answer the questions of this study, both temporal and aerodynamic measurements were obtained for the both anticipatory and carryover nasal airflow from participants' production of utterances containing VNV sequence. These measurements included the following:

1. Absolute duration for anticipatory nasal flow, and carryover nasal flow segments.

2. Proportional duration for both anticipatory and carryover nasal flow segments computed as the absolute duration of each nasal flow segment divided by the total utterance duration. This is done to control possible variability in utterance length or speech rate.

3. Volumes of anticipatory and carryover nasal airflow segments measured in milliliters.

4. Ratios of the volumes for anticipatory and carryover nasal airflow segments. This is computed as nasal air flow volume divided by oral-plusnasal airflow volume. This measurement is important to control possible variation in respiratory force and allowed the observation of oral-nasal coupling patterns.

\section{Statistical Analysis}

Means, standard deviations and coefficients of variation (CVs) for nasal airflow volume, ratios of nasal-plus oral airflow volume, and absolute and proportional durations of nasal flow segments were computed. Mixed design $3 \times 2 \times 2 \times 2$ ANOVAs were used to determine possible age group (three levels), gender (two levels), vowel context (two levels), and production level (two levels) effects on the mean data for each temporal and aerodynamic measurement. Post hoc differences among age groups were determined using a Tukey test.

To calculate within subject variability, (COVs) were computed as the standard deviation divided by the mean of each temporal and aerodynamic measurement for each speaker. Between groups $3 \times 2$ ANOVAs were used to determine possible age group and gender effect on the resulting CVs. Alpha level was set at 0.05 to test for statistical significance. 


\section{CHAPTER 4. RESULTS}

\section{Descriptive Statistics}

Table 2 summarizes means and standard deviations of the absolute duration of anticipatory nasal airflow in seconds for the three groups for the production of /ana/ and /ini/ in two production levels, level I (with say) vs. level II (without say). Mean durations of nasal airflow for younger girls during their production of /ana/ at level I and level II of production were $0.138 \mathrm{~s}(\mathrm{SD}=.034)$ and $0.154 \mathrm{~s}(\mathrm{SD}=.038)$, respectively. In the case of /ini/, mean durations of anticipatory nasal airflow were $0.132 \mathrm{~s}(\mathrm{SD}=.028)$ for level I production and $0.148 \mathrm{~s}(\mathrm{SD}=.022)$ for level II. For younger boys, mean durations of anticipatory nasal airflow were $0.135 \mathrm{~s}(\mathrm{SD}=.032)$ and $0.141 \mathrm{~s}(\mathrm{SD}=.024)$ for level I and level II productions of /ana/, respectively. As for /ini/, mean anticipatory nasal airflow durations were 0.109.s $(\mathrm{SD}=.024)$ for level I and $0.126 \mathrm{~s}(\mathrm{SD}=.029)$ for level II, respectively.

For the older children, group mean durations, in seconds, of anticipatory nasal airflow for girls were $0.096 \mathrm{~s}(\mathrm{SD}=.018)$ and $0.111 \mathrm{~s}(\mathrm{SD}=.020)$ for level I and II productions of /ana/, respectively, and $0.102 \mathrm{~s}(\mathrm{SD}=.026)$ and $0.107 \mathrm{~s}(\mathrm{SD}=.024)$ for levels I and II productions of /ini/, respectively. Group mean durations for boys were $0.094 \mathrm{~s}(\mathrm{SD}=.035)$ for level I and $0.115 \mathrm{~s}(\mathrm{SD}=.028)$ for level II productions of /ana/. In the case of $/$ ini/, mean durations were $0.087 \mathrm{~s}(\mathrm{SD}=.023)$ and $0.116 \mathrm{~s}(\mathrm{SD}=.024)$ for level I and II, respectively.

With regard to adult speakers, group mean durations of anticipatory nasal airflow in seconds for women at level I and II of /ana/ were $0.092 \mathrm{~s}(\mathrm{SD}=.019)$ and $0.096 \mathrm{~s}$ $(\mathrm{SD}=.019)$, respectively. For /ini/, mean durations for women at level I and level II of production were $0.095 \mathrm{~s}(\mathrm{SD}=.015)$ and $0.100 \mathrm{~s}(\mathrm{SD}=.017)$, respectively. Mean durations of anticipatory nasal flow for men were $0.078 \mathrm{~s}(\mathrm{SD}=.020)$ and $0.090 \mathrm{~s}$ $(\mathrm{SD}=.024)$ for levels I and II productions of /ana/, respectively, and $0.064 \mathrm{~s}(\mathrm{SD}=.029)$ and $0.071 \mathrm{~s}(\mathrm{SD}=.021)$ for levels I and II productions of /ini/, respectively.

Table 3 summarizes means and standard deviations of the absolute duration of carryover nasal airflow in seconds for the three age groups. Group mean durations of carryover nasal airflow for younger girls during their production of /ana/ at level I and level II of production were $0.132 \mathrm{~s}(\mathrm{SD}=.038)$ and $0.151 \mathrm{~s}(\mathrm{SD}=.033)$, respectively. In the case of /ini/, mean group durations of carryover nasal airflow were $0.147 \mathrm{~s}$ $(\mathrm{SD}=.031)$ for level I and $0.166 \mathrm{~s}(\mathrm{SD}=.045)$ for level II of production. For younger boys, Group mean durations of carryover nasal airflow were $0.129 \mathrm{~s}(\mathrm{SD}=.032)$ and $0.131 \mathrm{~s}(\mathrm{SD}=.025)$ for level I and level II productions of /ana/, respectively. As for /ini/, mean durations were $0.137 \mathrm{~s}(\mathrm{SD}=.030)$ for level $\mathrm{I}$ and $0.149 \mathrm{~s}(\mathrm{SD}=.032)$ for level II of production.

Regarding the older children, group mean durations of carryover nasal airflow for girls were $0.128 \mathrm{~s}(\mathrm{SD}=.021)$ and $0.134 \mathrm{~s}(\mathrm{SD}=.022)$ for level I and II productions of 
Table 2. Descriptive statistics for the absolute duration of anticipatory nasal airflow in seconds as a function of age group, gender, and vowel height and production level.

\begin{tabular}{|c|c|c|c|c|c|c|}
\hline \multirow[b]{2}{*}{ Age group } & \multirow[b]{2}{*}{ Gender } & \multirow[b]{2}{*}{ Stat. } & \multicolumn{2}{|c|}{$/ \mathbf{a} /$} & \multicolumn{2}{|c|}{ /i/ } \\
\hline & & & Level I & Level II & Level I & Level II \\
\hline \multirow{8}{*}{$\begin{array}{l}\text { Younger } \\
\text { children }\end{array}$} & \multirow{4}{*}{$\begin{array}{l}\text { Female } \\
(n=10)\end{array}$} & $\mathrm{M}$ & 0.138 & 0.154 & 0.132 & 0.148 \\
\hline & & Min & 0.087 & 0.114 & 0.1 & 0.123 \\
\hline & & Max & 0.187 & 0.224 & 0.188 & 0.194 \\
\hline & & S.D. & 0.034 & 0.038 & 0.028 & 0.022 \\
\hline & \multirow{4}{*}{$\begin{array}{c}\text { Male } \\
(n=10)\end{array}$} & M & 0.135 & 0.141 & 0.109 & 0.126 \\
\hline & & Min & 0.101 & 0.112 & 0.072 & 0.091 \\
\hline & & Max & 0.204 & 0.188 & 0.157 & 0.182 \\
\hline & & S.D. & 0.032 & 0.024 & 0.024 & 0.029 \\
\hline \multirow{8}{*}{$\begin{array}{c}\text { Older } \\
\text { children }\end{array}$} & \multirow{4}{*}{$\begin{array}{l}\text { Female } \\
(n=10)\end{array}$} & $\mathrm{M}$ & 0.096 & 0.111 & 0.102 & 0.107 \\
\hline & & Min & 0.073 & 0.083 & 0.075 & 0.077 \\
\hline & & Max & 0.129 & 0.138 & 0.144 & 0.161 \\
\hline & & S.D. & 0.018 & 0.02 & 0.026 & 0.024 \\
\hline & \multirow{4}{*}{$\begin{array}{c}\text { Male } \\
(n=10)\end{array}$} & M & 0.094 & 0.115 & 0.087 & 0.116 \\
\hline & & Min & 0.042 & 0.076 & 0.056 & 0.086 \\
\hline & & Max & 0.156 & 0.159 & 0.117 & 0.157 \\
\hline & & S.D. & 0.035 & 0.028 & 0.023 & 0.024 \\
\hline \multirow[t]{8}{*}{ Adults } & \multirow{4}{*}{$\begin{array}{l}\text { Female } \\
(n=10)\end{array}$} & $\mathrm{M}$ & 0.092 & 0.096 & 0.095 & 0.1 \\
\hline & & Min & 0.059 & 0.072 & 0.062 & 0.073 \\
\hline & & Max & 0.116 & 0.139 & 0.114 & 0.134 \\
\hline & & S.D. & 0.019 & 0.019 & 0.015 & 0.017 \\
\hline & \multirow{4}{*}{$\begin{array}{l}\text { Male } \\
(n=10)\end{array}$} & M & 0.078 & 0.09 & 0.064 & 0.071 \\
\hline & & Min & 0.053 & 0.062 & 0.018 & 0.038 \\
\hline & & Max & 0.112 & 0.128 & 0.097 & 0.104 \\
\hline & & S.D. & 0.02 & 0.024 & 0.029 & 0.021 \\
\hline
\end{tabular}

Level I: Carrier phrase including "say" before VNV sequence.

Level II: Carrier phrase without "say" before VNV sequence. 
Table 3. Descriptive statistics for the absolute duration of carryover nasal airflow in seconds as a function of age group, gender, vowel height and production level.

\begin{tabular}{|c|c|c|c|c|c|c|}
\hline \multirow[b]{2}{*}{ Age group } & \multirow[b]{2}{*}{ Gender } & \multirow[b]{2}{*}{ Stat. } & \multicolumn{2}{|c|}{$/ \mathbf{a} /$} & \multicolumn{2}{|c|}{$/ \mathbf{i} /$} \\
\hline & & & Level I & Level II & Level I & Level II \\
\hline \multirow{8}{*}{$\begin{array}{l}\text { Younger } \\
\text { children }\end{array}$} & \multirow{4}{*}{$\begin{array}{l}\text { Female } \\
(n=10)\end{array}$} & $\mathrm{M}$ & 0.134 & 0.151 & 0.147 & 0.166 \\
\hline & & Min & 0.082 & 0.107 & 0.107 & 0.113 \\
\hline & & Max & 0.194 & 0.203 & 0.2 & 0.248 \\
\hline & & S.D. & 0.038 & 0.036 & 0.031 & 0.045 \\
\hline & \multirow{4}{*}{$\begin{array}{l}\text { Male } \\
(n=10)\end{array}$} & M & 0.129 & 0.131 & 0.137 & 0.149 \\
\hline & & Min & 0.095 & 0.095 & 0.111 & 0.109 \\
\hline & & Max & 0.191 & 0.173 & 0.193 & 0.215 \\
\hline & & S.D. & 0.032 & 0.025 & 0.03 & 0.032 \\
\hline \multirow{8}{*}{$\begin{array}{c}\text { Older } \\
\text { children }\end{array}$} & \multirow{4}{*}{$\begin{array}{l}\text { Female } \\
(n=10)\end{array}$} & $\mathrm{M}$ & 0.128 & 0.134 & 0.145 & 0.148 \\
\hline & & Min & 0.093 & 0.108 & 0.113 & 0.096 \\
\hline & & Max & 0.152 & 0.167 & 0.176 & 0.203 \\
\hline & & S.D. & 0.021 & 0.022 & 0.024 & 0.033 \\
\hline & \multirow{4}{*}{$\begin{array}{l}\text { Male } \\
(n=10)\end{array}$} & $\mathrm{M}$ & 0.145 & 0.163 & 0.16 & 0.194 \\
\hline & & Min & 0.08 & 0.09 & 0.132 & 0.143 \\
\hline & & Max & 0.211 & 0.245 & 0.259 & 0.363 \\
\hline & & S.D. & 0.051 & 0.047 & 0.039 & 0.062 \\
\hline \multirow[t]{8}{*}{ Adults } & \multirow{4}{*}{$\begin{array}{l}\text { Female } \\
(n=10)\end{array}$} & $\mathrm{M}$ & 0.127 & 0.134 & 0.154 & 0.16 \\
\hline & & Min & 0.07 & 0.087 & 0.129 & 0.137 \\
\hline & & Max & 0.168 & 0.196 & 0.203 & 0.208 \\
\hline & & S.D. & 0.035 & 0.036 & 0.02 & 0.02 \\
\hline & \multirow{4}{*}{$\begin{array}{l}\text { Male } \\
(n=10)\end{array}$} & M & 0.145 & 0.13 & 0.151 & 0.16 \\
\hline & & Min & 0.069 & 0.089 & 0.074 & 0.07 \\
\hline & & Max & 0.41 & 0.234 & 0.196 & 0.206 \\
\hline & & S.D. & 0.099 & 0.047 & 0.042 & 0.044 \\
\hline
\end{tabular}

Level I: Carrier phrase including "say" before VNV sequence.

Level II: Carrier phrase without "say" before VNV sequence. 
/ana/, respectively, and $0.145 \mathrm{~s}(\mathrm{SD}=.024)$ and $0.148 \mathrm{~s}(\mathrm{SD}=.033)$ for levels I and II productions of /ini/, respectively. Group mean durations for boys were $0.145 \mathrm{~s}$ $(\mathrm{SD}=.051)$ for level I and $0.163 \mathrm{~s}(\mathrm{SD}=.047)$ for level II productions of /ana/. In the case of /ini/, mean carryover nasal airflow durations were $0.160 \mathrm{~s}(\mathrm{SD}=.039)$ and $0.194 \mathrm{~s}$ $(\mathrm{SD}=.062)$ for level I and II, respectively.

With regard to adult speakers, group mean durations of carryover nasal airflow for women at level I and II of /ana/ were $0.127 \mathrm{~s}(\mathrm{SD}=.035)$ and $0.134 \mathrm{~s}(\mathrm{SD}=.036)$, and $/$ ini/ were $0.154(\mathrm{SD}=.020)$ and $0.160 \mathrm{~s}(\mathrm{SD}=.020)$. For men, mean carryover duration was $0.145 \mathrm{~s}(\mathrm{SD}=.099)$ and $0.130 \mathrm{~s}(\mathrm{SD}=.047)$ for levels I and II productions of /ana/, respectively, and $0.151 \mathrm{~s}(\mathrm{SD}=.042)$ for level I and $0.160 \mathrm{~s}(\mathrm{SD}=.044)$ for level II productions of /ini/, respectively.

Table 4 summarizes descriptive statistics for the proportional duration of anticipatory nasal airflow (absolute duration of anticipatory nasal flow divided by the entire duration of the VNV sequence) for the three age groups. Mean proportional duration of anticipatory nasal airflow for younger girls in the case of /ana/ were 0.360 $(\mathrm{SD}=.037)$ and $0.365(\mathrm{SD}=.043)$ at level I and level II of production, respectively. In the case of /ini/, mean proportional duration were $0.322(\mathrm{SD}=.040)$ for level I production and $0.342(\mathrm{SD}=.040)$ for level II. Group mean proportional durations of anticipatory nasal airflow for younger boys were $0.352(\mathrm{SD}=.025)$ and 0.358 $(\mathrm{SD}=.030)$ for level I and level II productions of /ana/, respectively. For /ini/, mean proportional durations for younger boys were $0.288(\mathrm{SD}=.022)$ for level I and 0.306 $(\mathrm{SD}=.038)$ for level II of production.

For the older children, group mean proportional durations of anticipatory nasal airflow for girls were $0.281(\mathrm{SD}=.037)$ and $0.303(\mathrm{SD}=.035)$ for level I and II productions of /ana/, respectively, and $0.250(\mathrm{SD}=.036)$ and $0.274(\mathrm{SD}=.026)$ for levels I and II productions of /ini/, respectively. Group mean proportional durations for boys were $0.253(\mathrm{SD}=.057)$ for level I and $0.280(\mathrm{SD}=.039)$ for level II productions of /ana/. In the case of /ini/, mean proportional durations of anticipatory nasal airflow for boys were $0.229(\mathrm{SD}=.049)$ and $0.253(\mathrm{SD}=.032)$ for levels I and II, respectively.

Regarding adult speakers, group mean proportional durations of anticipatory nasal airflow for women at levels I and II productions of /ana/ were $0.269(\mathrm{SD}=.026)$ and $0.270(\mathrm{SD}=.030)$, respectively, In the case of /ini/ group mean proportional durations for women were $0.263(\mathrm{SD}=.028)$ and $0.265(\mathrm{SD}=.026)$ at levels I and II of production, respectively. Mean proportional durations of anticipatory nasal airflow for men were $0.231(\mathrm{SD}=.045)$ and $0.255(\mathrm{SD}=.051)$ for level I and II productions of /ana/, respectively. For /ini/, mean proportional durations of anticipatory nasal airflow for men were $0.166(\mathrm{SD}=.067)$ and $0.184(\mathrm{SD}=.04)$ for level I and level II productions, respectively.

Table 5 summarizes the descriptive statistics of the proportional duration of carryover nasal airflow (ratio of the duration of carryover nasal flow to the duration of the entire VNV sequence) for the three age groups. Group mean proportional durations of 
Table 4. Descriptive statistics for the proportional duration of anticipatory nasal airflow as a function of age group, gender, vowel height and production level.

\begin{tabular}{|c|c|c|c|c|c|c|}
\hline \multirow[b]{2}{*}{ Age group } & \multirow[b]{2}{*}{ Gender } & \multirow[b]{2}{*}{ Stat. } & \multicolumn{2}{|c|}{$/ \mathbf{a} /$} & \multicolumn{2}{|c|}{$/ \mathbf{i} /$} \\
\hline & & & Level I & Level II & Level I & Level II \\
\hline \multirow{8}{*}{$\begin{array}{l}\text { Younger } \\
\text { children }\end{array}$} & \multirow{4}{*}{$\begin{array}{l}\text { Female } \\
(n=10)\end{array}$} & $\mathrm{M}$ & 0.36 & 0.365 & 0.322 & 0.342 \\
\hline & & Min & 0.293 & 0.315 & 0.238 & 0.249 \\
\hline & & Max & 0.408 & 0.459 & 0.386 & 0.383 \\
\hline & & S.D. & 0.037 & 0.043 & 0.04 & 0.04 \\
\hline & \multirow{4}{*}{$\begin{array}{c}\text { Male } \\
(n=10)\end{array}$} & $\mathrm{M}$ & 0.352 & 0.358 & 0.288 & 0.306 \\
\hline & & Min & 0.321 & 0.321 & 0.261 & 0.255 \\
\hline & & Max & 0.393 & 0.4 & 0.329 & 0.368 \\
\hline & & S.D. & 0.025 & 0.03 & 0.022 & 0.038 \\
\hline \multirow{8}{*}{$\begin{array}{c}\text { Older } \\
\text { children }\end{array}$} & \multirow{4}{*}{$\begin{array}{l}\text { Female } \\
(n=10)\end{array}$} & $\mathrm{M}$ & 0.281 & 0.303 & 0.25 & 0.274 \\
\hline & & Min & 0.227 & 0.258 & 0.21 & 0.238 \\
\hline & & Max & 0.34 & 0.346 & 0.307 & 0.328 \\
\hline & & S.D. & 0.037 & 0.035 & 0.036 & 0.026 \\
\hline & \multirow{4}{*}{$\begin{array}{l}\text { Male } \\
(n=10)\end{array}$} & M & 0.253 & 0.28 & 0.229 & 0.253 \\
\hline & & Min & 0.178 & 0.232 & 0.167 & 0.21 \\
\hline & & Max & 0.334 & 0.375 & 0.304 & 0.296 \\
\hline & & S.D. & 0.057 & 0.039 & 0.049 & 0.032 \\
\hline \multirow[t]{8}{*}{ Adults } & \multirow{4}{*}{$\begin{array}{l}\text { Female } \\
(n=10)\end{array}$} & $\mathrm{M}$ & 0.269 & 0.27 & 0.263 & 0.265 \\
\hline & & Min & 0.215 & 0.227 & 0.202 & 0.218 \\
\hline & & Max & 0.3 & 0.328 & 0.313 & 0.304 \\
\hline & & S.D. & 0.026 & 0.03 & 0.028 & 0.026 \\
\hline & \multirow{4}{*}{$\begin{array}{l}\text { Male } \\
(n=10)\end{array}$} & $\mathrm{M}$ & 0.231 & 0.255 & 0.166 & 0.184 \\
\hline & & Min & 0.163 & 0.192 & 0.06 & 0.129 \\
\hline & & Max & 0.332 & 0.373 & 0.262 & 0.251 \\
\hline & & S.D. & 0.045 & 0.051 & 0.067 & 0.042 \\
\hline
\end{tabular}

Level I: Carrier phrase including "say" before VNV sequence.

Level II: Carrier phrase without "say" before VNV sequence. 
Table 5. Descriptive statistics for the proportional duration of carryover nasal airflow as a function of age group, gender, vowel height and production level.

\begin{tabular}{|c|c|c|c|c|c|c|}
\hline \multirow[b]{2}{*}{ Age group } & \multirow[b]{2}{*}{ Gender } & \multirow[b]{2}{*}{ Stat. } & \multicolumn{2}{|c|}{$/ \mathbf{a} /$} & \multicolumn{2}{|c|}{$/ \mathbf{i} /$} \\
\hline & & & Level I & Level II & Level I & Level II \\
\hline \multirow{8}{*}{$\begin{array}{l}\text { Younger } \\
\text { children }\end{array}$} & \multirow{4}{*}{$\begin{array}{l}\text { Female } \\
(n=10)\end{array}$} & $\mathrm{M}$ & 0.346 & 0.359 & 0.362 & 0.447 \\
\hline & & Min & 0.268 & 0.3 & 0.327 & 0.393 \\
\hline & & Max & 0.416 & 0.439 & 0.416 & 0.542 \\
\hline & & S.D. & 0.049 & 0.042 & 0.028 & 0.048 \\
\hline & \multirow{4}{*}{$\begin{array}{l}\text { Male } \\
(n=10)\end{array}$} & $\mathrm{M}$ & 0.34 & 0.333 & 0.352 & 0.417 \\
\hline & & Min & 0.296 & 0.299 & 0.304 & 0.362 \\
\hline & & Max & 0.395 & 0.369 & 0.417 & 0.459 \\
\hline & & S.D. & 0.033 & 0.024 & 0.035 & 0.034 \\
\hline \multirow{8}{*}{$\begin{array}{c}\text { Older } \\
\text { children }\end{array}$} & \multirow{4}{*}{$\begin{array}{l}\text { Female } \\
(n=10)\end{array}$} & $\mathrm{M}$ & 0.372 & 0.367 & 0.385 & 0.435 \\
\hline & & Min & 0.282 & 0.264 & 0.322 & 0.359 \\
\hline & & Max & 0.411 & 0.428 & 0.426 & 0.504 \\
\hline & & S.D. & 0.042 & 0.05 & 0.034 & 0.047 \\
\hline & \multirow{4}{*}{$\begin{array}{l}\text { Male } \\
(n=10)\end{array}$} & $\mathrm{M}$ & 0.394 & 0.392 & 0.39 & 0.469 \\
\hline & & Min & 0.318 & 0.337 & 0.325 & 0.391 \\
\hline & & Max & 0.48 & 0.489 & 0.503 & 0.601 \\
\hline & & S.D. & 0.061 & 0.047 & 0.055 & 0.055 \\
\hline \multirow[t]{8}{*}{ Adults } & \multirow{4}{*}{$\begin{array}{l}\text { Female } \\
(n=10)\end{array}$} & $\mathrm{M}$ & 0.366 & 0.371 & 0.426 & 0.488 \\
\hline & & Min & 0.256 & 0.29 & 0.391 & 0.445 \\
\hline & & Max & 0.456 & 0.431 & 0.482 & 0.524 \\
\hline & & S.D. & 0.059 & 0.049 & 0.026 & 0.024 \\
\hline & \multirow{4}{*}{$\begin{array}{l}\text { Male } \\
(n=10)\end{array}$} & M & 0.358 & 0.363 & 0.4 & 0.47 \\
\hline & & Min & 0.233 & 0.261 & 0.239 & 0.33 \\
\hline & & Max & 0.48 & 0.531 & 0.529 & 0.546 \\
\hline & & S.D. & 0.078 & 0.082 & 0.083 & 0.069 \\
\hline
\end{tabular}

Level I: Carrier phrase including "say" before VNV sequence.

Level II: Carrier phrase without "say" before VNV sequence. 
carryover nasal airflow for younger girls during their production of /ana/ at level I and level II of production were $0.346(\mathrm{SD}=.049)$ and $0.359(\mathrm{SD}=.042)$, respectively. In the case of /ini/, mean proportional durations of carryover nasal airflow were 0.362 $(\mathrm{SD}=.028)$ for level I and $0.447(\mathrm{SD}=.048)$ for level II of production. For younger boys, mean proportional durations of carryover nasal airflow were $0.340(\mathrm{SD}=.033)$ and $0.333(\mathrm{SD}=.024)$ for level I and level II productions of /ana/, respectively, and in the case of /ini/, mean proportional durations for younger boys were $0.352(\mathrm{SD}=.035)$ for level I and $0.435(\mathrm{SD}=.047)$ for level II of production, respectively.

For the older children, group mean proportional durations of carryover nasal airflow for girls were $0.372(\mathrm{SD}=.042)$ and $0.367(\mathrm{SD}=.050)$ for level I and II productions of /ana/, respectively, and $0.385(\mathrm{SD}=.034)$ and $0.435(\mathrm{SD}=.047)$ for levels I and II productions of /ini/, respectively. Group mean proportional durations of carryover nasal airflow for boys were $0.394(\mathrm{SD}=.061)$ for level I and $0.392(\mathrm{SD}=.047)$ for level II productions of /ana/. In the case of /ini/, group mean proportional durations of carryover nasal airflow for older boys were $0.390(\mathrm{SD}=.055)$ and $0.469(\mathrm{SD}=.055)$ for level I and II, respectively.

For adult speakers, group mean proportional durations of carryover nasal airflow for women at levels I and II of /ana/ were $0.366(\mathrm{SD}=.059)$ and $0.371(\mathrm{SD}=.049)$, respectively. In the case of /ini/, group mean proportional durations for women were $0.366(\mathrm{SD}=.59)$ and $0.371(\mathrm{SD}=.049)$ for levels I and II, respectively. Group mean proportional durations of carryover nasal airflow for men were $0.358(\mathrm{SD}=.078)$ and $0.363(\mathrm{SD}=.082)$ for levels I and II productions of /ana/, respectively. Men's mean proportional durations were $0.400(\mathrm{SD}=.083)$ for level I and $0.470(\mathrm{SD}=.069)$ for II productions of /ini/, respectively.

Summary of descriptive statistics for the volume of anticipatory nasal flow, in milliliters, for the three age groups are shown on Table 6. For younger children, girls' mean volumes of anticipatory nasal airflow were $7.507 \mathrm{ml}(\mathrm{SD}=5.471)$ and $8.774 \mathrm{ml}$ $(\mathrm{SD}=5.085)$ at level I and level II of productions of /ana/, respectively. In the case of /ini/, mean volumes of anticipatory nasal airflow were $7.562 \mathrm{ml}(\mathrm{SD}=5.264)$ for level I production and $9.822 \mathrm{ml}(\mathrm{SD}=3.318)$ for level II. Group mean volumes of anticipatory nasal airflow for boys were $6.469 \mathrm{ml}(\mathrm{SD}=5.751)$, and $6.559 \mathrm{ml}(\mathrm{SD}=4.038)$ for level I and level II productions of /ana/, respectively. As for /ini/, mean volumes for younger boys were $6.787 \mathrm{ml}(\mathrm{SD}=3.130)$ for level I and $7.546 \mathrm{ml}(\mathrm{SD}=3.471)$ for level II, respectively.

For the older children, group mean volumes of anticipatory nasal airflow for girls were $6.256 \mathrm{ml}(\mathrm{SD}=3.534)$ and $9.572 \mathrm{ml}(\mathrm{SD}=8.303)$ for level I and II productions of /ana/, respectively, and $7.822 \mathrm{ml}(\mathrm{SD}=3.922)$ and $10.006 \mathrm{ml}(\mathrm{SD}=4.887)$ for levels I and II productions of /ini/, respectively. Group mean anticipatory nasal airflow volumes for boys were $3.866 \mathrm{ml}(\mathrm{SD}=3.098)$ for level I and $5.566 \mathrm{ml}(\mathrm{SD}=3.826)$ for level II productions of /ana/. In the case of /ini/, group mean volumes for older boys were 4.635 $\mathrm{ml}(\mathrm{SD}=2.919)$ and $6.6 \mathrm{ml}(\mathrm{SD}=2.915)$ for levels I and II, respectively. 
Table 6. Descriptive statistics for the absolute volume of anticipatory nasal airflow in milliliters as a function of age group, gender, vowel height and production level.

\begin{tabular}{|c|c|c|c|c|c|c|}
\hline \multirow[b]{2}{*}{ Age group } & \multirow[b]{2}{*}{ Gender } & \multirow[b]{2}{*}{ Stat. } & \multicolumn{2}{|c|}{$/ \mathbf{a} /$} & \multicolumn{2}{|c|}{$/ \mathbf{i} /$} \\
\hline & & & Level I & Level II & Level II & Level II \\
\hline \multirow{8}{*}{$\begin{array}{l}\text { Younger } \\
\text { children }\end{array}$} & \multirow{4}{*}{$\begin{array}{l}\text { Female } \\
(n=10)\end{array}$} & $\mathrm{M}$ & 7.507 & 8.774 & 7.562 & 9.822 \\
\hline & & Min & 3.749 & 3.737 & 1.701 & 3.092 \\
\hline & & Max & 21.264 & 21.766 & 16.593 & 19.958 \\
\hline & & S.D. & 5.471 & 5.085 & 5.264 & 5.318 \\
\hline & \multirow{4}{*}{$\begin{array}{l}\text { Male } \\
(n=10)\end{array}$} & M & 6.469 & 6.559 & 6.787 & 7.546 \\
\hline & & Min & 2.293 & 2.742 & 3.785 & 3.466 \\
\hline & & Max & 21.186 & 15.528 & 13.722 & 15.014 \\
\hline & & S.D. & 5.751 & 4.038 & 3.13 & 3.471 \\
\hline \multirow{8}{*}{$\begin{array}{c}\text { Older } \\
\text { children }\end{array}$} & \multirow{4}{*}{$\begin{array}{l}\text { Female } \\
(n=10)\end{array}$} & $\mathrm{M}$ & 6.256 & 9.572 & 7.822 & 10.006 \\
\hline & & Min & 3.303 & 3.862 & 3.294 & 3.382 \\
\hline & & Max & 14.135 & 32.229 & 14.602 & 18.735 \\
\hline & & S.D. & 3.534 & 8.303 & 3.922 & 4.887 \\
\hline & \multirow{4}{*}{$\begin{array}{c}\text { Male } \\
(n=10)\end{array}$} & $\mathrm{M}$ & 3.866 & 5.566 & 4.635 & 6.6 \\
\hline & & Min & 1.087 & 2.452 & 2.331 & 2.686 \\
\hline & & Max & 11.46 & 14.225 & 11.163 & 13.234 \\
\hline & & S.D. & 3.098 & 3.826 & 2.919 & 2.915 \\
\hline \multirow[t]{8}{*}{ Adults } & \multirow{4}{*}{$\begin{array}{l}\text { Female } \\
(n=10)\end{array}$} & M & 3.44 & 4.814 & 5.475 & 6.769 \\
\hline & & Min & 1.767 & 1.389 & 3.443 & 3.498 \\
\hline & & Max & 7.69 & 9.638 & 11.406 & 10.417 \\
\hline & & S.D. & 1.849 & 2.487 & 2.394 & 2.412 \\
\hline & \multirow{4}{*}{$\begin{array}{l}\text { Male } \\
(n=10)\end{array}$} & $\mathrm{M}$ & 3.775 & 4.728 & 3.09 & 3.513 \\
\hline & & Min & 1.286 & 2.127 & 0.34 & 1.163 \\
\hline & & Max & 8.126 & 7.959 & 6.626 & 7.345 \\
\hline & & S.D. & 2.171 & 1.91 & 2.083 & 2.079 \\
\hline
\end{tabular}

Level I: Carrier phrase including "say" before VNV sequence. Level II: Carrier phrase without "say" before VNV sequence. 
Regarding adult speakers, group mean volumes of anticipatory nasal airflow for women at level I and II of /ana/ were $3.440 \mathrm{ml}(\mathrm{SD}=1.849)$ and $4.814 \mathrm{ml}(\mathrm{SD}=2.487)$, respectively. In the case of /ini/, mean volumes of anticipatory nasal airflow segment were $5.475 \mathrm{ml}(\mathrm{SD}=2.394)$ and $6.769 \mathrm{ml}(\mathrm{SD}=2.412)$ for levels I and II, respectively. For men, group mean volumes of anticipatory nasal airflow were $3.775 \mathrm{ml}(\mathrm{SD}=2.171)$ and $4.728 \mathrm{ml}(\mathrm{SD}=1.91)$ for levels I and II productions of /ana/, respectively. In the case of /ini/, group mean volumes for men were $3.09 \mathrm{ml}(\mathrm{SD}=2.083)$ for level I and $3.513 \mathrm{ml}$ $(\mathrm{SD}=2.079)$ for level II.

Table 7 contains a summary of descriptive statistics for the volume of carryover nasal flow in milliliters for the three age groups. Group mean volumes of carryover nasal airflow for younger girls were $4.592 \mathrm{ml}(\mathrm{SD}=3.042)$ and $6.866 \mathrm{ml}(\mathrm{SD}=6.086)$ at level I and level II of productions of /ana/, respectively. In the case of /ini/, group mean volumes were $10.345 \mathrm{ml}(\mathrm{SD}=7.766)$ for level $\mathrm{I}$ and $10.969 \mathrm{ml}(\mathrm{SD}=6.041)$ for level II of production. Group mean volumes of carryover nasal airflow for younger boys were $5.081 \mathrm{ml}(\mathrm{SD}=6.081)$ and $4.723 \mathrm{ml}(\mathrm{SD}=2.573)$ for level I and level II productions of /ana/, respectively. As for /ini/, mean carryover nasal airflow volumes for younger boys were $8.313 \mathrm{ml}(\mathrm{SD}=4.602)$ for level I and $9.837 \mathrm{ml}(\mathrm{SD}=6.540)$ for level II of production.

For the older children, group mean volumes of carryover nasal airflow for older girls were $5.804 \mathrm{ml}(\mathrm{SD}=3.357)$ and $7.148 \mathrm{ml}(\mathrm{SD}=4.209)$ for level I and II productions of /ana/, respectively, and $13.330 \mathrm{ml}(\mathrm{SD}=6.698)$ and $14.354 \mathrm{ml}$ $(\mathrm{SD}=7.081)$ for levels I and II productions of /ini/, respectively. Group mean volumes of carryover nasal airflow for older boys were $4.172 \mathrm{ml}(\mathrm{SD}=2.903)$ for level I and 7.458 $\mathrm{ml}(\mathrm{SD}=8.19)$ for level II productions of /ana/. In the case of /ini/, mean volumes of carryover nasal airflow for older boys were $9.527 \mathrm{ml}(\mathrm{SD}=6.484)$ and $13.633 \mathrm{ml}$ $(\mathrm{SD}=9.917)$ for levels I and II, respectively.

Regarding adult speakers, group mean volumes of carryover nasal airflow for women at level I and II of /ana/ were $4.358 \mathrm{ml}(\mathrm{SD}=2.834)$ and $5.004 \mathrm{ml}(\mathrm{SD}=2.931)$. In the case of /ini/, mean volumes of carryover nasal flow were $11.203 \mathrm{ml}(\mathrm{SD}=3.837)$ and $12.902 \mathrm{ml}(\mathrm{SD}=6.522)$ for levels I and II, respectively. For men, group mean volumes of carryover nasal airflow were $6.399 \mathrm{ml}(\mathrm{SD}=5.166)$ and $6.847 \mathrm{ml}$ $(\mathrm{SD}=6.541)$ for levels I and II productions of /ana/, respectively. Group mean volumes of carryover nasal airflow for men were $12.130 \mathrm{ml}(\mathrm{SD}=8.863)$ for level I and $14.539 \mathrm{ml}$ $(\mathrm{SD}=12.104)$ for level II productions of /ini/.

Table 8 summarizes the descriptive statistics for the ratio of nasal to oral-plusnasal airflow volume obtained from anticipatory nasal airflow segment for the three age groups. Group mean ratios of anticipatory nasal airflow volume for younger girls were $0.354(\mathrm{SD}=.091)$ and $0.368(\mathrm{SD}=.064)$ at level I and level II of productions of /ana/, respectively. In the case of /ini/, mean ratios of anticipatory nasal airflow were 0.527 $(\mathrm{SD}=.143)$ for level I production and $0.538(\mathrm{SD}=.114)$ for level II. Group mean ratios of the volume of anticipatory nasal airflow for Boys were $0.350(\mathrm{SD}=.107)$ and 0.351 $(\mathrm{SD}=.106)$ for level I and level II productions of /ana/, respectively. For /ini/, mean 
Table 7. Descriptive statistics for the absolute volume of carryover nasal airflow in milliliters as a function of age group, gender, vowel height and production level.

\begin{tabular}{|c|c|c|c|c|c|c|}
\hline \multirow[b]{2}{*}{ Age group } & \multirow[b]{2}{*}{ Gender } & \multirow[b]{2}{*}{ Stat. } & \multicolumn{2}{|c|}{$/ \mathbf{a} /$} & \multicolumn{2}{|c|}{$/ \mathbf{i} /$} \\
\hline & & & Level I & Level II & Level I & Level II \\
\hline \multirow{8}{*}{$\begin{array}{l}\text { Younger } \\
\text { children }\end{array}$} & \multirow{4}{*}{$\begin{array}{l}\text { Female } \\
(n=10)\end{array}$} & M & 4.592 & 6.866 & 10.345 & 10.969 \\
\hline & & Min & 1.303 & 2.244 & 4.838 & 5.881 \\
\hline & & Max & 10.661 & 22.413 & 29.155 & 24.837 \\
\hline & & S.D. & 3.042 & 6.086 & 7.766 & 6.041 \\
\hline & \multirow{4}{*}{$\begin{array}{l}\text { Male } \\
(n=10)\end{array}$} & $\mathrm{M}$ & 5.081 & 4.723 & 8.313 & 9.837 \\
\hline & & Min & 1.796 & 1.989 & 4.189 & 4.267 \\
\hline & & Max & 22.051 & 10.721 & 16.516 & 23.977 \\
\hline & & S.D. & 6.081 & 2.573 & 4.602 & 6.54 \\
\hline \multirow{8}{*}{$\begin{array}{c}\text { Older } \\
\text { children }\end{array}$} & \multirow{4}{*}{$\begin{array}{l}\text { Female } \\
(n=10)\end{array}$} & M & 5.804 & 7.148 & 13.33 & 14.354 \\
\hline & & Min & 1.67 & 2.238 & 4.065 & 4.009 \\
\hline & & Max & 12.583 & 14.394 & 23.216 & 24.264 \\
\hline & & S.D. & 3.357 & 4.209 & 6.698 & 7.081 \\
\hline & \multirow{4}{*}{$\begin{array}{l}\text { Male } \\
(n=10)\end{array}$} & $\mathrm{M}$ & 4.172 & 7.458 & 9.527 & 13.633 \\
\hline & & Min & 1.713 & 1.943 & 2.884 & 3.823 \\
\hline & & Max & 9.301 & 28.474 & 25.648 & 38.914 \\
\hline & & S.D. & 2.903 & 8.109 & 6.484 & 9.917 \\
\hline \multirow[t]{8}{*}{ Adults } & \multirow{4}{*}{$\begin{array}{l}\text { Female } \\
(n=10)\end{array}$} & $\mathrm{M}$ & 4.359 & 5.004 & 11.203 & 11.498 \\
\hline & & Min & 1.685 & 1.877 & 6.375 & 6.534 \\
\hline & & Max & 9.804 & 9.402 & 18.422 & 19.003 \\
\hline & & S.D. & 2.834 & 2.931 & 3.837 & 3.901 \\
\hline & \multirow{4}{*}{$\begin{array}{l}\text { Male } \\
(n=10)\end{array}$} & $\mathrm{M}$ & 6.399 & 6.847 & 12.13 & 14.539 \\
\hline & & Min & 2.144 & 2.968 & 3.579 & 3.538 \\
\hline & & Max & 17.648 & 24.641 & 28.907 & 38.267 \\
\hline & & S.D. & 5.166 & 6.541 & 8.863 & 12.104 \\
\hline
\end{tabular}

Level I: Carrier phrase including "say" before VNV sequence.

Level II: Carrier phrase without "say" before VNV sequence. 
Table 8. Descriptive statistics for the ratio of nasal to oral-plus-nasal airflow volume related to anticipatory nasal flow segment as a function of age, gender, vowel type and production level.

\begin{tabular}{|c|c|c|c|c|c|c|}
\hline \multirow[b]{2}{*}{ Age group } & \multirow[b]{2}{*}{ Gender } & \multirow[b]{2}{*}{ Stat. } & \multicolumn{2}{|c|}{$/ \mathbf{a} /$} & \multicolumn{2}{|c|}{$/ \mathbf{i} /$} \\
\hline & & & Level I & Level II & Level I & Level II \\
\hline \multirow{8}{*}{$\begin{array}{l}\text { Younger } \\
\text { children }\end{array}$} & \multirow{4}{*}{$\begin{array}{l}\text { Female } \\
(n=10)\end{array}$} & $\mathrm{M}$ & 0.354 & 0.368 & 0.527 & 0.538 \\
\hline & & Min & 0.21 & 0.285 & 0.261 & 0.32 \\
\hline & & Max & 0.514 & 0.501 & 0.749 & 0.752 \\
\hline & & S.D. & 0.091 & 0.064 & 0.143 & 0.114 \\
\hline & \multirow{4}{*}{$\begin{array}{c}\text { Male } \\
(n=10)\end{array}$} & $\mathrm{M}$ & 0.35 & 0.351 & 0.557 & 0.564 \\
\hline & & Min & 0.207 & 0.204 & 0.424 & 0.424 \\
\hline & & Max & 0.547 & 0.599 & 0.717 & 0.69 \\
\hline & & S.D. & 0.107 & 0.106 & 0.101 & 0.085 \\
\hline \multirow{8}{*}{$\begin{array}{l}\text { Older } \\
\text { children }\end{array}$} & \multirow{4}{*}{$\begin{array}{l}\text { Female } \\
(n=10)\end{array}$} & $\mathrm{M}$ & 0.323 & 0.345 & 0.542 & 0.549 \\
\hline & & Min & 0.169 & 0.198 & 0.321 & 0.344 \\
\hline & & Max & 0.449 & 0.526 & 0.668 & 0.698 \\
\hline & & S.D. & 0.082 & 0.096 & 0.131 & 0.11 \\
\hline & \multirow{4}{*}{$\begin{array}{l}\text { Male } \\
(n=10)\end{array}$} & $\mathrm{M}$ & 0.32 & 0.316 & 0.491 & 0.529 \\
\hline & & Min & 0.147 & 0.183 & 0.367 & 0.42 \\
\hline & & Max & 0.494 & 0.514 & 0.645 & 0.647 \\
\hline & & S.D. & 0.132 & 0.123 & 0.084 & 0.078 \\
\hline \multirow[t]{8}{*}{ Adults } & \multirow{4}{*}{$\begin{array}{l}\text { Female } \\
(n=10)\end{array}$} & $\mathrm{M}$ & 0.334 & 0.363 & 0.648 & 0.69 \\
\hline & & Min & 0.234 & 0.221 & 0.45 & 0.455 \\
\hline & & Max & 0.597 & 0.56 & 0.876 & 0.884 \\
\hline & & S.D. & 0.113 & 0.128 & 0.132 & 0.133 \\
\hline & \multirow{4}{*}{$\begin{array}{c}\text { Male } \\
(n=10)\end{array}$} & $\mathrm{M}$ & 0.327 & 0.341 & 0.419 & 0.366 \\
\hline & & Min & 0.228 & 0.211 & 0.188 & 0.177 \\
\hline & & Max & 0.462 & 0.659 & 0.697 & 0.568 \\
\hline & & S.D. & 0.092 & 0.13 & 0.164 & 0.131 \\
\hline
\end{tabular}

Level I: Carrier phrase including "say" before VNV sequence.

Level II: Carrier phrase without "say" before VNV sequence. 
ratios of anticipatory nasal airflow volume for younger boys were $0.557(\mathrm{SD}=.101)$ for level I and $0.564(\mathrm{SD}=.085)$ for level II.

For the older children, group mean ratios of anticipatory nasal airflow volume for girls were $0.323(\mathrm{SD}=.082)$ and $0.345(\mathrm{SD}=.096)$ for level I and II productions of /ana/, respectively. For /ini/, mean ratios for older girls were $0.542(\mathrm{SD}=.131)$ and 0.549 $(\mathrm{SD}=.110)$ for levels I and II of production, respectively. Group mean ratios of anticipatory nasal airflow volume for older boys were $0.320(\mathrm{SD}=.132)$ for level I and $0.316(\mathrm{SD}=.123)$ for level II productions of /ana/.

Regarding adult speakers, group mean ratios of anticipatory nasal airflow volume for women at level I and II of /ana/ were $0.334(\mathrm{SD}=.113)$ and $0.363(\mathrm{SD}=.128)$, respectively. In the case of /ini/, mean ratios of were $0.648(\mathrm{SD}=.132)$ and 0.690 $(\mathrm{SD}=.133)$ for levels I and II, respectively. Group mean ratios of anticipatory nasal airflow volume for men were $0.327(\mathrm{SD}=.092)$ and $0.341(\mathrm{SD}=.130)$ for levels I and II productions of /ana/, respectively. For/ini/, group mean ratios for men were 0.419 $(\mathrm{SD}=.164)$ for level I and $0.366(\mathrm{SD}=.131)$ for level II productions of /ini/.

Table 9 summarizes the descriptive statistics for the ratio of nasal to oral-plusnasal airflow volume obtained from carryover nasal airflow segment for the three age groups. Group mean ratios of carryover nasal airflow volume for younger girls were $0.358(\mathrm{SD}=.076)$ and $0.374(\mathrm{SD}=.078)$ at level I and level II of productions of /ana/, respectively. In the case of /ini/, means ratios for younger girls were $0.617(\mathrm{SD}=.134)$ for level I production and $0.546(\mathrm{SD}=.110)$ for level II. Group mean ratios of carryover nasal airflow volume for younger boys were $0.401(\mathrm{SD}=.111)$ and $0.416(\mathrm{SD}=.101)$ for level I and level II productions of /ana/, respectively. As for /ini/, ratios for younger boys were $0.52(\mathrm{SD}=.118)$ for level I and $0.597(\mathrm{SD}=.142)$ for level II.

As for the older children, group mean ratios of carryover nasal airflow volume for older girls were $0.337(\mathrm{SD}=.079)$ and $0.376(\mathrm{SD}=.100)$ for level I and II productions of /ana/, respectively. For older girls, /ini/ ratios were $0.625(\mathrm{SD}=.124)$ and $0.620(\mathrm{SD}=$ .107) for levels I and II of production, respectively. Group mean ratios of carryover nasal airflow volume for older boys were $0.322(\mathrm{SD}=.063)$ for level I and $0.354(\mathrm{SD}=.133)$ for level II productions of /ana/. In the case of /ini/, mean ratios for older boys were 0.571 $(\mathrm{SD}=.171)$ and $0.548(\mathrm{SD}=.137)$ for levels I and II, respectively.

Regarding adult speakers, group mean ratios of carryover nasal airflow volume for women at level I and II of /ana/ were $0.356(\mathrm{SD}=.133)$ and $0.327(\mathrm{SD}=.114)$. In the case of /ini/, mean ratios for women were $0.715(\mathrm{SD}=.099)$ and $0.715 \mathrm{ml}(\mathrm{SD}=.089)$ for levels I and II, respectively. Group mean ratios of carryover nasal airflow volume for men were $0.412(\mathrm{SD}=.078)$ and $0.423(\mathrm{SD}=.120)$ for levels I and II productions of /ana/, respectively. For /ini/ mean ratios for men were $0.484(\mathrm{SD}=.156)$ for level I and $0.484(\mathrm{SD}=.146)$ for level II of production. 
Table 9. Descriptive statistics for the ratio of nasal to oral-plus-nasal airflow volume related to carryover nasal flow segment as a function of age, gender, vowel type and production level.

\begin{tabular}{|c|c|c|c|c|c|c|}
\hline \multirow[b]{2}{*}{ Age group } & \multirow[b]{2}{*}{ Gender } & \multirow[b]{2}{*}{ Stat. } & \multicolumn{2}{|c|}{$/ \mathbf{a} /$} & \multicolumn{2}{|c|}{$/ \mathbf{i} /$} \\
\hline & & & Level I & Level II & Level I & Level II \\
\hline \multirow{8}{*}{$\begin{array}{l}\text { Younger } \\
\text { children }\end{array}$} & \multirow{4}{*}{$\begin{array}{l}\text { Female } \\
(n=10)\end{array}$} & $\mathrm{M}$ & 0.358 & 0.374 & 0.617 & 0.546 \\
\hline & & Min & 0.216 & 0.206 & 0.325 & 0.327 \\
\hline & & Max & 0.488 & 0.513 & 0.755 & 0.693 \\
\hline & & S.D. & 0.076 & 0.078 & 0.134 & 0.11 \\
\hline & \multirow{4}{*}{$\begin{array}{l}\text { Male } \\
(n=10)\end{array}$} & $\mathrm{M}$ & 0.401 & 0.416 & 0.526 & 0.597 \\
\hline & & Min & 0.243 & 0.279 & 0.3 & 0.412 \\
\hline & & Max & 0.608 & 0.559 & 0.685 & 0.832 \\
\hline & & S.D. & 0.111 & 0.101 & 0.118 & 0.142 \\
\hline \multirow{8}{*}{$\begin{array}{c}\text { Older } \\
\text { children }\end{array}$} & \multirow{4}{*}{$\begin{array}{l}\text { Female } \\
(n=10)\end{array}$} & $\mathrm{M}$ & 0.337 & 0.376 & 0.625 & 0.62 \\
\hline & & Min & 0.181 & 0.257 & 0.367 & 0.37 \\
\hline & & Max & 0.457 & 0.591 & 0.797 & 0.71 \\
\hline & & S.D. & 0.079 & 0.1 & 0.124 & 0.107 \\
\hline & \multirow{4}{*}{$\begin{array}{l}\text { Male } \\
(n=10)\end{array}$} & $\mathrm{M}$ & 0.322 & 0.354 & 0.571 & 0.548 \\
\hline & & Min & 0.233 & 0.251 & 0.334 & 0.387 \\
\hline & & Max & 0.455 & 0.689 & 0.782 & 0.725 \\
\hline & & S.D. & 0.063 & 0.133 & 0.171 & 0.137 \\
\hline \multirow[t]{8}{*}{ Adults } & \multirow{4}{*}{$\begin{array}{l}\text { Female } \\
(n=10)\end{array}$} & M & 0.356 & 0.327 & 0.715 & 0.715 \\
\hline & & Min & 0.144 & 0.165 & 0.536 & 0.546 \\
\hline & & Max & 0.633 & 0.488 & 0.859 & 0.853 \\
\hline & & S.D. & 0.133 & 0.114 & 0.099 & 0.089 \\
\hline & \multirow{4}{*}{$\begin{array}{l}\text { Male } \\
(n=10)\end{array}$} & $\mathrm{M}$ & 0.412 & 0.432 & 0.484 & 0.484 \\
\hline & & Min & 0.283 & 0.233 & 0.297 & 0.332 \\
\hline & & Max & 0.507 & 0.612 & 0.842 & 0.764 \\
\hline & & S.D. & 0.078 & 0.12 & 0.156 & 0.146 \\
\hline
\end{tabular}

Level I: Carrier phrase including "say" before VNV sequence. Level II: Carrier phrase without "say" before VNV sequence. 


\section{Statistical Results}

\section{Temporal Measurements}

The results of the mixed design $3 \times 2 \times 2 \times 2$ ANOVA of the effects of age group (younger children, older children, and adults), gender (male vs. female), and the repeated measures vowel type (high $=/ \mathrm{i} / \mathrm{vs}$. low $=/ \mathrm{a} /$ ) and production level (with say vs. without say) indicated the following regarding the absolute duration of anticipatory nasal airflow: main age group effect $\left(\mathrm{F}_{(1,54)}=30.365, p<.001\right)$, gender effect $\left(\mathrm{F}_{(1,54)}=5.468, p<.05\right)$, vowel type effect $\left(\mathrm{F}_{(1,54)}=6.894, p<.05\right)$, production level effect $\left(\mathrm{F}_{(1,54)}=44.775\right.$, $p<.001)$, and a significant interaction between vowel type and gender $\left(\mathrm{F}_{(1,54)}=5.510\right.$, $p<.05)($ see Table 10).

Results of independent sample t-tests revealed that female speakers exhibited longer duration of anticipatory nasal airflow on high vowel contexts compared to male speakers $(\mathrm{t}=-3.030, p<.01)$ and no significant difference was detected between male and female speakers on low vowel contexts (see Figures 5 and 6). A Post hoc Tukey test revealed all three age groups to be significantly different from each other with younger children showing the longest anticipatory nasal airflow interval followed by older children and then adult speakers who showed the shortest duration. In addition, all subjects showed shorter duration of anticipatory nasal airflow when the VNV sequence was produced with 'say' as opposed to without 'say' (see Figure 7).

The results of the mixed design $2 \times 2 \times 2 \times 3$ ANOVA with regard to the absolute duration of carryover nasal airflow are shown in Table 11. No significant gender or age group effect was found; however, there was significant of vowel type $\left(\mathrm{F}_{(1,54)}=17.09\right.$, $p<.001)$ and production level $\left(\mathrm{F}_{(1,54)}=10.73, p<.01\right)$ effects on the absolute duration of carryover nasal airflow segment. All speakers, regardless of age and gender, produced longer duration of carryover nasal airflow in low vowel contexts (see Figure 8) and without 'say' preceding the VNV sequence (see Figure 9).

Mixed design $3 \times 2 \times 2 \times 2$ ANOVA were also performed on the proportional durations of anticipatory and carryover nasal airflow (ratio of duration of nasal airflow segment to entire VNV sequence duration). The results of the mixed design ANOVA with repeated measures regarding time ratio of anticipatory nasal airflow are shown on Table 12.

The ANOVA analysis revealed main effects of age group $\left(\mathrm{F}_{(1,54)}=53.005\right.$, $p<.001)$, gender $\left(\mathrm{F}_{(1,54)}=17.817, p<.001\right)$, vowel type $\left(\mathrm{F}_{(1,54)}=76.982, p<.001\right)$ and production level $\left(\mathrm{F}_{(1,54)}=20.329, p<.001\right)$. In addition, a significant vowel type and gender and age group interaction $\left(\mathrm{F}_{(1,54)}=5.588, p<.01\right)$ was revealed. Specifically, the time ratio of anticipatory nasal airflow was greater when the utterance was not produced with "say" preceding the VNV sequence for all speakers. A subsequent 2 way ANOVA with age group and gender as fixed factors was performed for low vowel contexts. 
Table 10. Results of $2 \times 2 \times 2 \times 3$ ANOVA for the absolute duration of anticipatory nasal airflow.

\begin{tabular}{|c|c|c|c|c|c|}
\hline Effect & $\mathrm{F}$ & $\begin{array}{c}\text { Hypothesis } \\
\text { df }\end{array}$ & Error df & Sig. & $\begin{array}{c}\text { Observed } \\
\text { power }\end{array}$ \\
\hline Gender & 5.468 & 1 & 54 & $.023 *$ & .632 \\
\hline Age group & 30.365 & 2 & 54 & $.000 *$ & 1.000 \\
\hline Gender $\mathrm{x}$ age group & 1.161 & 2 & 54 & .321 & .244 \\
\hline VT & 6.894 & 1 & 54 & $.011^{*}$ & .732 \\
\hline VT x gender & 5.510 & 1 & 54 & $.023 *$ & .635 \\
\hline VT $x$ age group & 1.755 & 2 & 54 & .183 & .352 \\
\hline VT $\mathrm{x}$ gender $\mathrm{x}$ age group & .825 & 2 & 54 & .444 & .184 \\
\hline PL & 44.775 & 1 & 54 & $.000 *$ & 1.000 \\
\hline PL $x$ gender & 2.114 & 1 & 54 & .152 & .298 \\
\hline PL $x$ age group & 2.612 & 2 & 54 & .083 & .499 \\
\hline PL $x$ gender $x$ age group & 2.269 & 2 & 54 & .113 & .442 \\
\hline VT x PL & .029 & 1 & 54 & .865 & .053 \\
\hline VT x PL x gender & .886 & 1 & 54 & .351 & .152 \\
\hline VT $x$ PL $x$ age group & .346 & 2 & 54 & .709 & .103 \\
\hline $\begin{array}{l}\text { VT } x \text { PL } x \text { gender } x \text { age } \\
\text { group }\end{array}$ & .627 & 2 & 54 & .538 & .150 \\
\hline
\end{tabular}

$*=$ significant at Alpha $=.05$.

$\mathrm{VT}=$ vowel type (high vs. low).

$\mathrm{PL}=$ production level: Level I (with say) vs. level II (without say).

$\mathrm{F}=$ between-groups variance/within-groups variance.

$\mathrm{df}=$ degrees of freedom. 


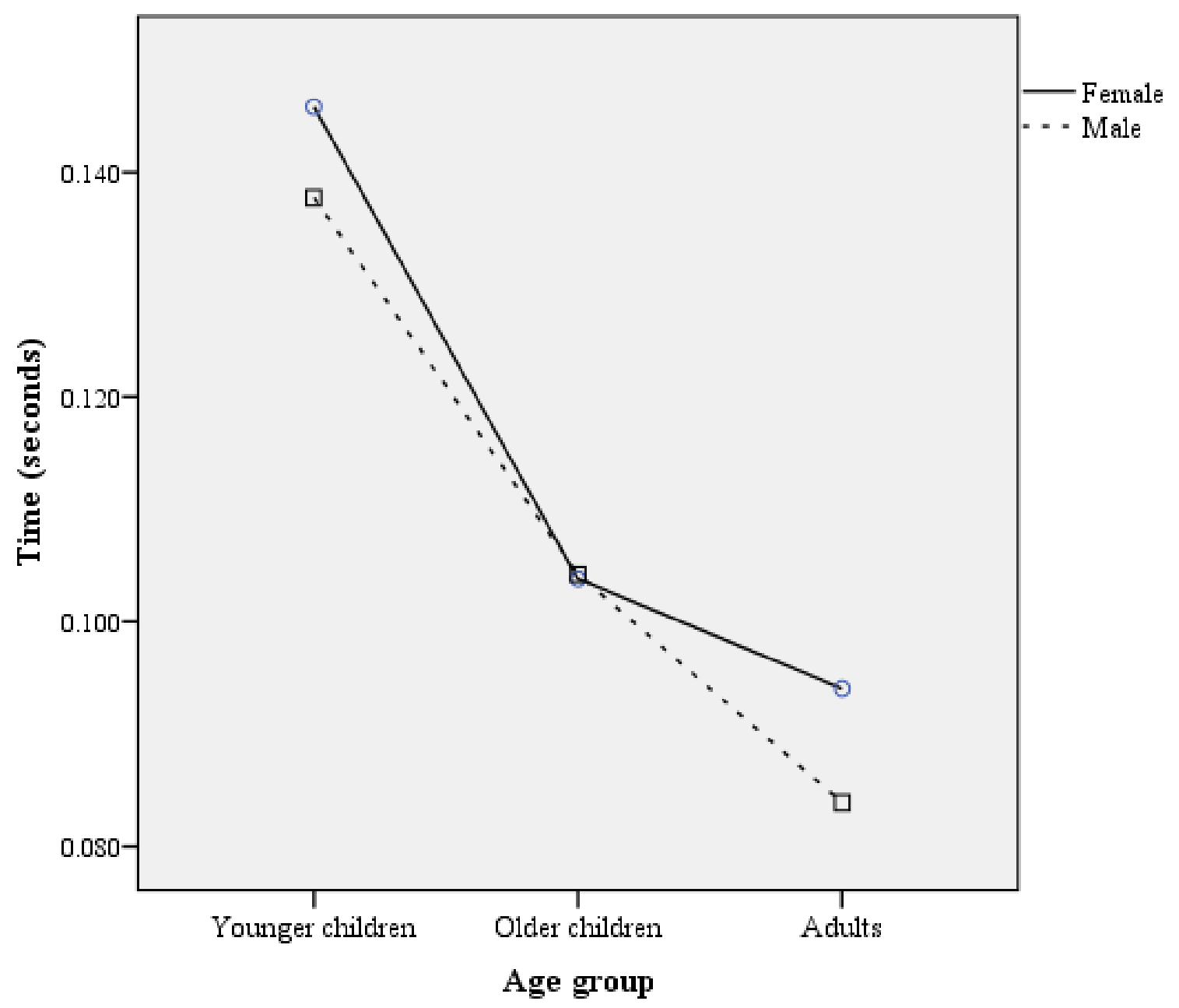

Figure 5. Absolute duration (sec) of anticipatory nasal airflow during the production of /ana/ as a function of age group and gender of the speakers. 


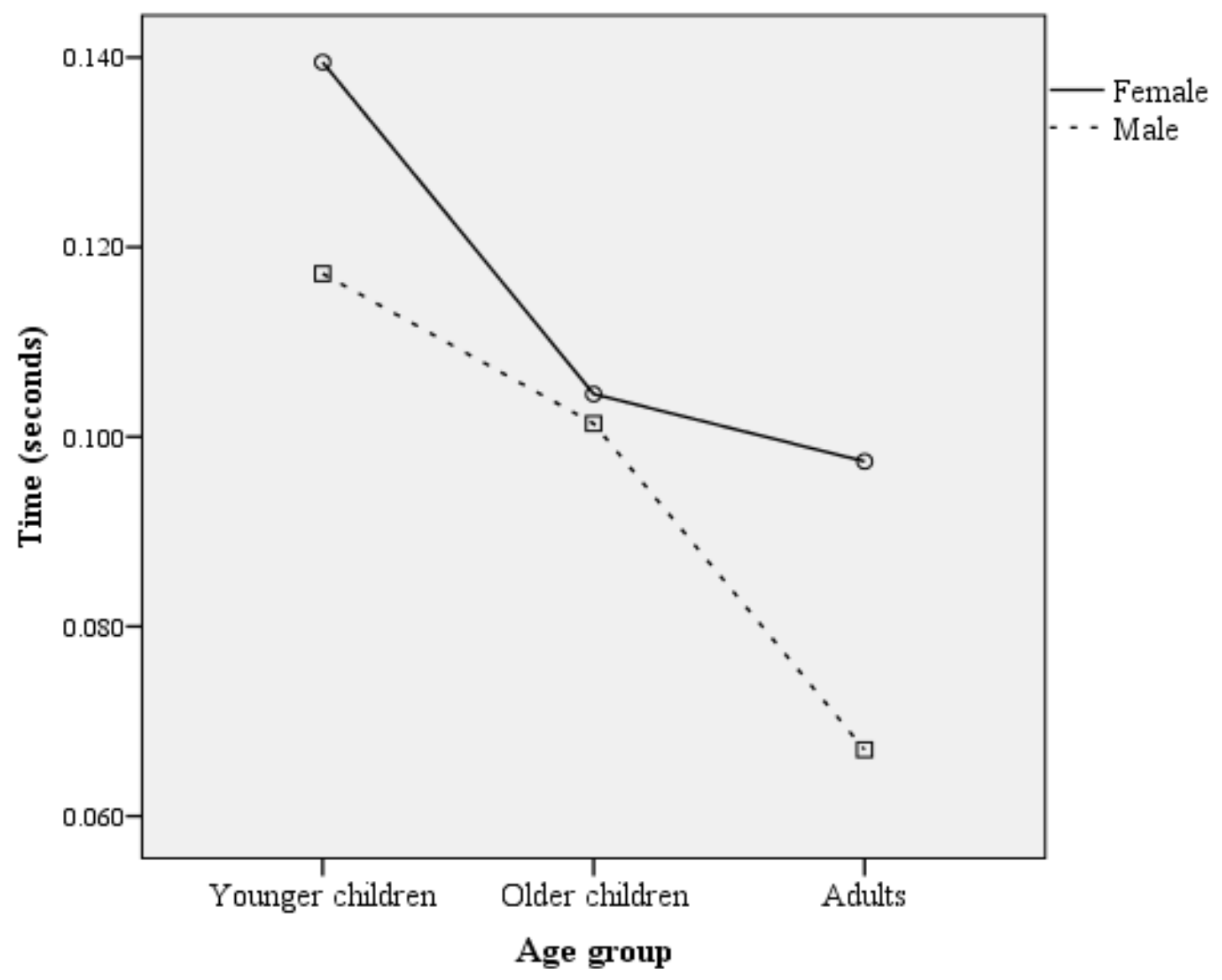

Figure 6. Absolute duration (sec) of anticipatory nasal airflow during the production of /ini/ as a function of age group and gender of the speakers. 


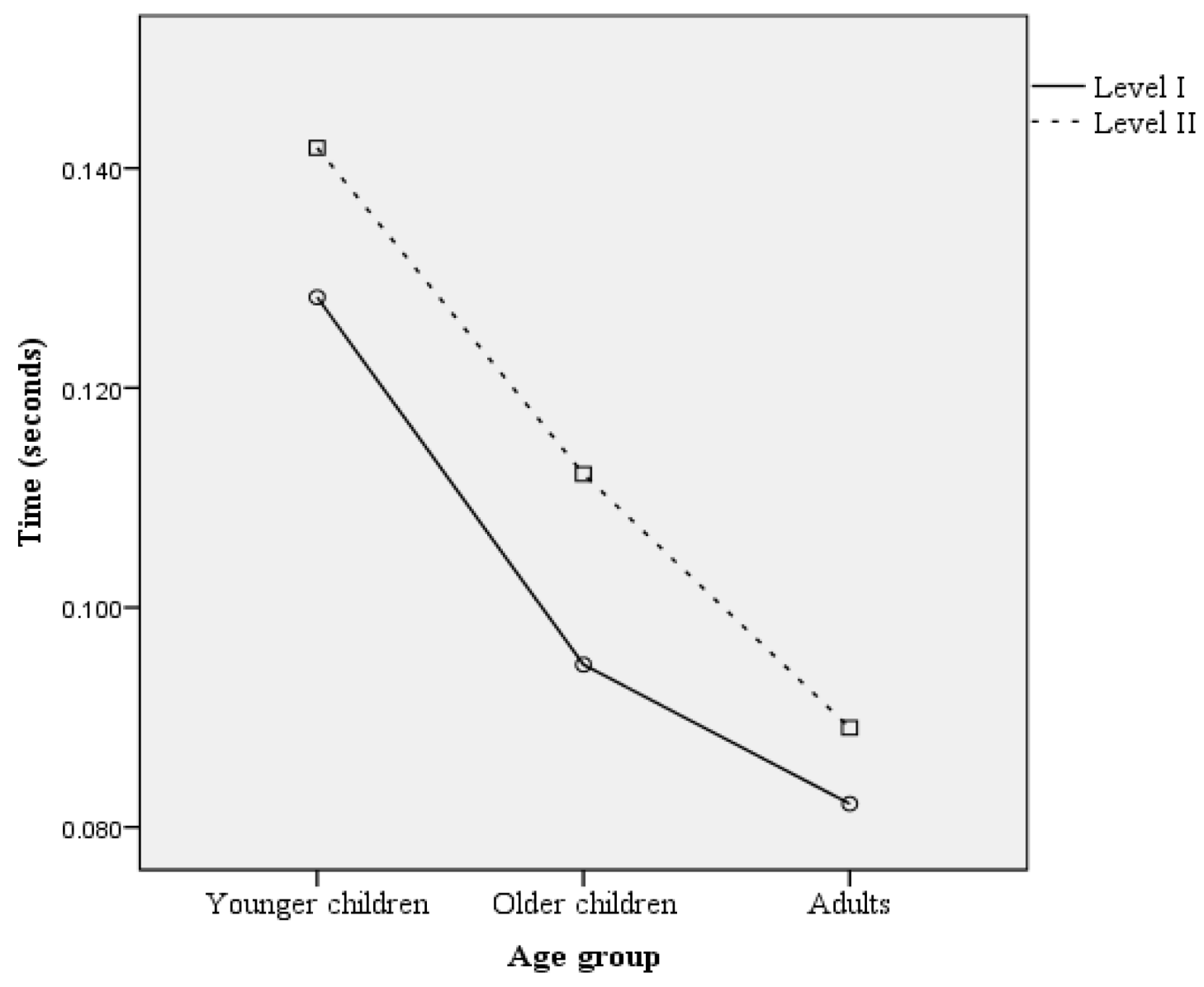

Figure 7. Absolute duration (sec) of anticipatory nasal airflow as a function of age group and production level. 
Table 11. Results of $2 \times 2 \times 2 \times 3$ ANOVA for the absolute duration of carryover nasal airflow.

\begin{tabular}{lccccc}
\hline Effect & F & Hypothesis df & Error df & Sig. & Observed power \\
\hline Gender & 0.411 & 1 & 54 & 0.524 & 0.097 \\
Age group & 0.393 & 2 & 54 & 0.677 & 0.11 \\
Gender x age group & 1.756 & 2 & 54 & 0.182 & 0.352 \\
VT & 17.09 & 1 & 54 & $.000 *$ & 0.982 \\
VT x gender & 0.006 & 1 & 54 & 0.937 & 0.051 \\
VT x age group & 0.35 & 2 & 54 & 0.707 & 0.103 \\
VT x gender x age group & 0.318 & 2 & 54 & 0.729 & 0.098 \\
PL & 10.731 & 1 & 54 & $.002 *$ & 0.896 \\
PL x gender & 0.003 & 1 & 54 & 0.956 & 0.05 \\
PL x age group & 1.925 & 2 & 54 & 0.156 & 0.382 \\
PL x gender x Age group & 3.017 & 2 & 54 & 0.057 & 0.561 \\
VT x PL & 1.716 & 1 & 54 & 0.196 & 0.251 \\
VT x PL x gender & 2.329 & 1 & 54 & 0.133 & 0.323 \\
VT x PL x age group & 0.077 & 2 & 54 & 0.926 & 0.061 \\
$\begin{array}{l}\text { VT x PL x gender x age } \\
\text { group }\end{array}$ & 0.221 & 2 & 54 & 0.802 & 0.083 \\
\hline
\end{tabular}

$*=$ significant at Alpha $=.05$.

$\mathrm{VT}=$ vowel type (high vs. low).

$\mathrm{PL}=$ production level: Level I (with say) vs. level II (without say).

$\mathrm{F}=$ between-groups variance/within-groups variance.

$\mathrm{df}=$ degrees of freedom. 


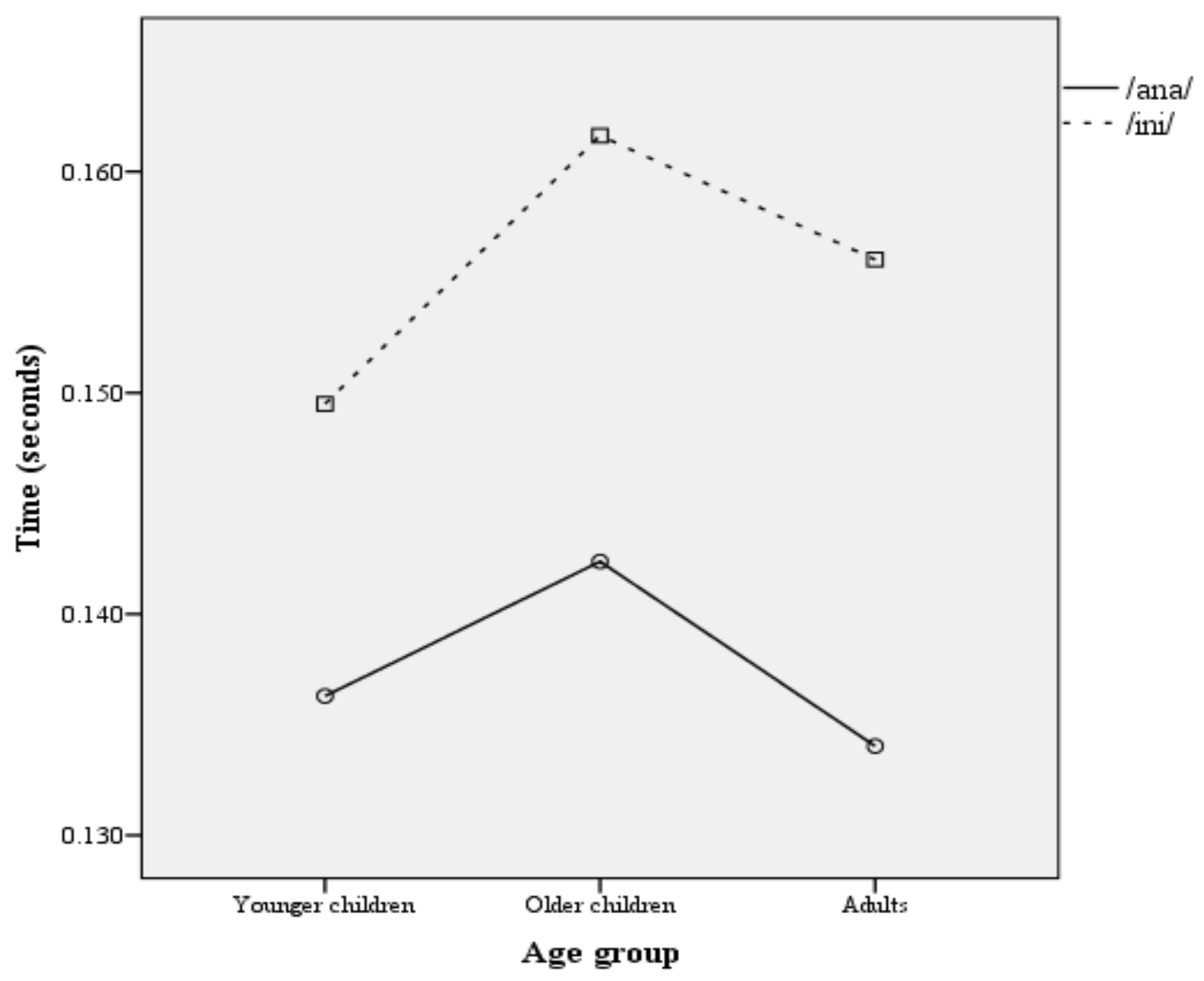

Figure 8. Absolute duration (sec) of carryover nasal airflow as a function of age group and vowel type. 


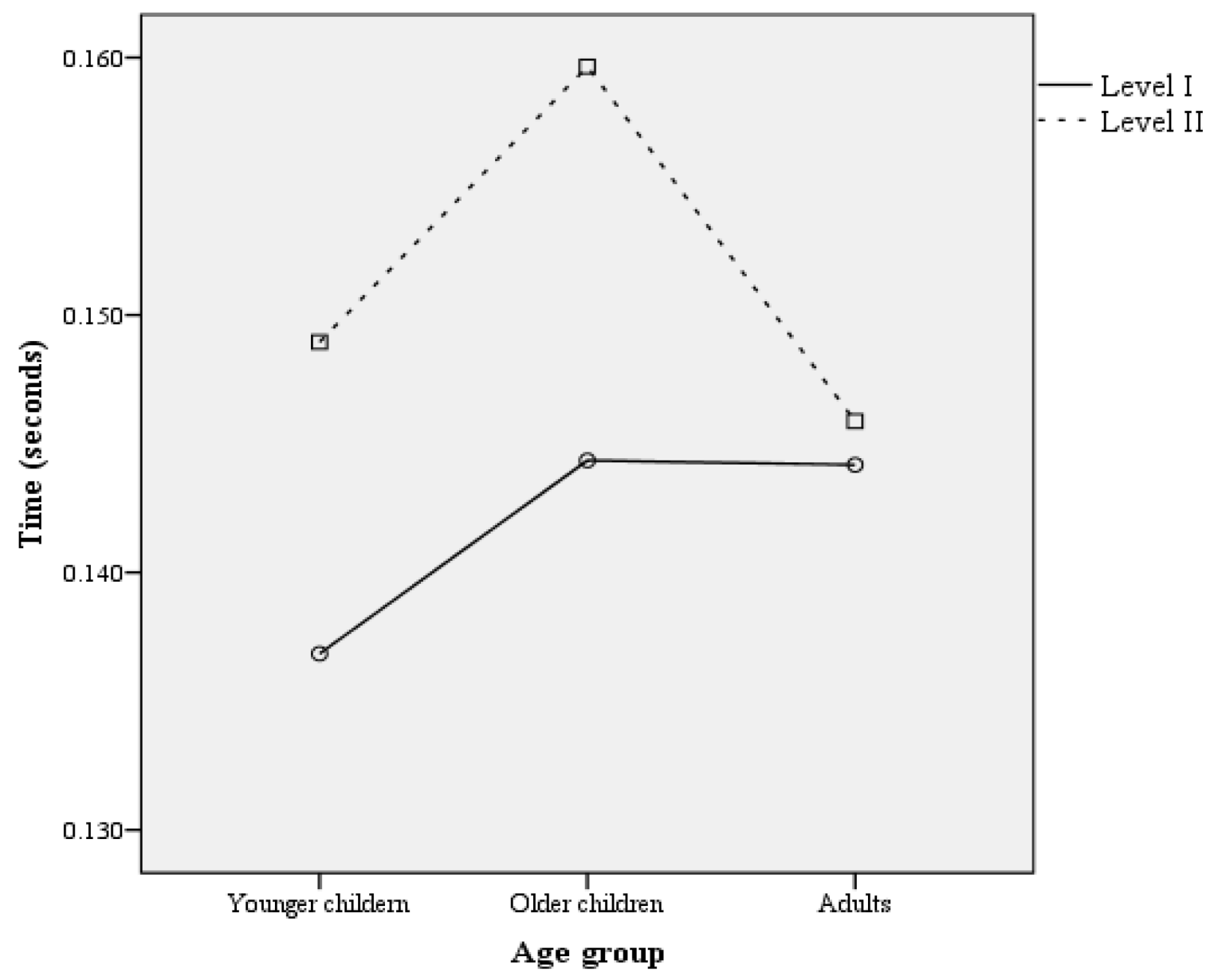

Figure 9. Absolute duration (sec) of carryover nasal airflow as a function of age group and production level. 
Table 12. Results of $2 \times 2 \times 2 \times 3$ ANOVA for the proportional duration of anticipatory nasal airflow.

\begin{tabular}{lccccc}
\hline Effect & F & Hypothesis df & Error df & Sig. & Observed power \\
\hline Gender & 17.817 & 1 & 54 & $.000^{*}$ & 0.986 \\
Age group & 53.005 & 2 & 54 & $.000^{*}$ & 1 \\
Gender x age group & 2.154 & 2 & 54 & 0.126 & 0.422 \\
VT & 76.928 & 1 & 54 & $.000^{*}$ & 1 \\
VT x gender & 11.733 & 1 & 54 & $.001^{*}$ & 0.92 \\
VT x age group & 1.334 & 2 & 54 & 0.272 & 0.276 \\
VT x gender x age group & 5.588 & 2 & 54 & $.006^{*}$ & 0.837 \\
PL & 20.329 & 1 & 54 & $.000^{*}$ & 0.993 \\
PL x gender & 0.928 & 1 & 54 & 0.34 & 0.157 \\
PL x age group & 1.401 & 2 & 54 & 0.255 & 0.288 \\
PL x gender x age group & 0.716 & 2 & 54 & 0.493 & 0.165 \\
VT x PL & 0.427 & 1 & 54 & 0.516 & 0.098 \\
VT x PL x gender & 0.218 & 1 & 54 & 0.642 & 0.074 \\
VT x PL x age group & 0.859 & 2 & 54 & 0.429 & 0.19 \\
$\begin{array}{l}\text { VT x PL x gender x age } \\
\text { group }\end{array}$ & 0.016 & 2 & 54 & 0.984 & 0.052 \\
\hline
\end{tabular}

$*=$ significant at Alpha $=.05$.

$\mathrm{VT}=$ vowel type (high vs. low).

$\mathrm{PL}=$ production level: Level I (with say) vs. level II (without say).

$\mathrm{F}=$ between-groups variance/within-groups variance.

$\mathrm{df}=$ degrees of freedom. 
The ANOVA revealed significant age group $(\mathrm{F}=47.070, p<.001)$ effect on the proportional duration of anticipatory nasal airflow for low vowel contexts. A Post hoc Tukey test revealed that younger children showed significantly greater ratio of anticipatory nasal airflow than both older children and adult speakers on low vowel contexts (see Figure 10). Another 2 way ANOVA was performed on high vowel contexts with age group and gender as fixed factors. The ANOVA revealed significant age group $(\mathrm{F}=37.529, p<.001)$, gender $(\mathrm{F}=28.123 . p<.001)$ effects, as well as a significant age group and gender interaction $(\mathrm{F}=5.250, p<.01)$. A post hoc Tukey test revealed all three age groups to be significantly different from each other with younger children showing the greatest temporal ratio of anticipatory nasal airflow followed by older children and then adult speakers (see Figure 11). Independent sample t-tests revealed that female speakers showed greater temporal ratio of anticipatory nasal airflow only for high vowel context compared to their male counterparts at adult age group $(\mathrm{t}=-5.001$, $p<.001)$ and younger children group $(\mathrm{t}=-2.371, P<.05)$.

With regard to the time ratio of carryover nasal airflow, ANOVA analysis revealed significant age group $\left(\mathrm{F}_{(1,54)}=4.285, p<.05\right)$, vowel type $\left(\mathrm{F}_{(1,54)}=91.391\right.$, $p<.001)$ and production level $\left(\mathrm{F}_{(1,54)}=134.209, p<.001\right)$ effects; moreover, significant vowel type by age group $\left(\mathrm{F}_{(1,54)}=4.840, p<.001\right)$ and vowel type by production level $\left(\mathrm{F}_{(1,54)}=103.498, p<.001\right)$ interactions were observed. No significant gender effect was found (see Table 13).

A post hoc Tukey analysis showed no significant difference in the ratio of carryover nasal airflow between the three age groups on low vowel context. On the other hand, adult speakers had greater time ratio of carryover nasal airflow than the two children groups for the high vowel contexts (see Figure 12). In addition, time ratio of carry over nasal airflow was similar for both production levels (with say vs. without say) at low vowel context, but the ratio was greater when the utterance was produced without 'say' than with 'say' on high vowel context for all speakers (see Figure 13).

\section{Aerodynamic Measurements}

In addition to the temporal measurements, a mixed design $2 \times 2 \times 2 \times 3$ ANOVA was performed to test the effects of age group, gender, vowel type and production level on the absolute volume (in milliliters) as well as proportional volume (nasal to oral-plusnasal airflow) of nasal airflow segments corresponding to anticipatory and carryover velar coarticulation.

In the case of absolute air volume of anticipatory nasal airflow, $2 \times 2 \times 2 \times 3$ ANOVA showed main effects for age group $\left(\mathrm{F}_{(1,54)}=4.338, p<.05\right)$, gender $\left(\mathrm{F}_{(1,54)}=5.076, p<.05\right)$, and production level $\left(\mathrm{F}_{(1,54)}=53.847, p<.001\right)$. Also production level and age group $\left(\mathrm{F}_{(1,54)}=4.289, p<.05\right)$, and production level and gender $\left(\mathrm{F}_{(1,54)}=5.870, p<.05\right)$ interactions were found (see Table 14$)$. The results of a post hoc Tukey test indicated that younger children produced significantly greater nasal airflow volume than adult speakers on both vowel types and production levels (see Figure 14). 


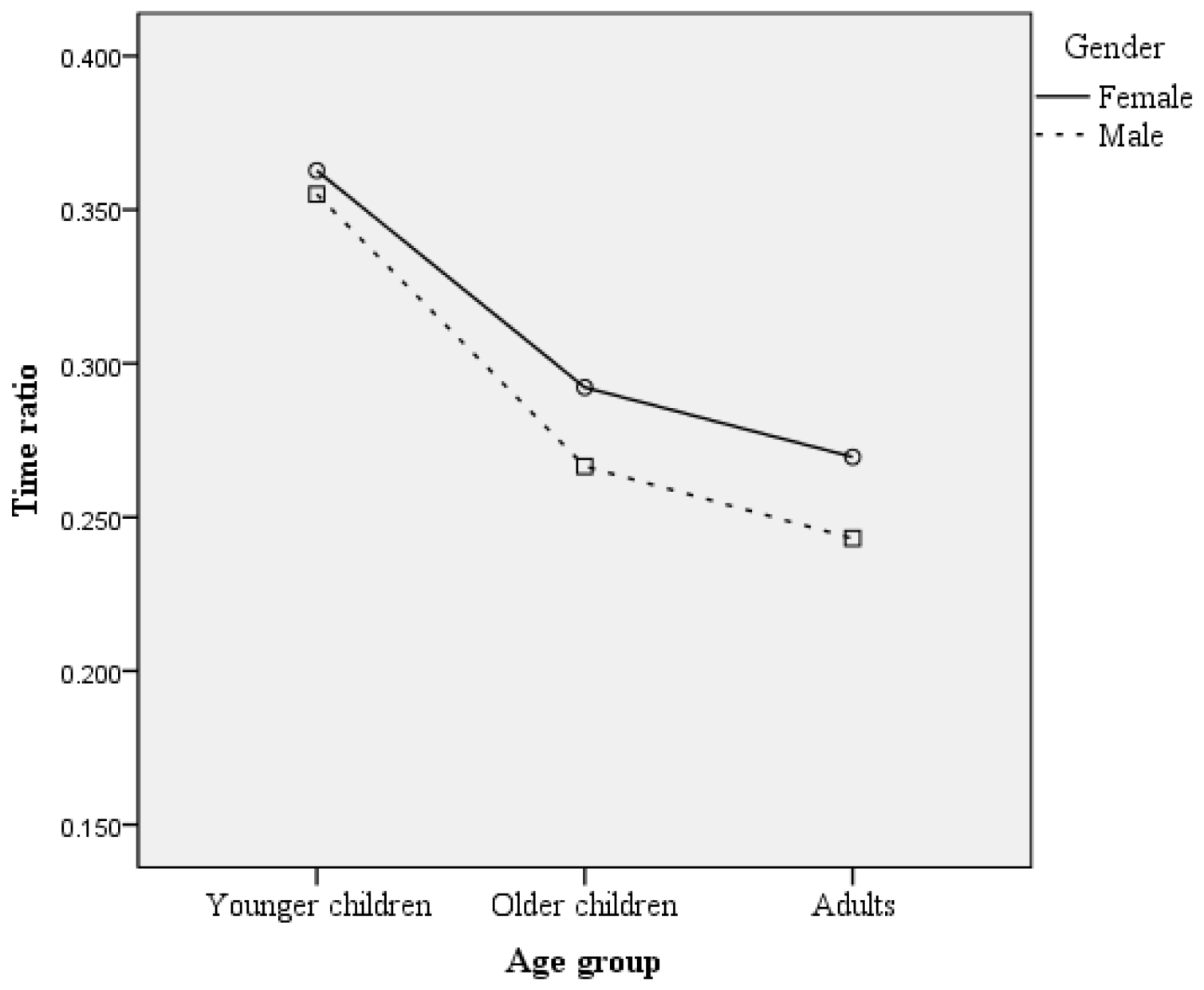

Figure 10. Proportional duration of anticipatory nasal airflow during the production of /ana/ as a function of age group and gender of the speakers. 


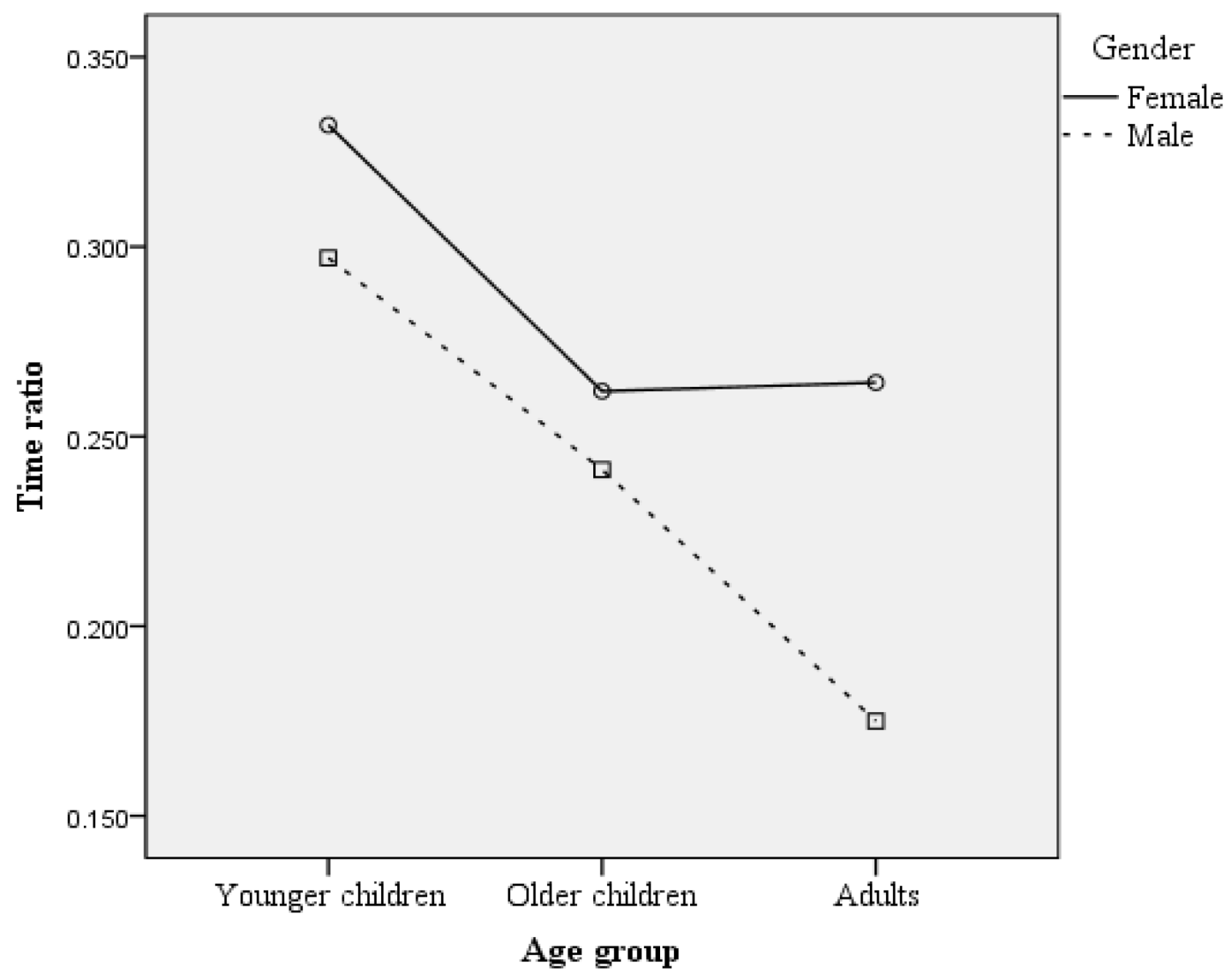

Figure 11. Proportional duration of anticipatory nasal airflow during the production of /ini/ as a function of age group and gender of the speakers. 
Table 13. Results of $2 \times 2 \times 2 \times 3$ ANOVA for the proportional duration of carryover nasal airflow.

\begin{tabular}{|c|c|c|c|c|c|}
\hline Effect & $\mathrm{F}$ & $\begin{array}{l}\text { Hypothesis } \\
\text { df }\end{array}$ & $\begin{array}{c}\text { Error } \\
\text { df }\end{array}$ & Sig. & $\begin{array}{c}\text { Observed } \\
\text { power }\end{array}$ \\
\hline Gender & .120 & 1 & 54 & .730 & .063 \\
\hline Age group & 4.285 & 2 & 54 & $.019 *$ & .724 \\
\hline Gender $x$ age group & 1.388 & 2 & 54 & .258 & .286 \\
\hline VT & 91.391 & 1 & 54 & $.000 *$ & 1.000 \\
\hline VT $x$ gender & .389 & 1 & 54 & .535 & .094 \\
\hline VT $x$ age group & 4.840 & 2 & 54 & $.012 *$ & .778 \\
\hline VT $x$ gender $\mathrm{x}$ age group & .078 & 2 & 54 & .925 & .061 \\
\hline PL & 134.209 & 1 & 54 & $.000 *$ & 1.000 \\
\hline PL $x$ gender & .001 & 1 & 54 & .977 & .050 \\
\hline PL $x$ age group & .685 & 2 & 54 & .508 & .160 \\
\hline PL $x$ gender $x$ age group & 3.150 & 2 & 54 & .051 & .581 \\
\hline VT x PL & 103.498 & 1 & 54 & $.000 *$ & 1.000 \\
\hline VT x PL x gender & .738 & 1 & 54 & .394 & .135 \\
\hline VT x PL x age group & .198 & 2 & 54 & .821 & .079 \\
\hline $\begin{array}{l}\text { VT x PL x gender } x \text { age } \\
\text { group }\end{array}$ & .367 & 2 & 54 & .694 & .106 \\
\hline
\end{tabular}

$*=$ significant at Alpha $=.05$.

$\mathrm{VT}=$ vowel type (high vs. low).

$\mathrm{PL}=$ production level: Level I (with say) vs. level II (without say).

$\mathrm{F}=$ between-groups variance/within-groups variance.

$\mathrm{df}=$ degrees of freedom. 


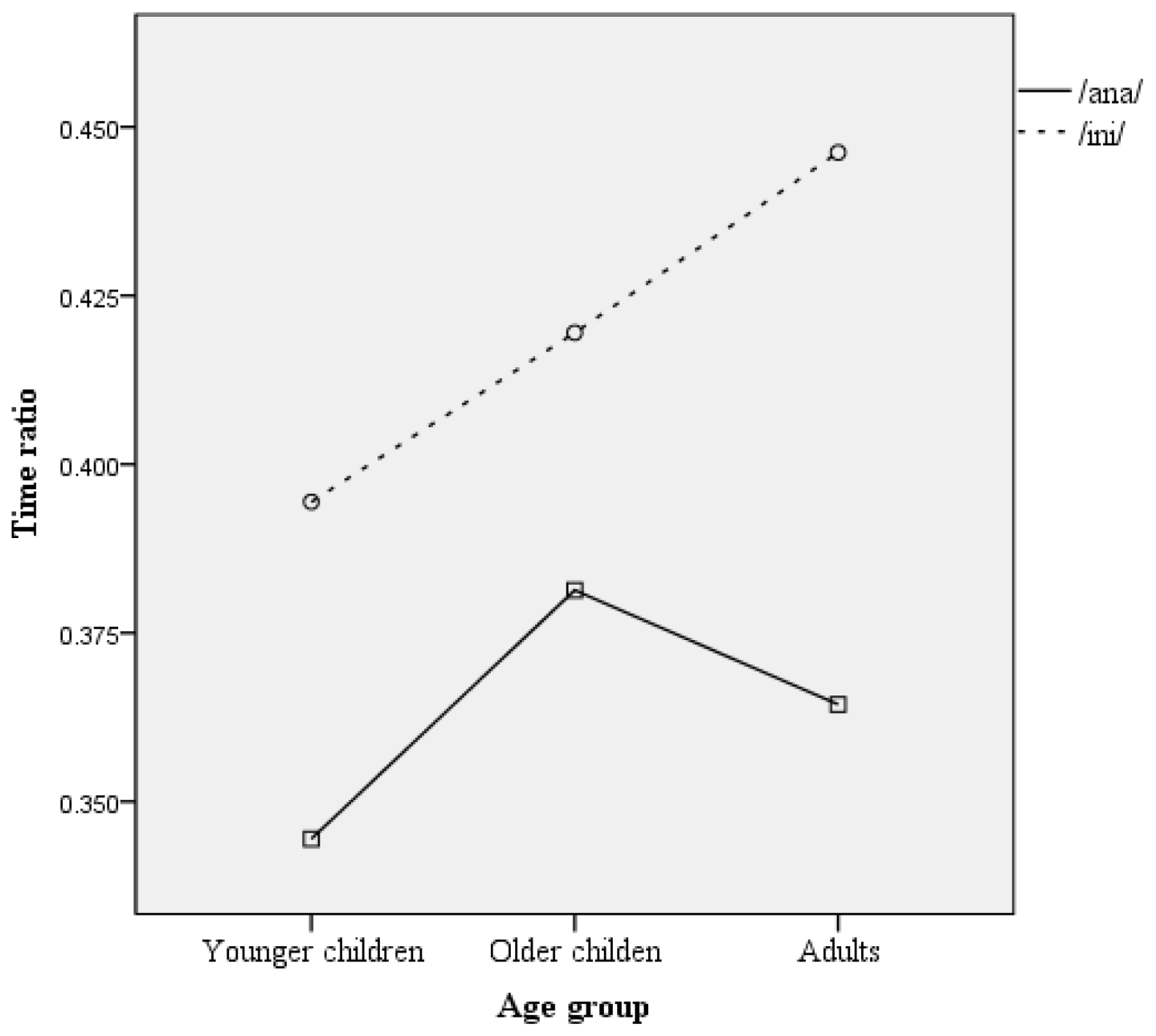

Figure 12. Proportional duration of carryover nasal airflow as a function of vowel type and age group of the speakers. 


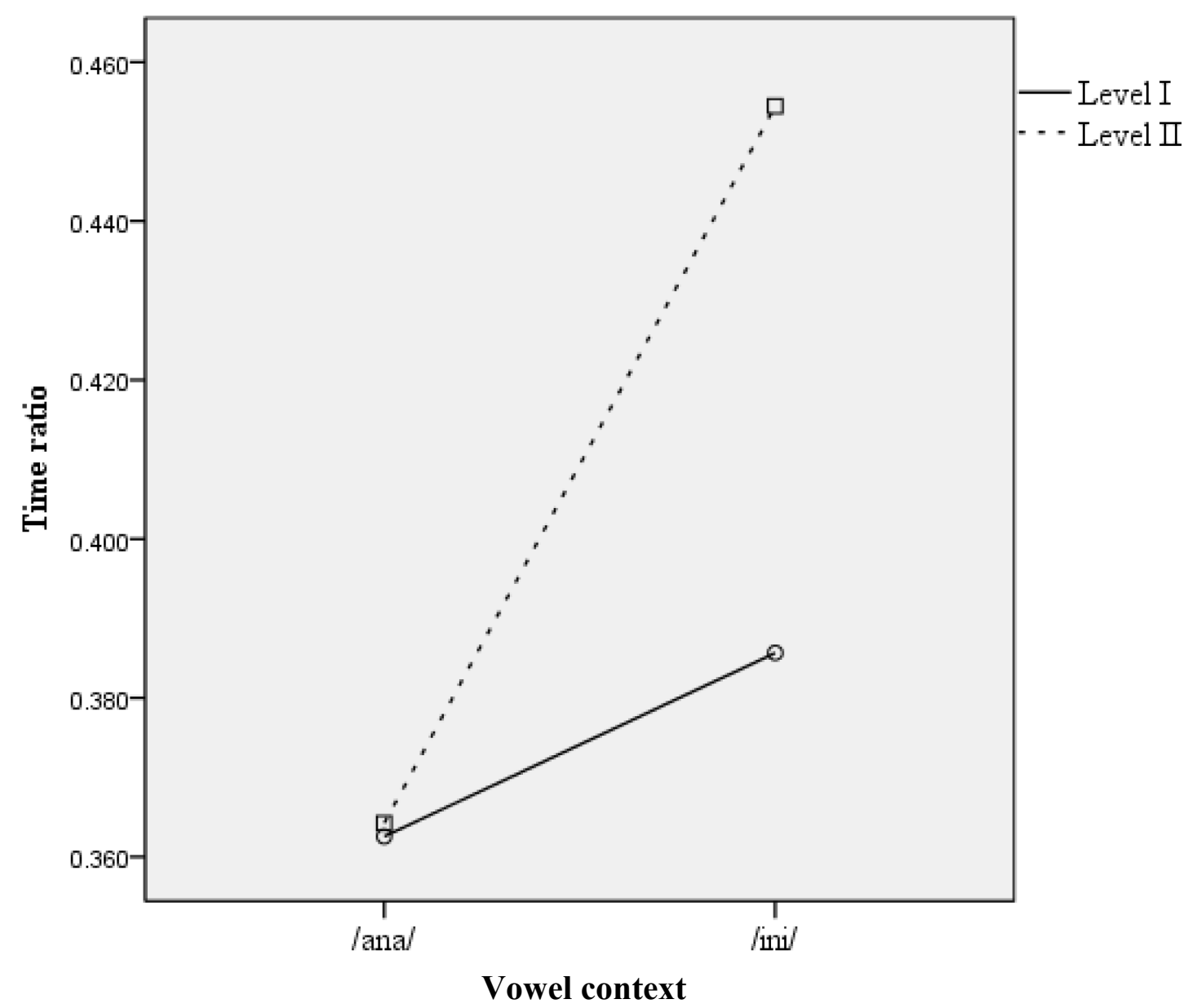

Figure 13. Proportional duration of carryover nasal airflow as a function of vowel type and production level. 
Table 14. Results of $2 \times 2 \times 2 \times 3$ ANOVA for the absolute volume (ml) of anticipatory nasal airflow.

\begin{tabular}{|c|c|c|c|c|c|}
\hline Effect & $\mathrm{F}$ & $\begin{array}{l}\text { Hypothesis } \\
\text { df }\end{array}$ & Error df & Sig. & $\begin{array}{c}\text { Observed } \\
\text { power }\end{array}$ \\
\hline Gender & 5.076 & 1 & 54 & $.028 *$ & .600 \\
\hline Age group & 4.338 & 2 & 54 & $.018 *$ & .729 \\
\hline Gender $\mathrm{x}$ age group & .430 & 2 & 54 & .653 & .116 \\
\hline VT & 3.399 & 1 & 54 & .071 & .441 \\
\hline VT $x$ gender & .123 & 2 & 54 & .885 & .068 \\
\hline VT $x$ age group & 1.709 & 1 & 54 & .197 & .250 \\
\hline VT $x$ gender $\mathrm{x}$ age group & 1.719 & 2 & 54 & .189 & .346 \\
\hline PL & 53.847 & 1 & 54 & $.000 *$ & 1.000 \\
\hline PL $x$ gender & 4.289 & 2 & 54 & $.019 *$ & .724 \\
\hline PL $x$ age group & 5.870 & 1 & 54 & $.019 *$ & .663 \\
\hline PL $x$ gender $x$ age group & .255 & 2 & 54 & .776 & .088 \\
\hline VT x PL & .005 & 1 & 54 & .945 & .051 \\
\hline VT x PL $x$ gender & .809 & 2 & 54 & .450 & .181 \\
\hline VT x PL x age group & .054 & 1 & 54 & .817 & .056 \\
\hline $\begin{array}{l}\text { VT x PL } x \text { gender } x \text { age } \\
\text { group }\end{array}$ & .443 & 2 & 54 & .644 & .119 \\
\hline
\end{tabular}

$*=$ significant at Alpha $=.05$.

$\mathrm{VT}=$ vowel type (high vs. low).

$\mathrm{PL}=$ production level: Level I (with say) vs. level II (without say).

$\mathrm{F}=$ between-groups variance/within-groups variance.

$\mathrm{df}=$ degrees of freedom. 


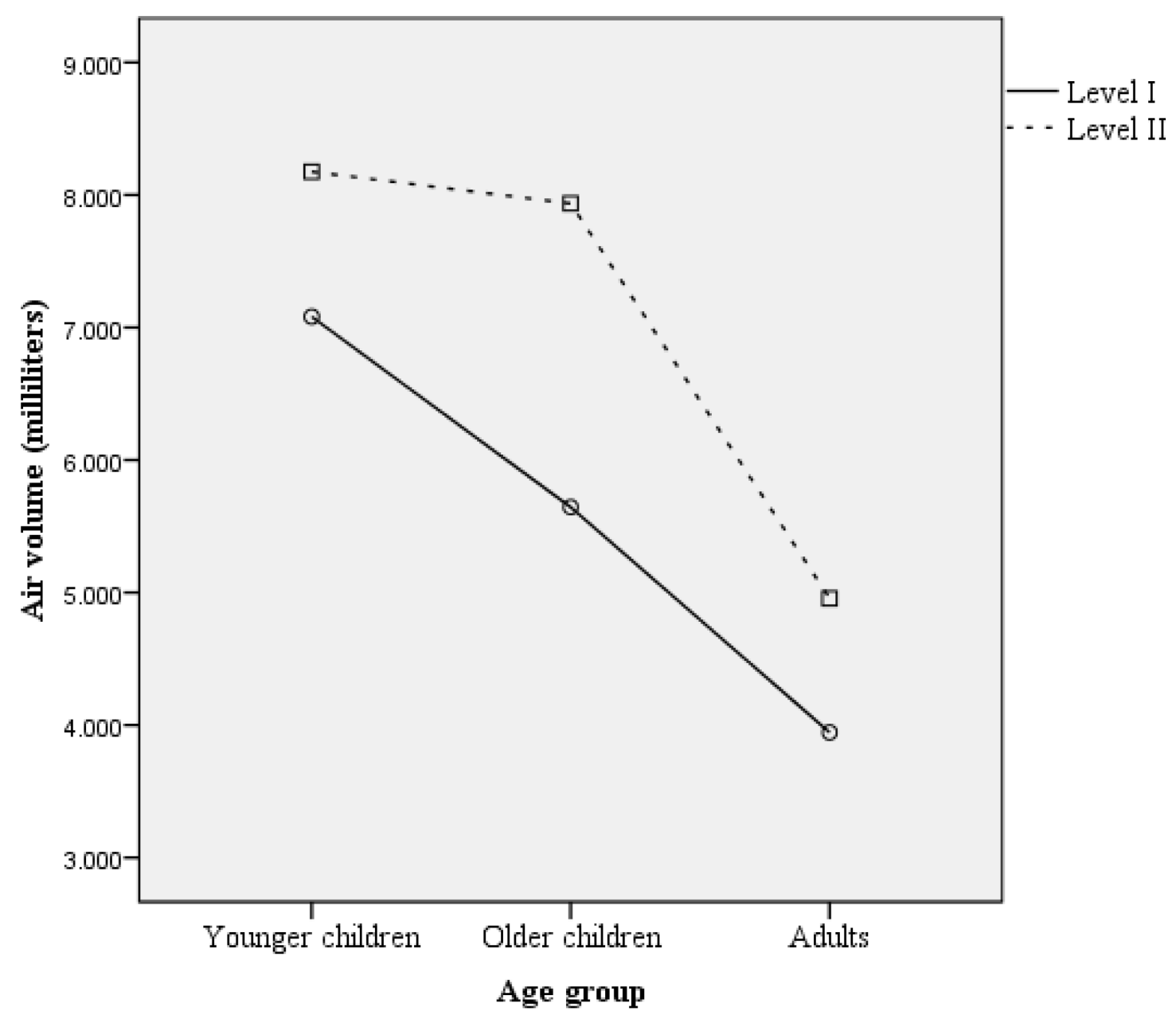

Figure 14. Absolute volume ( $\mathrm{ml}$ ) of anticipatory nasal airflow as a function of age group and production level. 
Even though older children did not differ from younger children and adults, they showed a trend toward producing less nasal airflow volume than younger children and more than adult speakers. In addition, female speakers showed increased volume of anticipatory nasal airflow on level II of production (without say) (see Figure 15).

The results of the $2 \times 2 \times 2 \times 3$ ANOVA on the absolute volume of carryover nasal airflow revealed main effects only for vowel type $\left(\mathrm{F}_{(1,54)}=112.982, p<.001\right)$ and production level $\left(\mathrm{F}_{(1,54)}=17.157, p<.001\right)$ (see Table 15$)$. In addition a significant age group, vowel type and production level interaction was found $\left(\mathrm{F}_{(1,54)}=5.362, p<.05\right)$. No effects of age or gender were found. A subsequent mixed $3 \times 2 \times 2$ ANOVA was performed with gender effect being excluded from the design. Significant vowel type $\left(\mathrm{F}_{(1,57)}=117.438, p<.001\right)$ and production level $\left(\mathrm{F}_{(1,57)}=16.494, p<.001\right)$ effects were only found. In general, all speakers regardless of age or gender showed increased volume of carryover nasal airflow on high rather than low vowel contexts. In addition, increased carryover nasal airflow volume was found on level II of production (without say) compared to level I (with say) (see Figure 16).

In addition to the absolute values of nasal flow volumes (in milliliters), repeated measures $2 \times 2 \times 2 \times 3$ ANOVA was performed on the ratios of anticipatory and carryover nasal airflow segment. Ratios were computed as nasal to oral-plus-nasal flow volume for each nasal airflow segment.

In the case of ratio of nasal to oral-plus-nasal airflow volume related to anticipatory nasal airflow, ANOVA revealed main effects for gender $\left(\mathrm{F}_{(1,54)}=4.633\right.$, $p<.05)$, and vowel type $\left(\mathrm{F}_{(1,54)}=164.509, p<.001\right)$. A significant vowel type and gender and age group interaction was found $\left(\mathrm{F}_{(1,54)}=8.636, p<.01\right)$ (see Table 16). Independent sample t-tests were performed to test the difference between male and female speakers for each age group.t-test revealed a significant difference between male and female adult speakers $(\mathrm{t}=-4.710, p<.001)$ on high vowel contexts. No significant difference between male and female speakers for the two children group. Women showed greater ratio of anticipatory nasal airflow than men on high vowel contexts. No age or gender effect was found on low vowels context (see Figures 17 and 18).

Regarding the ratio of nasal to oral-plus-nasal airflow related to carryover coarticulation, ANOVA revealed main effects for vowel type $\left(\mathrm{F}_{(1,54)}=169.168, p<.001\right)$, and a significant interaction between vowel type and production level and gender and age group $\left(\mathrm{F}_{(1,54)}=4.205, p<.05\right)$ was found (see Table 17).

Further analysis $3 \times 2 \times 2$ ANOVA with age and gender as the group variables and production level as the repeated measure was performed on low vowel contexts. Results of the ANOVA revealed no significant age, gender, or production level effects on low vowel contexts. Another $3 \times 2$ x 2 ANOVA was performed on high vowels and revealed a significant production level and gender and age group interaction $\left(\mathrm{F}_{(1,54)}=7.946, p<.001\right)$. 


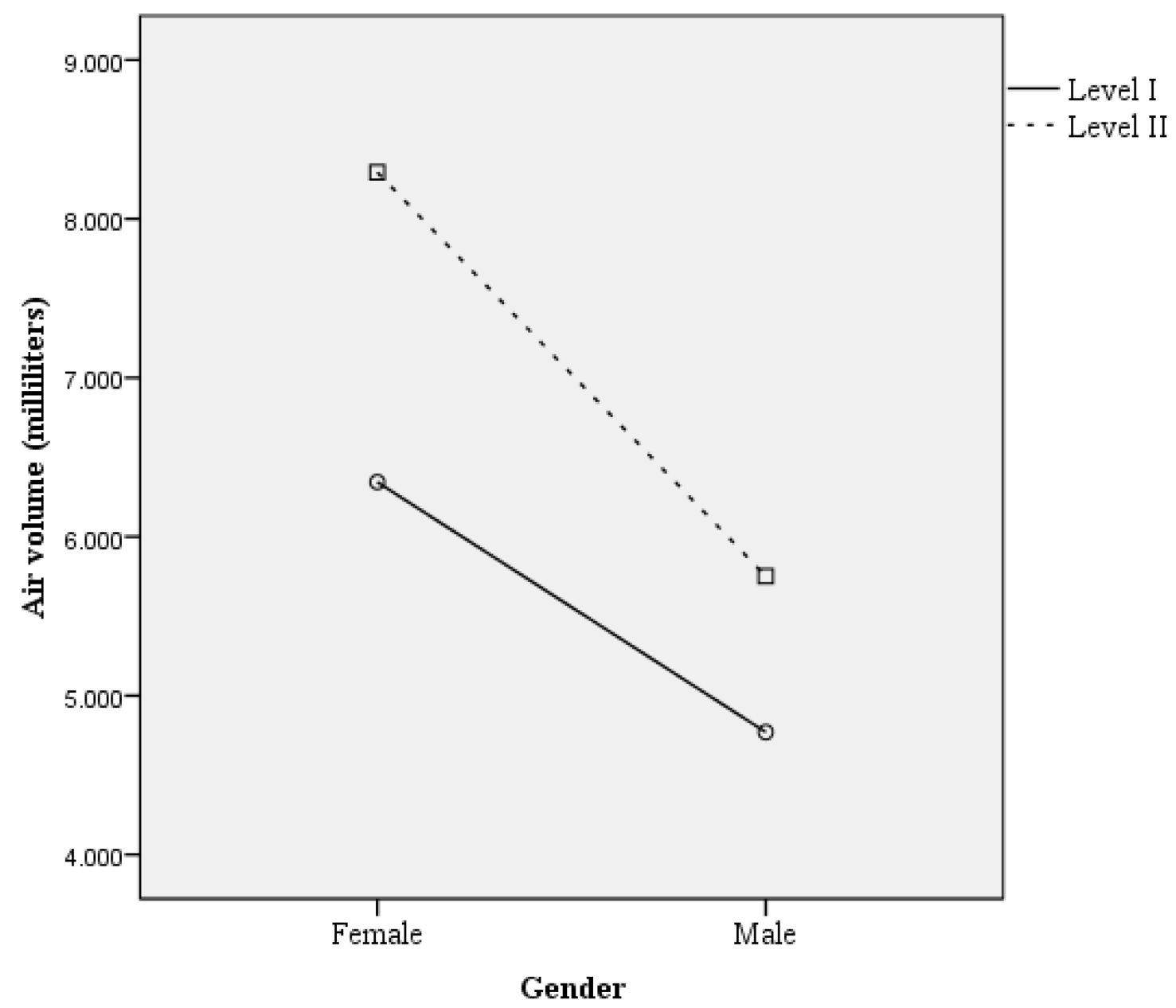

Figure 15. Absolute volume ( $\mathrm{ml})$ of anticipatory nasal airflow as a function of gender and production level. 
Table 15. Results of $2 \times 2 \times 2 \times 3$ ANOVA for the absolute volume (ml) of carryover nasal airflow.

\begin{tabular}{|c|c|c|c|c|c|}
\hline Effect & $\mathrm{F}$ & $\begin{array}{l}\text { Hypothesis } \\
\text { df }\end{array}$ & Error df & Sig. & $\begin{array}{c}\text { Observed } \\
\text { power }\end{array}$ \\
\hline Gender & 0.026 & 1 & 54 & 0.872 & 0.053 \\
\hline Age group & 0.591 & 2 & 54 & 0.557 & 0.143 \\
\hline Gender $\mathrm{x}$ age group & 0.582 & 2 & 54 & 0.562 & 0.142 \\
\hline VT & 112.982 & 1 & 54 & $.000 *$ & 1 \\
\hline VT $x$ gender & 1.541 & 2 & 54 & 0.223 & 0.314 \\
\hline VT $\mathrm{x}$ age group & 0.476 & 1 & 54 & 0.493 & 0.104 \\
\hline VT $\mathrm{x}$ gender $\mathrm{x}$ age group & 0.18 & 2 & 54 & 0.835 & 0.077 \\
\hline PL & 17.157 & 1 & 54 & $.000 *$ & 0.982 \\
\hline PL $x$ gender & 1.88 & 2 & 54 & 0.162 & 0.374 \\
\hline PL $x$ age group & 1.5 & 1 & 54 & 0.226 & 0.225 \\
\hline PL $x$ gender $x$ age group & 1.895 & 2 & 54 & 0.16 & 0.377 \\
\hline VT x PL & 0.603 & 1 & 54 & 0.441 & 0.119 \\
\hline VT x PL x gender & 0.176 & 2 & 54 & 0.839 & 0.076 \\
\hline VT x PL x age group & 5.362 & 1 & 54 & $.024 *$ & 0.623 \\
\hline $\begin{array}{l}\text { VT } x \text { PL } x \text { gender } x \text { age } \\
\text { group }\end{array}$ & 0.472 & 2 & 54 & 0.626 & 0.123 \\
\hline
\end{tabular}

$*=$ significant at Alpha $=.05$.

$\mathrm{VT}=$ vowel type (high vs. low).

$\mathrm{PL}=$ production level: Level I (with say) vs. level II (without say).

$\mathrm{F}=$ between-groups variance/within-groups variance.

$\mathrm{df}=$ degrees of freedom. 


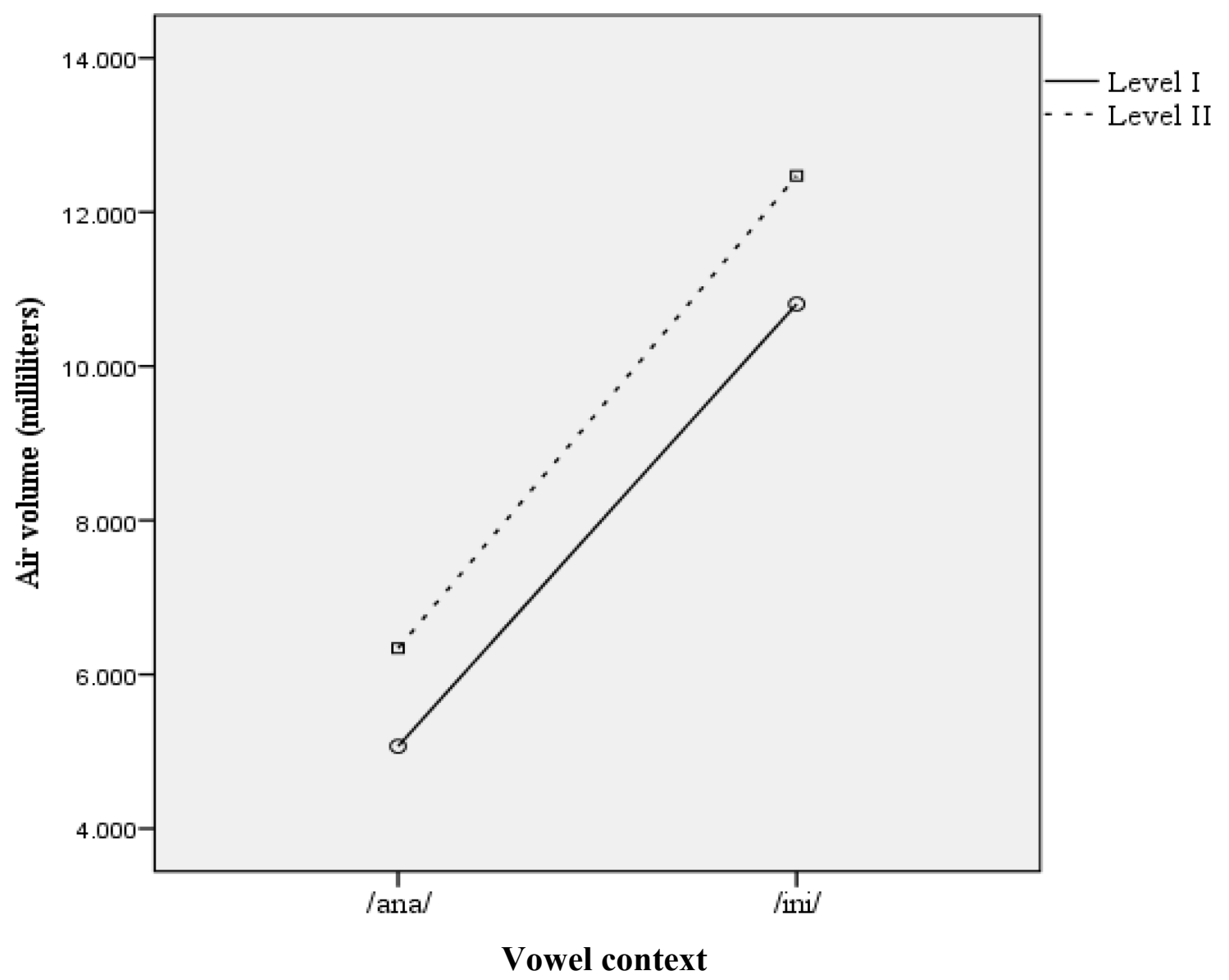

Figure 16. Absolute volume ( $\mathrm{ml})$ of carryover nasal flow as a function of vowel type and production level. 
Table 16. Results of $2 \times 2 \times 2 \times 3$ ANOVA for the ratio of nasal to oral-plus-nasal airflow related to anticipatory nasal airflow.

\begin{tabular}{|c|c|c|c|c|c|}
\hline Effect & $\mathrm{F}$ & $\begin{array}{c}\text { Hypothesis } \\
\text { df }\end{array}$ & $\begin{array}{c}\text { Error } \\
\text { df }\end{array}$ & Sig. & $\begin{array}{c}\text { Observed } \\
\text { power }\end{array}$ \\
\hline Gender & 6.026 & 1 & 54 & $.017^{*}$ & .674 \\
\hline Age group & .418 & 2 & 54 & .661 & .114 \\
\hline Gender $\mathrm{x}$ age group & 4.516 & 2 & 54 & .015 & .747 \\
\hline VT & 164.509 & 1 & 54 & $.000 *$ & 1.000 \\
\hline VT $x$ gender & 8.230 & 1 & 54 & $.006^{*}$ & .804 \\
\hline VT $\mathrm{x}$ age group & .050 & 2 & 54 & .951 & .057 \\
\hline VT $\mathrm{x}$ gender $\mathrm{x}$ age group & 8.636 & 2 & 54 & $.001 *$ & .960 \\
\hline PL & .568 & 1 & 54 & .454 & .115 \\
\hline PL $x$ gender & .997 & 1 & 54 & .323 & .165 \\
\hline PL $x$ age group & .490 & 2 & 54 & .616 & .126 \\
\hline PL $x$ gender $x$ age group & 2.702 & 2 & 54 & .076 & .513 \\
\hline VT x PL & .568 & 1 & 54 & .454 & .115 \\
\hline VT $x$ PL $x$ gender & .997 & 1 & 54 & .323 & .165 \\
\hline VT x PL x age group & .490 & 2 & 54 & .616 & .126 \\
\hline
\end{tabular}

$*=$ significant at Alpha $=.05$.

$\mathrm{VT}=$ vowel type (high vs. low).

$\mathrm{PL}=$ production level: Level I (with say) vs. level II (without say).

$\mathrm{F}=$ between-groups variance/within-groups variance.

$\mathrm{df}=$ degrees of freedom. 


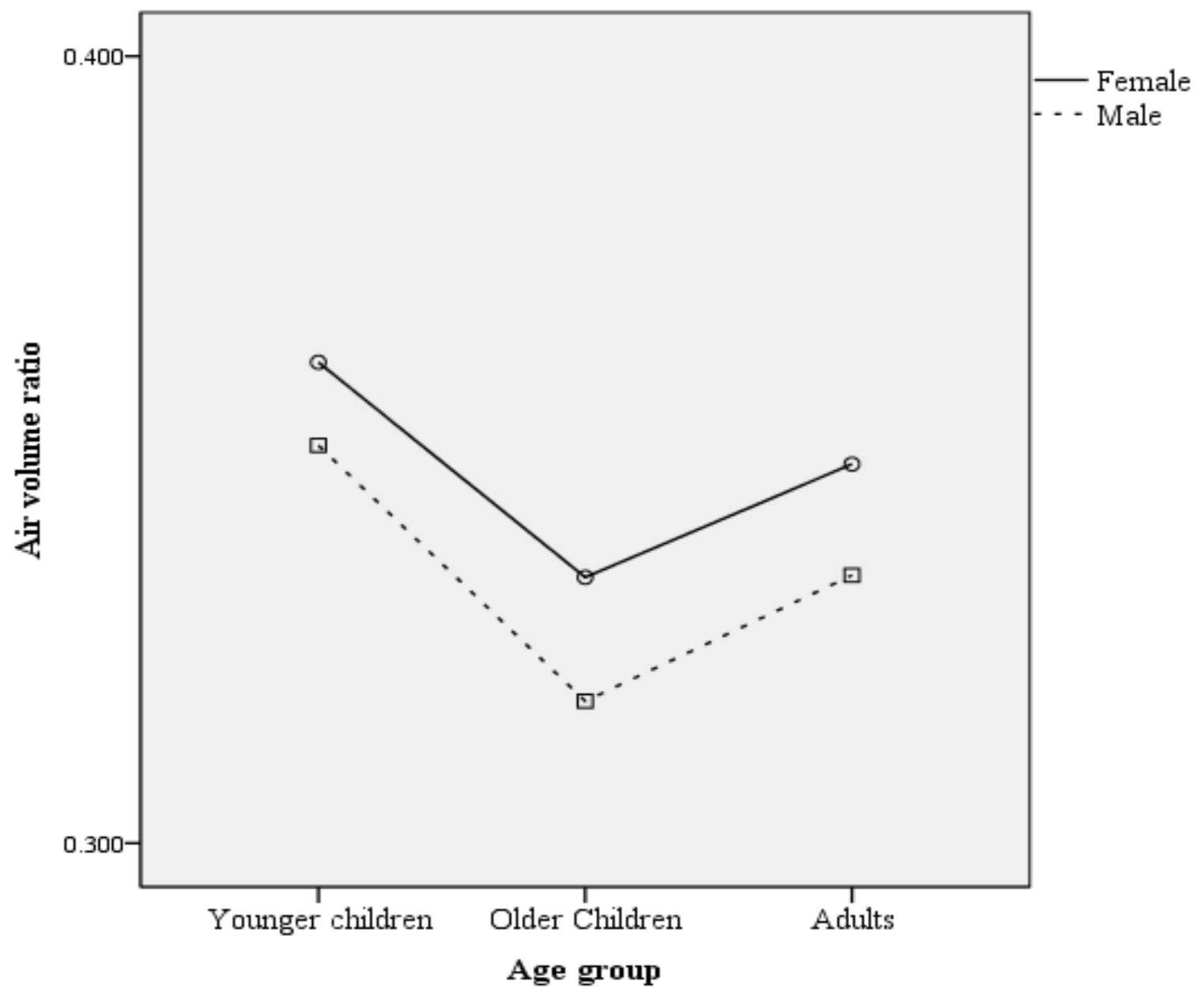

Figure 17. Ratio of anticipatory nasal to oral-plus-nasal airflow as during the production of /ana/ as a function of age and gender of the speakers. 


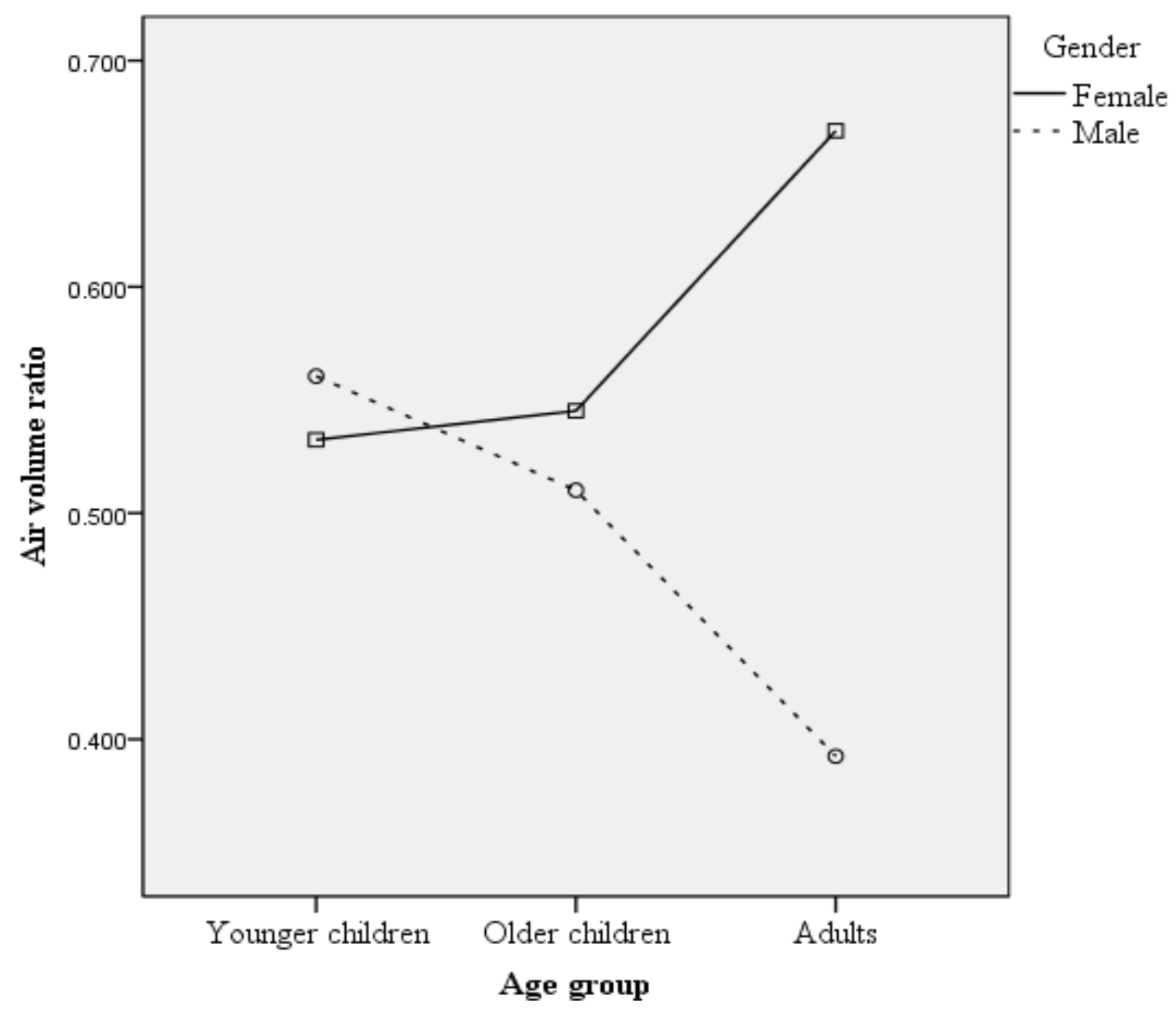

Figure 18. Ratio of anticipatory nasal to oral-plus-nasal airflow volume during the production of /ini/ as a function of age group and gender of the speakers. 
Table 17. Results of $2 \times 2 \times 2 \times 3$ ANOVA for the ratio of nasal to oral-plus-nasal airflow related to carryover nasal airflow.

\begin{tabular}{|c|c|c|c|c|c|}
\hline Effect & $\mathrm{F}$ & $\begin{array}{l}\text { Hypothesis } \\
\text { df }\end{array}$ & $\begin{array}{c}\text { Error } \\
\text { df }\end{array}$ & Sig. & $\begin{array}{c}\text { Observed } \\
\text { power }\end{array}$ \\
\hline Gender & 2.210 & 1 & 54 & .143 & .309 \\
\hline Age group & .278 & 2 & 54 & .759 & .092 \\
\hline Gender $\mathrm{x}$ age group & 1.208 & 2 & 54 & .307 & .253 \\
\hline VT & 169.168 & 1 & 54 & $.000 *$ & 1.000 \\
\hline VT x gender & 17.596 & 1 & 54 & $.000 *$ & .985 \\
\hline VT $\mathrm{x}$ age group & 1.151 & 2 & 54 & .324 & .243 \\
\hline VT $\mathrm{x}$ gender $\mathrm{x}$ age group & 6.894 & 2 & 54 & $.002 *$ & .909 \\
\hline PL & .663 & 1 & 54 & .419 & .126 \\
\hline PL $x$ gender & 5.310 & 1 & 54 & $.025 *$ & 619 \\
\hline PL $x$ age group & .361 & 2 & 54 & 699 & .105 \\
\hline PL $x$ gender $x$ age group & 4.022 & 2 & 54 & $.024 *$ & .694 \\
\hline VT x PL & 2.054 & 1 & 54 & .158 & .291 \\
\hline VT x PL x gender & 1.011 & 1 & 54 & .319 & .167 \\
\hline VT x PL $x$ age group & 1.140 & 2 & 54 & .327 & .241 \\
\hline $\begin{array}{l}\text { VT } x \text { PL } x \text { gender } x \text { age } \\
\text { group }\end{array}$ & 4.205 & 2 & 54 & $.020 *$ & .715 \\
\hline
\end{tabular}

$*=$ significant at Alpha $=.05$.

$\mathrm{VT}=$ vowel type (high vs. low).

$\mathrm{PL}=$ production level: Level I (with say) vs. level II (without say).

$\mathrm{F}=$ between-groups variance/within-groups variance.

$\mathrm{df}=$ degrees of freedom. 
A subsequent two way ANOVA was performed with age group and gender as fixed factors and Level I production (say /ini/ again) as the dependent variable. The result of the ANOVA revealed a significant effect of gender $(\mathrm{F}=12.798, p<.001)$ on the ratio of carryover nasal airflow at level I production of "say /ini/ again". Female speakers demonstrated greater nasal airflow ratio than male speakers on high vowel contexts regardless of age group (see Figure 19). As for level II production (/ini/ again), another 2 way ANOVA was performed with age group and gender as fixed variable. The ANOVA revealed main gender $(\mathrm{F}=20.532, p<.001)$ and age group by gender interaction $(\mathrm{F}=6.525, p<.01)$ effects. Independent sample $\mathrm{t}$-test showed that women had greater ratio of carryover nasal airflow than men when "ini again" was produced $(\mathrm{t}=-4.280$, $p<.01)$. No significant difference between male and female speakers for the two children group was detected (see Figure 20).

\section{Speakers' Variability}

Coefficient of Variation (CV) was obtained for each speaker and variable as a measure of within speaker variability. CVs were computed as the SD divided by the M for each speaker and variable. Analysis of variance (ANOVA) procedures were used on the computed CVs to determine possible age (three levels) and sex (two levels). Post hoc differences among age groups were determined using Tukey test.

Table 18 shows the mean CVs of the absolute duration of anticipatory nasal flow (T1) as a function of age and gender of the speaker. It also shows the variables with significant age group, gender and age group by gender interaction $(p<.05)$. Post hoc analysis revealed younger and older children have significantly greater variability than adults of duration of anticipatory nasal flow at both low vowel contexts (i.e., /ana/) and one high vowel context, "say/ini/ again". ANOVA analysis showed male speakers to exhibit greater variability on low vowel contexts. Significant age group by gender interaction was found for both high vowel context with men showing greater variability than women for "say /ini/ again" $(\mathrm{t}=2.931, p<.01)$ and "/ini/ again" $(\mathrm{t}=4.861$, $p<.001)$.

The table also displays CVs for carryover nasal flow (T2). Post hoc analysis showed younger children to have greater variability than both older children and adults for the production of "say /ana/ again" and both high vowel productions. ANOVA revealed that male speakers showed greater variability than female speakers for the production of high vowel contexts. No age group by gender interaction was found.

Table 19 demonstrates mean CVs for the absolute volume of anticipatory and carryover nasal flow as a function of age and gender of the speakers. In the case of the volume of anticipatory nasal airflow (F1), no age group effect was found for the production of both low and high vowel context. ANOVA revealed male speakers exhibited greater variability than female speakers for one low vowel context, "say /ana/ again". In addition men showed greater variability than women for the production of “/ini/ again" ( $\mathrm{t}=4.517, p<.001)$. 


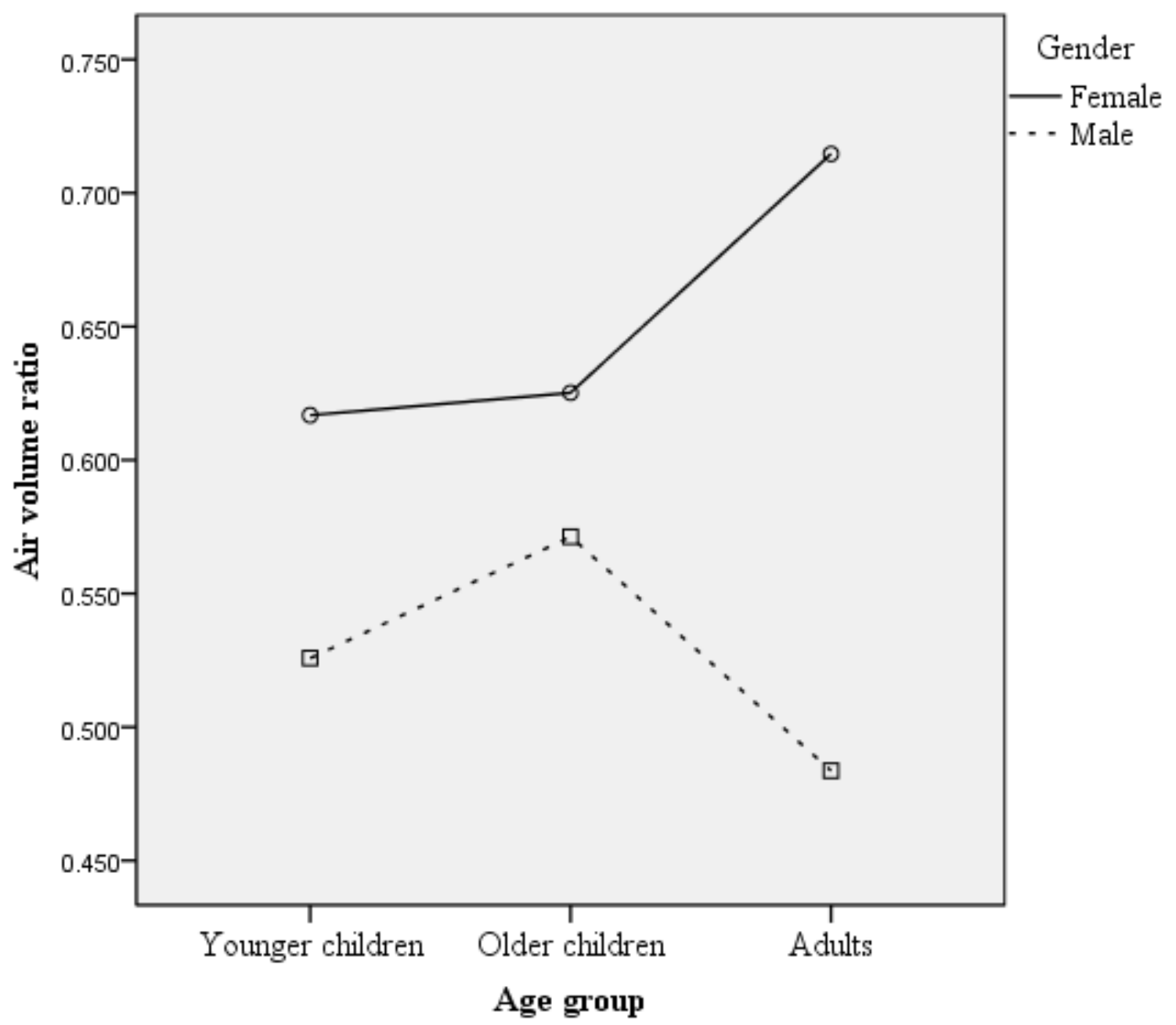

Figure 19. Ratio of carryover nasal to oral-plus-nasal airflow during the production of "say /ini/ again" as a function of age and gender of the speakers. 


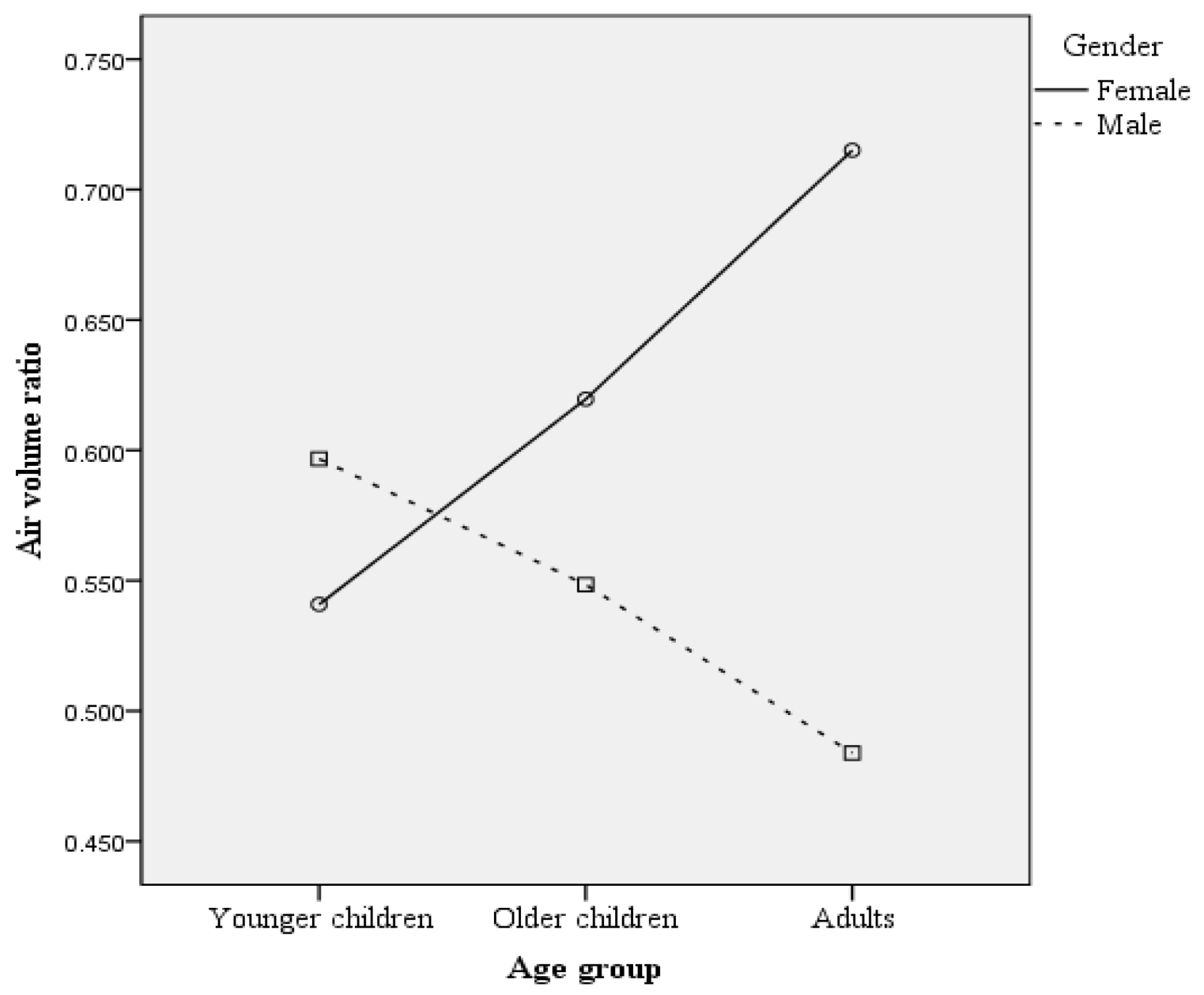

Figure 20. Ratio of carryover nasal to oral-plus-nasal airflow during the production of "/ini/ again" as a function of age group and gender of the speakers. 
Table 18. CVs of the absolute duration of anticipatory and carryover nasal airflow as a function of age group and gender.

\begin{tabular}{|c|c|c|c|c|c|c|c|c|c|}
\hline \multirow{2}{*}{ Variable } & \multicolumn{3}{|c|}{ Younger children } & \multicolumn{3}{|c|}{ Older children } & \multicolumn{3}{|c|}{ Adults } \\
\hline & Female & Male & Total & Female & Male & Total & Female & Male & Total \\
\hline T1_say ana†* & 0.144 & 0.234 & 0.189 & 0.191 & 0.246 & 0.218 & 0.126 & 0.172 & 0.149 \\
\hline $\mathrm{T} 1$ ana $\dagger^{*}$ & 0.165 & 0.195 & 0.18 & 0.15 & 0.233 & 0.191 & 0.12 & 0.126 & 0.123 \\
\hline T1_say ini $t^{*}$ & 0.214 & 0.295 & 0.254 & 0.264 & 0.212 & 0.238 & 0.126 & 0.232 & 0.179 \\
\hline T1_ini $\ddagger$ & 0.155 & 0.24 & 0.198 & 0.202 & 0.201 & 0.202 & 0.118 & 0.243 & 0.18 \\
\hline T2_say ana * & 0.202 & 0.197 & 0.199 & 0.135 & 0.158 & 0.147 & 0.129 & 0.16 & 0.145 \\
\hline $\mathrm{T} 2 \_$ana & 0.171 & 0.177 & 0.174 & 0.148 & 0.172 & 0.16 & 0.125 & 0.154 & 0.14 \\
\hline T2_say_ini $\dagger^{*} *$ & 0.14 & 0.211 & 0.176 & 0.134 & 0.137 & 0.136 & 0.098 & 0.126 & 0.112 \\
\hline T2_ini $\dagger^{*}$ & 0.14 & 0.194 & 0.167 & 0.113 & 0.15 & 0.131 & 0.077 & 0.116 & 0.096 \\
\hline
\end{tabular}

$\mathrm{T} 1=$ duration of anticipatory nasal flow.

$\mathrm{T} 2=$ duration of carryover nasal flow.

$*$ = Main age group effect.

$\dagger=$ Main gender effect.

$\ddagger=$ Main age group and gender interaction. 
Table 19. CVs of the absolute volume of anticipatory and carryover nasal airflow as a function of age group and gender.

\begin{tabular}{|c|c|c|c|c|c|c|c|c|c|}
\hline \multirow[t]{2}{*}{ Variable } & \multicolumn{3}{|c|}{ Younger children } & \multicolumn{3}{|c|}{ Older children } & \multicolumn{3}{|c|}{ Adults } \\
\hline & Female & Male & Total & Female & Male & Total & Female & Male & Total \\
\hline F1_say ana $\dagger$ & 0.364 & 0.436 & 0.4 & 0.273 & 0.416 & 0.344 & 0.295 & 0.346 & 0.321 \\
\hline F1_ana & 0.324 & 0.372 & 0.348 & 0.301 & 0.335 & 0.318 & 0.266 & 0.282 & 0.274 \\
\hline F1_say ini & 0.433 & 0.457 & 0.445 & 0.433 & 0.399 & 0.416 & 0.233 & 0.405 & 0.319 \\
\hline F1_ini + & 0.35 & 0.375 & 0.362 & 0.348 & 0.324 & 0.336 & 0.253 & 0.55 & 0.401 \\
\hline F2_say ana + & 0.323 & 0.351 & 0.337 & 0.228 & 0.381 & 0.304 & 0.269 & 0.236 & 0.252 \\
\hline $\mathrm{F} 2$ _ana $*$ & 0.417 & 0.371 & 0.394 & 0.263 & 0.324 & 0.293 & 0.263 & 0.237 & 0.25 \\
\hline F2_say_ini $\dagger^{*}$ & 0.242 & 0.447 & 0.344 & 0.225 & 0.297 & 0.261 & 0.202 & 0.26 & 0.231 \\
\hline F2_ini $\dagger^{*}$ & 0.317 & 0.341 & 0.329 & 0.21 & 0.312 & 0.261 & 0.15 & 0.19 & 0.17 \\
\hline
\end{tabular}

F1 = anticipatory nasal flow.

F2 = carryover nasal flow.

$*$ Main age group effect.

$\dagger=$ Main gender effect.

$\ddagger=$ Main age group and gender interaction. 
As for carryover nasal airflow (F2), post hoc analysis showed younger children are different from both older children and adults for "/ana/ again" and "say /ini/ again", also younger and older children are different from adults. All age group differences reflect an obvious reduction of variability with increasing age. ANOVA analysis revealed a main gender effect for the production of high vowel context with male speakers showing greater variability than female speakers. A significant age and gender interaction was found for "say /ana/ again". In this case of interaction, older boys showed greater variability than older girls $(\mathrm{t}=3.515, p<.01)$. 


\section{CHAPTER 5. DISCUSSION}

The present study investigated the effects of age, gender and vowel height on temporal and aerodynamic characteristics of nasal airflow segments related to anticipatory and carryover velar coarticulation. Sixty adult and children speakers with normal speech, language and hearing participated in the current study. Speakers produced sets of VNV sequences that reflected two vowel types, low and high, embedded in two carrier phrases (e.g., "say /ini/ again" vs. "/ini/ again"). Nasal and oral airflow were obtained from the speakers during the production of the speech tasks. Temporal and aerodynamic analysis was performed on the VNV sequences. The analysis included measuring the absolute and proportional duration of nasal airflow segments related to anticipatory and carryover velar coarticulation. The aerodynamic analysis included measuring the volume of nasal airflow in milliliters as well as measuring the ratio of nasal to oral-plus-nasal airflow for the aerodynamic segments related to anticipatory and carryover velar coarticulation.

\section{Age Effect}

Results of the temporal measurements showed a significant age effect on the absolute and proportional duration of anticipatory nasal airflow. Proportional duration was calculated to control for possible effect of speaking rate. The present study reported all three age groups (younger children, older children, and adults) to be statistically different from each other with respect to the absolute duration (in seconds) of anticipatory nasal airflow on both low and high vowel contexts. Younger children showed the longest anticipatory nasal airflow interval followed by the older children group and then followed by adult speakers in a pattern that reflects a reduction of the temporal domain of anticipatory velar coarticulation with increasing age.

Results obtained from the time ratio measurements supported the finding of those of the absolute measurements. Specifically, all age groups were significantly different from each other on high vowel environment following the pattern of reduction of duration with increasing age. Similarly, younger children showed greater proportional duration of anticipatory nasal airflow than both older children and adults for the low vowel environment. Even though the time ratio of anticipatory nasal airflow for older children was not significantly different from that of group adult speakers, older children exhibited a relatively higher time ratio of anticipatory nasal airflow than adult speakers did. These findings suggest that the mastery of adult-like anticipatory velar lowering is nearly established around nine years of age.

Two prominent theories have been proposed to describe the nature of the underlying units of speech organization used by children and their interrelations. One predicts that children's speech is more segmental and less coarticulated than adults' (Kent, 1983). This approach suggests that children initially learn to produce the sequence

of individual segments. Later, they modify their articulatory patterns based on 
interdependencies of adjacent segments. This view suggest that the mastery of the canonical articulatory patterns of individual segments is the principal process of the development of speech production and with increasing age, the degree of overlap increases and speech becomes more efficient and adult-like. Kent (1983) provided evidence of this view from data of lingual coarticulation. He studied the effect of the tongue gesture on a preceding vowel in CVC sequence produced by adult speakers and children between 3-4 years of age. He observed that in adults, F2 values appear to rise more rapidly during the final portion of the vowel immediately before closure for $/ \mathrm{k} /$ in the word box /baks/, which indicates that adult speakers anticipate the gesture of tongue body elevation required for the stop consonant $/ \mathrm{k} /$. On the other hand, children showed well-defined stabilization of the F2 frequency that lasted for certain duration of time.

The other theory of coarticulation in children's speech proposes that children's speech is less differentiated and characterized by more gestural overlap than adults' (Nittrouer et al., 1996). This view holds that the basic units of speech production in children are not phoneme-size phonetic unit rather they are syllable or word size units. They provide evidence that infant's vocalizations that consist of reduplicated and variegated syllables are undifferentiated consonant-vowel gestures. This syllabic and undifferentiated pattern of gestures continues during early word production. Later, as the child grows and gains more motor control, the syllable or word-size gesture is narrowed into smaller phonetic units that are closely related to their phonemic representation (Goodell \& Studdert-Kennedy, 1993). As the undifferentiated syllable-sized gesture narrows into smaller phonetic units, consonant and vowel interdependencies weakens and the degree of gestural overlap decreases as the child grow and gain more motor control.

Many studies have been conducted in support of this approach by showing that children speech is characterized by greater coarticulatory effects than adults (e.g., Repp, 1986; Nittrouer, Studdert-Kennedy \& McGowan, 1989; Nittrouer \& Whalen, 1989). Nittrouer at al. (1989) studied the effect of age on the extent of lingual coarticulation in fricative-vowel syllables. They studied the acoustic effect of $/ \mathrm{i} /$ and $/ \mathrm{u} /$ on the preceding $/ \mathrm{s} /$ and $/ \mathrm{J} /$ produced by eight adults and eight children for each of the ages $3,4,5$ and 7 . Analysis of F2 estimated values revealed a gradual decline of the influence of $/ \mathrm{i} /$ and $/ \mathrm{u} /$ on the preceding fricatives with increasing age.

Repp (1986) conducted a preliminary investigation of anticipatory coarticulation in children's speech. He analyzed / a /-consonant-vowel sequences produced by one 4year-old and one 9 -year-old. He reported that the younger child demonstrated stronger vowel influence on the preceding consonant than the older child.

Previous studies focused on aspects of lingual coarticulation to support the view that syllable-sizes gesture is the start point rather than the endpoint unit of speech organization. Even though the current study showed that the temporal domain of anticipatory nasal airflow is greater in younger children than in adult speakers, this finding is not sufficient to evaluate both approaches concerning anticipatory velar lowering. It is possible that the duration of anticipatory nasal airflow may depend on the duration of the vowel segment in the speech samples. In order to see whether children 
speech is more segmental or more overlapped than adults' speech, it is important to see when the onset of nasal flow started relative to the onset of oral airflow in $\mathrm{V}_{1}$ in VNV sequence. In the present study, the percentage of tokens where the onset of nasal airflow coincided with the onset of oral airflow and the percentage of tokens where the onset of nasal airflow began later relative to the onset oral airflow were calculated for all speakers during the production of high vowel contexts. A criterion of $10 \mathrm{~ms}$ difference was set to control for small fluctuations of airflow onsets (i.e., both airflow onsets where considered coinciding if the time difference between them was less than $10 \mathrm{~ms}$ ). In the case of "Say /ini/ again", the percentages of tokens with both airflow onsets coinciding were $76 \%$, $26 \%$ and $28 \%$ for younger children, older children and adult speakers, respectively. For "/ini/ again", the percentages of tokens with both airflow onsets coinciding were $97 \%$, $65 \%$ and $59 \%$ for younger children, older children and adult speakers, respectively.

These values obtained from the participants of the current study provide evidence from aerodynamic data related to velar coarticulation in support of the theory that the syllable is the start point rather than the end point in the development of speech planning. The finding that nasal and oral airflow onsets coincided for most tokens in younger children's productions suggests that they began the gesture of velar lowering approximately at the same time as the tongue gesture for the first vowel in VNV sequence. This reflects the lack of differentiation between the tongue movement gesture for the vowel and the velum lowering gesture for the nasal sound. With increasing age, children isolate the overlapped vowel and velar gesture and organize them in a way closely aligned to their perceived representation.

The view that the syllable is the initial unit of speech organization was supported by MacKneilage (1998) who proposed the Frame/Content Theory to account for both development of speech in children and the concept of the evolution of language in humans. McNeilage posited that the basic consonant-vowel syllable type developed from the mandibular movement of closing (for consonants) and opening (for vowels). These movements evolved from prior ingestion-related movements such as chewing and sucking. These mandibular movements constitute the "frame" of a syllable and the particular consonants and vowels within the "frame" form the "content". According to this theory, speech-like behaviors emerge when phonation is accompanied with the cyclic open-close movement of the jaw. The result of this combination is the syllable which becomes more elaborated with time as the motor control of the tongue, lips and velum increase.

The present study also investigated the effect of age on some aerodynamic aspects related to velar coarticulation. Findings of the study showed that younger children produced significantly greater nasal air volume, in milliliters, than adult speakers. The study also reported that older children did not differ from younger children and adults; though, they showed a trend toward producing less nasal airflow than younger children and more than adult speakers. As for the ratio of nasal to oral-plus nasal airflow, no significant difference among the three age groups was detected. Those finding suggest that children's speech is produced with increased respiratory effort relative to adult speakers. This is clearly manifested in the findings that even though children had 
increased absolute nasal airflow than adults, the absence of the effect of age on the nasal airflow ratio suggests that children produced greater oral airflow than the adult speakers. The present study, thus, indicates that the gradual decrease of respiratory effort for speech with increasing age is one aspect of developing adult-like speech production.

These findings are consistent with other studies that investigated age related differences on certain aerodynamic aspects of speech production (e.g., Netsell, Lotz, Peters \& Schulte, 1994; Stathopoulos \& Sapienza, 1997; Zajac, 2000). Zajac (2000) reported a decrease of oral air pressure during the production of $/ \mathrm{p} /$ with increasing age. These findings can be attributed to anatomical and physiological factors. In addition, Stathopoulos \& Sapienza (1997) found that children at 6 years of age show a tendency for larger lung and rib cage volume excursion than adults during speech production. In addition, Netsell et al. (1994) reported that the expiratory work of speech breathing is greater in preschool children than in older children and adults. They explained that younger children use the net expiratory muscle force during speech and as they grow, they use a combination of inspiratory and expiratory muscle force for more efficient expiration during speech production.

The view of gestural phonology on speech development (Browman \& Goldstein, 1986, 1989; Nittrouer et al., 1989) entails that as children grow, they learn to coordinate their articulatory gestures with the exact time and space relations as adult do. Based on that, it was hypothesized that all age groups in the current study will demonstrate anticipatory nasal airflow; however, the duration and/or the volume of nasal airflow related to velic lowering gesture will be different between children and adults. The present study indicated that each of the three age groups exhibited distinct temporal and aerodynamic pattern of anticipatory nasal airflow. These findings confirm to the hypothesis that children need to master adult-like spatiotemporal relations of articulatory gestures.

As for the age effect on carryover velar coarticulation, there were no significant differences between children and adult speakers on both duration (sec.) and volume (ml) of carryover nasal airflow, absolutely and proportionally, in most cases. This was consistent with other studies (Flege, 1988; Ha \& Kuehn, 2006), who reported insignificant differences in the timing of carryover coarticulation between children and adults. Both studies support the idea that anticipatory and carryover coarticulation has different underlying mechanisms. While anticipatory coarticulation involves high neuromotor control, carryover coarticulation is largely attributed to mechanical and inertial forces acting on the articulators (Bell-Berti, 1993).

\section{Gender and Vowel Height Effects}

The present study investigated the effect of gender and vowel height effects on the absolute and proportional duration of anticipatory and carryover nasal airflow in VNV sequence. Because of the interaction that was found between gender and vowel type (high vs. low), both were included into the same section. Regarding the duration of 
anticipatory nasal airflow, there were no significant gender differences for both absolute and proportional duration of anticipatory nasal airflow on low vowel context. On the other hand, findings of the current study reported that all female speakers regardless of age group exhibited longer absolute duration of anticipatory nasal airflow on high vowel contexts compared to male speakers; however, when it comes to the proportional duration of anticipatory nasal airflow, only women and younger girls exhibited significantly greater anticipatory time ratio than men and younger boys. It was also noticed that older girls showed slightly greater time ratio of anticipatory nasal flow than older boys, but the difference was not significant. It is also worth mentioning that even though female speakers of the current study showed greater duration of anticipatory nasal airflow than male speakers on high vowels, the difference between women and men is far greater than the difference between girls and boys. For example, mean anticipatory time ratio during the production of "say/ini/ again" was 0.322 and 0.288 for younger girls and boys, respectively, and 0.263 and 0.166 for women and men, respectively.

These results suggest that VP movement timing differs as a function of both vowel height and gender of the speakers when it comes to anticipatory velar lowering. They also suggest these gender differences exist at a young age and become more prominent in adult speakers.

As for the effects of vowel type and gender on the aerodynamic aspects of anticipatory nasal airflow, a significant vowel height by gender interaction was found for only the ratio of nasal to oral-plus-nasal airflow volume. Women showed greater ratio than men on high vowels, and no difference was found between boys and girls. These findings suggest that women produced /i/ with greater oral cavity impedance than men, thus, more air is redirected toward the nasal cavity. A similar interaction was found by Young et al. (2001) who reported that when compared to men, women exhibited increased nasal to oral-plus-nasal airflow ratios and reduced oral airflow at the midpoint of the first vowel in /ini/.

With regard to carryover nasal airflow, there were no significant gender differences for both the absolute and proportional duration. However, all speakers regardless of age and gender produced longer absolute and proportional duration of carryover nasal airflow in low vowel contexts. All speakers regardless of age and gender exhibited greater absolute nasal airflow volume on high vowels as compared to low vowels, but women more than men produced the second vowel in /ini/ with increased ratio of nasal to oral-plus-nasal flow which suggests that women also showed greater oral cavity impedance for carryover nasal flow.

The findings of the current study can be attributed to gender differences in in oralpharyngeal anatomy and differences in the production of high and low vowels. McKerns and Bzoch (1970), for example, used videofluoroscopy to suggest that women differed from men relative to the configuration of the VP structures and movement during closure. They further suggested that gender differences may exist in the insertion sites of VP mucles including levator veli palatini, palatoglossus, and palatopharyngeus. 
Moon, Smith, Folkins, Lemke, and Gartlan (1994) suggested that the position of the velum during speech was determined by the relative contributions of the VP muscles rather than a single muscle in isolation. Using electromyographic (EMG) and photodetection techniques, they suggested that palatoglossus and levator functioned as part of a coordinative structure to position the velum during $/ \mathrm{i} /$ but not during $/ \mathrm{a} /$.

Kuehn and Moon (1998) used a sensitive bulb device and Electromyography to measure the VP closure force across various phonetic contexts in adult speakers. They found that male speakers exhibited greater differences across various consonant categories than did the female speakers. They attributed these findings to the possibility that female may have reduced upward velar movement along the posterior pharyngeal wall (McKerns \& Bzoch , 1970) and thus, limited range of velar movement compared to male speakers. McKerns and Bzoch (1970) reported that male speakers elevated their velums an average of $10 \mathrm{~mm}$ above the hard palatal plane compared to an average of 5.5 $\mathrm{mm}$ for female speakers. In addition Zajac and Mayo (1996) found that male speakers achieved peak oral pressure for $/ \mathrm{p} /$ in "hamper" in less time than did female speakers.

It is possible that subtle gender differences in oral-pharyngeal anatomy and ranges of velar movement may interact with vowel-specific differences in muscle coordination might be responsible for the increase of oral cavity impedance for women and the longer duration of nasal airflow in female speakers of the current study.

Studies utilizing aerodynamic method of observation have investigated gender effect on aerodynamic aspects of anticipatory nasal airflow only in adult speakers (Hoit et al., 1994; Zajac et al., 1998). These studies have reported no differences between male and female speakers in the magnitude of anticipatory nasal airflow at the midpoint if the first vowel in /ini/. No temporal measurements were obtained by these studies. The present study provides a more comprehensive picture of how gender affects both temporal as well as aerodynamic aspects of anticipatory and carryover nasal airflow on different vowel heights. The surprising finding in the current study was that gender effect was even present at a young age in a similar pattern, although to a lesser degree than that of adult speakers. Clearly these findings warrant further investigation using more direct methods of observation. Those findings also have clinical implication on how to consider differences between boys and girls in temporal and aerodynamic VP function in various phonetic contexts for the assessment and remediation of deviant speech resonance.

Previous studies investigated the effect of vowel height on the absolute and proportional duration of the acoustic effect of velar coarticulation (Rochet \& Rochet, 1991; Ha \& Kuehn, 2006). These studies did not report any vowel height effect on the temporal aspects of the acoustic signal related to velar coarticulation. The discrepancy between those studies and the current study might be attributed to the fact that those studies did not test the effect of gender along with vowel height and/or the difference in the nature of acoustic and aerodynamic signals. 


\section{Effect of Production Level}

The present study investigated the effect of production level on the temporal and aerodynamic aspects of anticipatory and carryover nasal airflow. The VNV sequences were embedded in two carrier phrases reflecting two production levels: level I refers to the carrier phrase containing "say" prior to the VNV sequence (i.e., "say /ini/ again" and "say /ana/ again"). Level II refers to the carrier phrase without "say' preceding the VNV sequence (i.e., "/ini/ again" and "/ana/ again"). Those two levels of production were suggested to test the prediction of the coproduction model of coarticulation (Fowler, 1980; Fowler \& Saltzman, 1993) which proposes that articulatory gestures are stable and constrained by their inherent spatiotemporal structure. Based on this model, it was hypothesized that the extent of anticipatory nasal flow will be constricted and limited regardless of the number of vowels before the nasal sound.

Results of the study reflected a general pattern for the effect of production level. In most cases, all participants demonstrated shorter duration and decreased volume $(\mathrm{ml})$ of anticipatory nasal airflow during the production of level I (with say) as opposed to level II. These findings support the predictions of Coproduction model in the sense that anticipatory nasal airflow was limited to the vowel directly preceding the nasal sound and was not present during the production of 'say'. These patterns were also similar for the carryover nasal airflow. The findings that children also show a similar pattern of production level effect as adult speakers suggest that they coproduce their articulatory gestures in adult-like fashion though with longer duration.

The findings that the duration and the volume of anticipatory and carryover nasal airflow were reduced during the production of level I as opposed to level II can be attributed to the effect of speaking rate. Even though speakers were instructed to attempt only one utterance on a single breath, the number of syllables per breath differs between level I and II of production ( 5 and 4 respectively). Although the present study did not attempt to study the effect of speaking rate, it might have been responsible for those findings. Kent et al. (1974) noted that speakers may reduce the degree of VP opening at faster speaking rate as a sign of articulatory 'undershoot' to achieve the opening required for $/ \mathrm{n} /$ and the closure for a subsequent oral segment in a timely manner.

\section{Speakers' Variability}

A secondary objective was to determine the within-speaker variability of the temporal and aerodynamic measurements of anticipatory and carryover nasal airflow. All $\mathrm{CV}$ measures decreased in magnitude as a function of increasing age. These findings are consistent with previous acoustic studies (Eguchi \& Hirsh 1969; Tingley \& Allen, 1975; Kent \& Forner, 1980 ; Sereno \& Lieberman, 1987; Smith, 1991; Smith, Kenney \& Hussain, 1996) and articulatory measurements (Watkins \& Fromm, 1984; Sharkey \& Folkins, 1985; Smith \& Mclean-Muse 1985; Smith \& Goffman, 1998).

For example Kent and Forner (1980) reported that 4-year-old children had longer speech segment durations and greater variability of segment durations than adults and 
older children aged 6 and 12 years. In addition Zajac and Hacket (2002) reported that children 6 years of age exhibit longer duration and increased variability than older children and adult speakers on five out of six temporal measures of pressure-flow segments in $/ \mathrm{mp} /$ sequence in the word "hamper". Findings of the current study and other studies suggest that children's speech is characterizes by less stability, decreased rate of speech production and increased variability. As the child grows, these qualities gradually diminish reflecting the improvement occurring with neuromotor maturation.

Findings of the current study also reported greater CVs for male speakers, mostly older boys and men, when compared to female speakers on both temporal and aerodynamic measurement of anticipatory and carryover nasal airflow. The increased variability of male speakers was more evident on high vowel contexts than low vowel contexts. This finding may be attributed to the increased degree of velum upward movement in male speakers and thus varying ranges of velar movements in male speakers compared to female speakers (Mckerns \& Bzoch, 1970).

\section{Clinical and Research Implications}

Results of the current study can provide valuable information for the clinical setting. The assessment of VP function requires normative data to be available to distinguish between normal and deviant patterns of VP movement patterns. The present study provides some values regarding the normal ranges of the volumes of anticipatory and carryover nasal airflow as well as the normal ranges of oral-nasal coupling. In addition, the study also provides normative temporal data related to velar lowering and elevation. These norms were reported for male and female speakers of two children age groups and adult speakers for high and low vowel context.

These temporal and aerodynamic measurements can provide some objective and normative values to help with evaluation and guiding management decisions for many patients with disordered speech resonance; whether it is due to structural anomaly such as cleft palate, muscle weakness resulting from dysarthria or cerebral palsy or any other neuromotor etiology.

It is recommended that the evaluation of speech resonance must include different phonetic contexts, particularly high and low vowels. The study also provides genderspecific norms as it was observed female speakers showed greater duration and volume of nasal airflow than male speakers on high vowel contexts. The degree of the difference, however, varied across age groups with adult speakers exhibiting the greatest difference. These gender-specific norms will facilitate diagnosis and treatment decisions. For example, Kuehn (1991) has described a treatment technique that aims to strengthen the velopharyngeal musculature by providing continuing positive airway pressure (CPAP) through the nose while the patient is producing some speech tasks that involve lowering and elevation the velum. The key assumption behind this approach is that systematic exercises can increase the velocity and force of velar movement. Based on the finding that female speakers exhibited increased duration and volume of nasal airflow than male 
speakers it is recommended that in order to achieve the treatment objectives, female patients may need longer training periods and a higher level of positive air pressure than male patients to counteract their increased nasal flow volume.

The finding that younger children exhibited specific temporal and aerodynamic aspects of anticipatory nasal airflow segments can be used to guide treatment decisions for young children with repaired cleft palate who exhibit marginal VP dysfunction. A wait-and-see strategy may be appropriate if the child exhibits marginal VP dysfunction but with adequate VP closure and timing parameters are within age limit. This recommendation is based assuming that the primary surgery has optimized VP movement capabilities and the residual perceptual symptoms are related to the developmental aspects of segmental control.

An idea for future research is to replicate this study to collect normative data from a much larger sample size, wider age range and more regional dialects. The present study included limited speech tasks. Future research should add more speech samples to include more vowels and consonants with varied place and manner of articulation. For example, sustained vowels and sequences such as VCNV, VNCV, and VCV can be useful to study the normal ranges of temporal and aerodynamic aspects of VP function in various phonetic contexts.

Speech samples of the current study consisted of nonsense syllables. Future research should include language elements in the study of velar movement patterns and timing. Such study can be easier to conduct especially with young children as it is difficult to train them to produce the nonsense syllable without them imposing the linguistic stress. Including a linguistic item can help to compare VP movement and timing patterns during the production of words vs. nonsense syllable. If no difference was found, it can add to the validity of using nonsense syllable in research as well as clinical setting. In the current study, we have attempted to test the difference between producing nonsense syllables and real words on only two children. After collecting their speech samples, they were shown a picture of a girl called "Ana" and another picture of a dog called "Ini" (see Appendix D). Their speech samples were taken one more time after they were shown the pictures, no difference was found for both the duration and volume of nasal airflow between the nonsense syllable and the names.

The present study investigated certain temporal and aerodynamic parameters of VP coarticulation in speakers with normal hearing. Numerous studies reported that severe to profound hearing loss is often associated with hypernasality (e.g., Fletcher and Daly, 1976; Lapine, Stewart \&Tatchel, 1991). The high degree of nasality usually identified with speech of the deaf has generally been attributed to a limited ability to monitor and control the velopharyngeal valve auditorily. Ysunza and Vazquez (1993) found that velopharyngeal closure patterns and electromyographic activity of velopharyngeal muscles were similar for both normal hearing and hearing impaired groups. They did note, however, that the subjects' velopharyngeal activity lacked "rhythm and strength." These observations were taken as evidence that subjects with hearing impairments may 
present a functional disorder of the velopharyngeal valve related to absence of auditory regulation during phonation.

Other studies attributed the increased perception of nasality associated with the speech of individual with hearing impairments to the bizarre patterns of misarticulation, abnormal vocal pitch, and speech tempo irregularities that are part of the speech pattern (Stevens, Nickerson, Boothroyd \& Rollins, 1976; Fletcher \& Higgins, 1980). Future studies should provide a thorough description of various aspects of pressure-flow events in the speech of individuals with hearing impairments including hearing aid users and those fitted with cochlear implants. Possible differences may suggest specific pressureflow patterns for individuals with hearing impairments. Pressure-flow technique can then be tested as a possible useful visual feedback tool for the modification of abnormal speech resonance in individuals with hearing loss.

\section{Conclusions}

Findings of the present study along with several acoustic and kinematic studies have investigated the emerging speech patterns of children (e.g., Smith, 1978, Sharkey and Folkins, 1985; Nittrouer, 1993; Smith \& Goffman, 1998) arrived at the conclusion that increase in rate of speech production and decrease in variability with increasing age are general patterns in speech development and evidence of the improvement and maturation of neuromotor control.

The current study provides aerodynamic data related to velar coarticulation to support predictions of coproduction model regarding the extent of anticipatory coarticulation and predictions of gestural phonology on the nature of speech production units and the development of adult-like speech patterns. 


\section{LIST OF REFERENCES}

Al-Bamerni, A. (1983). Oral, velic and laryngeal coarticulation across languages. Unpublished doctoral dissertation, Oxford University.

Bauman-Waengler, J. (2000). Articulation and Phonological Impairment: A Clinical Focus. Needham Heights, MA: Allyn \& Bacon.

Beddor, P. S. (1993). Perception of nasal vowels. In M. K. Huffman, \& R. A. Krakow (Eds.), Phonetics and Phonology: Vol. 5: Nasals, Nasalization and the Velum (pp. 171-196). New York: Academic Press.

Bell-Berti, F. (1973).The velopharyngeal mechanism: An electromyographic study. Haskins Laboratories Status Report on Speech Research (Supplement), 117129.

Bell-Berti, F. (1976). An electromyographic study of velopharyngeal function in speech. Journal of Speech and Hearing Research, 19, 225-240.

Bell-Berti, F. (1980). A spatial-temporal model of velopharyngeal function. In N. J. Lass (Ed.), Speech and Language: Advances in Basic Research Practice (Vol. 4, pp. 291-316). New York: Academic Press.

Bell-Berti, F. (1993). Veli motor control: Segmental context. In M. K. Huffman, \& R. A. Krakow (Eds.), Phonetics and Phonology: Vol. 5: Nasals, Nasalization and the Velum (pp. 63-85). New York: Academic Press.

Bell-Berti, F., \& Baer, T. (1983). Velar position, port size, and vowel spectra. Proceedings of the $11^{\text {th }}$ International Congress on Acoustics, 4, 19-21.

Bell-Berti, F., Baer, T., Harris, K. S., \& Niimi, S. (1979). Coarticulatory effects of vowel quality on velar fusion. Phonetica, 36, 187-193.

Bell-Berti, F., \& Harris, K. (1979). Anticipatory coarticulation: Some implications from a study of lip rounding. Journal of the Acoustical Society of America, 65, 12681270 .

Bell-Berti, F., \& Harris, K. (1981). A temporal model of speech production. Phonetica. $38,9-20$.

Bell-Berti, F., \& Harris, K. (1982). Temporal patterns of coarticulation: Lip rounding. Journal of the Acoustical Society of America, 71, 449-454.

Bell-Berti, F., \& Krakow, R. (1991). Anticipatory velar lowering: A coproduction account. Journal of the Acoustical Society of America, 90, 112-123. 
Bell-Berti, F., Krakow, R., Gelfer, C., \& Boyce, S. (1995) Anticipatory and carryover effects: Implications for models of speech production. In F. Bell-Berti \& L. J. Raphael (Eds.), Producing Speech: Contemporary Issues: for Katherine Safford Harris (pp. 77-97). College Park, MD: American Institute of Physics.

Benguerel, A.P., \& Cowan, H. (1974). Coarticulation of upper lip protrusion in French. Phonetica, 30, 41-55.

Benguerel, A. P., \& Lafargue, A. (1981). Perception of vowel nasalization in French. Journal of Phonetics, 9, 309-321.

Browman, C., \& Goldstein, L. (1986). Towards an articulatory phonology. Phonological Yearbook, 3, 219-252.

Browman, C., \& Goldstein, L. (1989). Articulatory gestures as phonological units. Phonology, 6, 201-251.

Chomsky, N., \& Halle, M. (1968). The Sound Pattern of English. New York: Harper and Row.

Clumeck, H. (1976). Patterns of soft palate movements in six languages. Journal of Phonetics, 4, 337-351.

Dalston, R. M., \& Warren, D. W. (1986). Comparison of Tonar II, pressure-flow, and listener judgments of hypemasality in the assessment of velopharyngeal function. Cleft Palate Journal, 23, 108-115.

Daniloff, R., \& Hammarberg, R. (1973). On defining coarticulation. Journal of Phonetics, 1, 239-248.

Daniloff, R., \& Moll, K. L. (1968). Coarticulation of lip rounding. Journal of Speech and Hearing Research, 11, 707-721.

Eguchi, S., \& Hirsh, I. J. (1969). Development of speech sounds in children. Acta Otolaryngologica, 257 (Supplement), 30-43.

Fant, G. (1960). Acoustic Theory of Speech Production. The Hague: Mouton.

Farnetani, E., \& Recasens, D. (1999). Coarticulation models in recent speech production theories. In W. J. Hardcastle \& N. Hewlett (Eds.), Coarticulation: Theory, Data, and Techniques (pp. 31-80). Cambridge: University Press.

Flege, J. (1988). Anticipatory and carry-over nasal coarticulation in the speech of children and adults. Journal of Speech and Hearing Research 31, 525- 536. 
Fletcher, S. G., \& Daly, D. A. (1976). Nasalance in utterances of hearing-impaired speakers. Journal of Communication Disorders, 9, 63-73.

Fletcher, S. G., \& Higgins, J. M. (1980). Performance of children with severe to profound auditory impairment in instrumentally guided reduction of nasal resonance. Journal of Speech and Hearing Disorders, 45, 181-194.

Fowler, C. (1980). Coarticulation and theories of extrinsic timing. Journal of Phonetics, $8,113-133$.

Fowler, C. (1992). Phonological and articulatory characteristics of spoken language. Haskins Laboratories Status Report on Speech Research SR-10911, 10, 1-12.

Fowler, C., Rubin, P., Remez, R., \& Turvey, M. (1980). Implications for speech production of a general theory of action. In B. Butterworth (Ed.), Language Production (pp. 371-420). London: Academic Press.

Fowler, C., \& Saltzman, E. (1993). Coordination and coarticulation in speech production. Language and Speech, 36, 171-195.

Fritzell, B. (1969). A combined electromyographic and cineradiographic study: Activity of the levator and palatoglossus muscles in relation to velar movements. Acta Oto-Laryngologica, 250 (Supplement), 50-68.

Goodell, E. W., \& Studdert-Kennedy, M. (1993). Acoustic evidence for the development of gestural coordination in the speech of 2-year-olds: A longitudinal study. Journal of Speech and Hearing Research, 36, 707-727.

Ha, S., \& Kuehn, D. (2006). Temporal characteristics of nasalization in children and adult speakers of American English and Korean during production of three vowel contexts. Journal of Acoustical Society of America, 120, 1622-1630.

Ha, S., Sim, H., Zhi, M., \& Kuehn, D. P. (2004). An acoustic study of the temporal characteristics of nasalization in children with and without cleft palate. Cleft Palate Craniofacial Journal. 41(5), 535-543.

Hajek, J. (1997). Universals of Sound Change in Nasalization. Boston: Blackwell Publishers.

Hammarberg, R. (1976). The metaphysics of coarticulation. Journal of Phonetics, 4, 353363.

Henderson, J. (1984). Velopharyngeal function in oral and nasal vowels. A crosslanguage study. Unpublished doctoral dissertation, University of Connecticut. 
Henke, W. (1966). Dynamic articulatory model of speech production using computer simulation. Unpublished doctoral dissertation, Massachusetts Institute of Technology.

Hodge, M. (1989). A comparison of spectral-temporal measures across speaker age: Implications for an acoustic characterization of speech maturation. Unpublished doctoral dissertation, University of Wisconson-Madison.

Hoit, J. D., Watson, P. J., Hixon, K. E., McMahon, P., \& Johnson, C. L. (1994). Age and velopharyngeal function during speech production. Journal of Speech and Hearing Research, 37, 295-302.

House, A. S., \& Stevens, K. N. (1956). Analog studies of the nasalization of vowels. Journal of Speech and Hearing Disorders, 21, 218-232.

Jakobson, R., Fant, G., \& Halle, M. (1952). Preliminaries to Speech Analysis: the Distinctive Features and Their Correlates. Cambridge: MIT Press.

Katz, W. F., \& Bharadwja, S. (2001). Coarticulation in fricative-vowel syllables produced by children and adults: A preliminary report. Clinical Linguistics and Phonetics, 15, 139-143.

Katz, W. F., Kripke, C., \& Tallal, P. (1991). Anticipatory coarticulation in the speech of adults and young children: Acoustic, perceptual, and video data. Journal of Speech and Hearing Research, 34, 1222-1232.

Kelso, J. A., Tuller, B., Vatikiotis-Bateson, E., \& Fowler, C. A. (1984). Functionally specific articulatory cooperation following jaw perturbations during speech: Evidence for coordinative structures. Journal of Experimental Psychology: Human Perception and Performance, 10, 812-832.

Kent, R. (1983). The segmental organization of speech. In P. MacNeilage (Ed.), The Production of Speech (pp. 57-89). New York: Springer-Verlag.

Kent, R. D., \& Forner, L, L. (1980). Speech segment durations in sentence recitations by children and adults. Journal of Phonetics, 8, 157-168.

Kent, R. D., Carney, P. J., \& Severeid, L. R. (1974). Velar movement and timing: Evaluation of a model for binary control. Journal of Speech and Hearing Research, 17, 470-488.

Kent, R., \& Minifie, F. (1977). Coarticulation in recent speech production models. Journal of Phonetics 5, 115-133. 
Khwaileh, F., \& Ha, S. (2008, November). Temporal aspects of aerodynamic segments of velopharyngeal coarticulation in children and adults. Technical paper presentation at the Annual Convention of the American Speech-LanguageHearing Association (ASHA), Chicago, IL.

Kuehn, D. P. (1976). A cineradiographic investigation of velar movement variables in two normals. Cleft Palate Journal, 13, 88-103.

Kuehn, D. P. (1991). New therapy for treating hypernasal speech using continuous positive airway pressure (CPAP). Plastic and Reconstructive Surgery, 88, 959966.

Kuehn, D. P., \& Moon, J. B. (1998). Velopharyngeal closure force and levator veli palatini activation levels in varying phonetic contexts. Journal of Speech, Language, and Hearing Research, 41, 51-62.

Lapine, P. R., Stewart, M. G., \& Tatchell, J. (1991). Application of nasometry to speech samples of hearing-impaired children. Perceptual and Motor Skills, 73, 467475.

Leeper, H. A., Tissington, M. L., \& Munhall, K. G. (1998). Temporal characteristics of velopharyngeal function in children. Cleft Palate-Craniofacial Journal. 35, 215-221.

Locke, J. L. (1983). Phonological acquisition and change. New York: Academic Press.

Locke, J. L. (1986). The linguistic significance of babbling. In B. Lindblom, \& R. Zetterstrom (Eds.), Precursors of Early Speech (pp. 143-160). New York: Stockton Press.

Lubker, J. F. (1968). An electromyographic-cinefluorographic investigation of velar function during normal speech production. Cleft-Palate Journal, 5, 1-18.

Lubker, J. F., \& Moll, K. L. (1965). Simultaneous oral-nasal air flow measurements and cinefluorographic observations during speech production. Cleft Palate Journal, 2, 257-272.

Maeda, S. (1993). Acoustics of vowel nasalization and articulatory shifts in French nasal vowels. In M. K. Huffman, \& R. A. Krakow (Eds.), Phonetics and Phonology: Vol. 5: Nasals, Nasalization and the Velum (pp. 147-167). New York: Academic Press.

MacNeilage, P. F. (1998). The frame/content theory of evolution of speech production, Behavioral and Brain Sciences, 21, 499-546. 
MacNeilage, P. F., \& DeClerk, J. L. (1969) On the motor control of coarticulation in CVC monosyllables. Journal of the Acoustical Society of America, 45, 1217 1233.

McKerns, D., \& Bzoch, K. R. (1970). Variations in velopharyngeal valving: The factor of sex. Cleft Palate Journal, 7, 652-662.

Moll, K. (1962). Velopharyngeal closure in vowels. Journal of Speech and Hearing Research, 5, 30-37.

Moll, K., \& Daniloff, R. G. (1971). An investigation of the timing of velar movements during speech. Journal of the Acoustical Society of America, 50, 678-684.

Moll, K. L., \& Shriner, T. H. (1967). Preliminary investigation of a new concept of velar activity during speech. Cleft Palate Journal, 4, 58-69.

Moon, J. B., Khehn, D. P., \& Huisman, J.J. (1994). Measurement of velopharyngeal closure force during vowel production. Cleft Palate-Craniofacial Journal, 31, 356-363.

Netsell, R., Lotz, W. K., Peters, J. E., \& Schulte, L. (1994). Developmental patterns of laryngeal and respiratory function for speech production. Journal of Voice, 8, $123-131$.

Nittrouer, S., Studdert-Kennedy, M., \& McGowan, R. S. (1989). The emergence of phonetic segments: Evidence from the spectral structure of fricative-vowel syllables spoken by children and adults. Journal of Speech and Hearing Research, 32, 120-132.

Nittrouer, S., \& Whalen, D. H. (1989). The perceptual effects of child-adult differences in fricative-vowel coarticulation. Journal of the Acoustic Society of America, 86, 1266-1276.

Ohala, J. J. (1971). Monitoring soft palate movements in speech, Vol. 2. Berkeley: Project on Linguistic Analysis, University of California (pp. 13-27).

Ohala, J. J. (1975). Phonetic explanations for nasal sound patterns. In C. Ferguson, L. Hyman, \& J. J. Ohala (Eds.), Nasalfest: Papers from a Symposium on Nasals and Nasalization (pp. 289-316). Department of Linguistics, Stanford University.

PERCI-SARS (Version 3.43) [Computer software]. Chapel Hill, NC: Microtronics, Inc.

Repp, B. H. (1986). Some observations on the development of anticipatory coarticulation. Journal of the Acoustic Society of America, 79, 1616-1619. 
Rochet, A.P., \& Rochet, B. L. (1991). The effect of vowel height on patterns of assimilation nasality in French and English. Proceedings 12th International Congress of Phonetic Science, Aix-en-Provence, Vol.3, 54-57.

Saltzman, E., \& Munhall, K. (1989). A dynamical approach to gestural patterning in speech production. Ecological Psychology, 1, 333-382.

Seaver, E. J., Dalston, R. M., Leeper, H. A., \& Adams, L. E. (1991). A study of nasometric values for normal nasal resonance. Journal of Speech and Hearing Research, 34, 715-721.

Sereno, J. A., Baum, S. R., Marean, G. C., \& Lieberman, P. (1987). Acoustic analyses and perceptual data on anticipatory labial coarticulation in adults and children. Journal of the Acoustic Society of America, 81, 512-519.

Sereno, J. A., \& Lieberman, P. (1987). Developmental aspects of lingual coarticulation. Journal of Phonetics, 15, 247-257.

Sharkey, S. G., \& Folkins, J. W. (1985). Variability of lip and jaw movements in children and adults: Implications for the development of speech motor control. Journal of Speech and Hearing Research, 28, 8-15.

Smit, A. B., Hand, L., Frelinger, J. J., Bernthal, J. E., \& Bird, A. (1990). The Iowa articulation norms project and its Nebraska replication. Journal of Speech and Hearing Disorders, 55, 779-798.

Smith, B. L. (1991). Relationships between duration and temporal variability in children's speech. Journal of the Acoustical Society of America, 91, 2165-2174.

Smith, A., \& Goffman, L. (1998). Stability and patterning of speech movement in children and adult. Journal of Speech, Language, and Hearing Research, 41, 18-30.

Smith, B. L., \& McLean-Muse, A. (1986). Articulatory movement characteristics of labial consonant productions by children. Journal of the Acoustical Society of America, 80, 1321-1327.

Smith, B.L., Kenney, M. K., \& Hussain S. (1996). A longitudinal investigation of duration and temporal variability in children's speech production. Journal of the Acoustical Society of America, 99, 2344-2349.

Stathopoulos, E. T., \& Weismer, G. (1985). Oral airflow and intraoral air pressure: A comparative study of children, youths, and adults. Folia Phoniatrica, 37, 152159. 
Stathopoulos, E. T., \& Sapienza, C. M. (1997). Developmental changes in laryngeal and respiratory function with variations in sound pressure level. Journal of Speech, Language, and Hearing Research, 40, 595-614.

Stevens, K. (1998). Acoustic Phonetics. Cambridge: MIT Press.

Stevens, K. N., Fant, G., \& Hawkins, S. (1987). Some acoustical and perceptual characteristics of nasal vowels. In R. Channon, \& L. Shockey (Eds.), In Honour of Ilse Lehiste (pp. 241-254). Dordrecht, Holland: Foris.

Stevens, K. N., Nickerson, R. S., Boothroyd, A., \& Rollins, A. M. (1976). Assessment of nasalization in the speech of deaf children. Journal of Speech and Hearing Research, 19, 393-416.

Studdert-Kennedy, M. (1987). The phoneme as a perceptuomotor structure. In A. Allport, D. MacKay, W. Prinz \& E. Scheerer (Eds.), Language Perception and Production (pp. 67-84). London: Academic Press.

Sussman, J. E. (1995). HONC measures in men and women: Validity and variability. Cleft Palate-Craniofacial Journal, 32, 37-48.

Thompson, A., \& Hixon, T. (1979). Nasal air flow during normal speech production. Cleft Palate Journal, 16, 412-420.

Tingly, B., \& Allen, G. (1975). Development of speech timing control in children. Child Development, 46, 186-194.

Turnbaugh, K. R., Hoffman, P. R., \& Daniloff, R. G. (1985). Stop-vowel coarticulation in 3-year-old, 5-year-old, and adult speakers. Journal of the Acoustic Society of America, 77, 1256-1257.

Ushijima, T., \& Sawashima, M. (1972). Fiberscopic observation of velar movements during speech. Annual Bulletin of the Research Institute of Logopedics and Phoniatrics, 6, 25-38.

Vihman, M. M. (1991). Ontogeny of phonetic gestures: Speech production. In I. G. Mattingly, \& M. Studdert-Kennedy (Eds), Modularity and the Motor Theory of Speech Perception: Proceedings of a Conference to Honor Alvin M. Liberman (pp. 69-84). Hillsdale, NJ: Lawrence Erlbaum Associates.

Vihman, M. M, Macken, M. A., Miller, R. Simmons, H., \& Miller, J. (1985). From babbling to speech: A re-assessment of the continuity issue. Language, 61, 397445.

Warren, D. W. (1979). Perci: A method for rating palatal efficiency. Cleft Palate Journal, 16, 279-285. 
Warren, D. W. (1984). A quantitative technique for assessing nasal airway impairment. American Journal of Orthodontics, 86, 306-314.

Warren, D. W., Dalston, R. M., \& Mayo, R. (1993). Hypernasality in the presence of "adequate" velopharyngeal closure. Cleft Palate-Craniofacial Journal, 30, 150154.

Warren, D. W., Dalston, R. M., Morr, K. E., Hairfield, W. M., \& Smith, L. R. (1989). The speech regulating system: Temporal and aerodynamic responses to velopharyngeal inadequacy. Journal of Speech and Hearing Research, 32, 566575.

Warren, D. W., \& DuBois, A. B. (1964). A pressure-flow technique for measuring velopharyngeal orifice area during continuous speech. Cleft Palate Journal, 1, $52-71$.

Watkins, K. L., \& Fromm, D. (1984). Labial coordination in children: Preliminary considerations. Journal of the Acoustical Society of America, 72, 629-632.

Young, L. H., Zajac, D. J., Mayo, R., \& Hooper, C. R. (2001). Effects of vowel height and vocal intensity on anticipatory nasal airflow in individuals with normal speech. Journal of Speech, Language and Hearing Research, 44, 52-60.

Ysunza, A., \& Vazquez, M. C. (1993). Velopharyngeal sphincter physiology in deaf individuals. Cleft Palate-Craniofacial Journal, 30, 141-143.

Zajac, D. J. (1997). Velopharyngeal function in young and older adult speakers: Evidence from aerodynamic studies. Journal of the Acoustical Society of America, 102, 1846-1852.

Zajac, D. J. (2000). Pressure-Flow Characteristics of $/ \mathrm{m} /$ and $/ \mathrm{p} /$ production in speakers without cleft palate: Developmental findings. Cleft Palate-Craniofacial Journal, 37, 469-477.

Zajac, D. J., \& Mayo, R. (1996). Aerodynamic and temporal aspects of velopharyngeal function in normal speakers. Journal of Speech and Hearing Research, 39, 1199-1207.

Zajac, D. J., Mayo, R., \& Kataoka, R. (1998). Nasal coarticulation in normal speakers: Are-examination of the effects of gender. Journal of Speech, Language, and Hearing Research, 41,503-510. 


\title{
APPENDIX A. CONSENT FORM
}

\section{Temporal and Aerodynamic Aspects of Velopharyngeal Coarticulation: Effects of Age, Gender and Vowel Height}

\author{
Principal Investigator: Fadwa Khwaileh, MA \\ Department of Audiology and Speech Pathology \\ 578 S. Stadium Hall \\ University of Tennessee \\ Knoxville, TN 37996-0740
}

Co-Investigator: $\quad$ Molly Erickson, Ph.D. (Faculty Advisor)

\section{INTRODUCTION:}

In this consent form, the word "you" means you and/or your child.

You are being given the opportunity to participate in this research study. Research studies include only people who choose to take part. Please read this consent form carefully and take your time making your decision. As your study doctor or study staff discusses this consent form with you, please ask him/her to explain any words or information that you do not clearly understand. We encourage you to talk with your family and friends before you decide to take part in this research study. The nature of the study, risks, inconveniences, discomforts, and other important information about the study are listed below. study.

Please tell the principal investigator if you are taking part in another research

The purpose of this study is to investigate whether certain aspects of timing and qualities of airflow related to speech production will change as children grow and whether these aspects differ between male and female speakers. Approximately 60 subjects with normal speech, language and hearing will be participating in this study. They will be divided into 3 age groups; 20 adult speakers (18+ years), 20 older children (9-11 years), and younger children (5-7 years). Each group will have equal gender distribution. All subjects will be participating locally.

The study will take place at the Cleft Palate Speech Science Lab at the Department of Audiology and Speech Pathology of The University of Tennessee, Room 435 South Stadium Hall, Knoxville, TN 37996.

Your participation in this study will last for one visit and will take a maximum of 1 hour. It is not anticipated that you will need to return for another session, unless 
deemed necessary by extenuating circumstances (i.e., computer issues, fatigue, or any other disruptive occurrences that may negatively impact the study).

\section{PROCEDURES TO BE FOLLOWED:}

All procedures are being completed for research purposes only. If you agree to participate in the study, you will be asked to complete a background information form. This form will contain identifying information, general health, racial/ethnic background, and speech, language and hearing history. All information on this form will remain confidential.

If you agree to participate in the study, the following procedures will occur:

- You will undergo visual examination of the oral cavity performed by the principal investigator to rule out undetected submucous cleft palate.

- You will be asked to practice certain speech tasks, "Say ini again" and "Say ana again", before we start recording your speech

- You will be wearing a special mask that collects air from your mouth and nose separately as you speak.

- A microphone will also be used to collect your voice signal as you speak. The microphone will be placed approximately five inches from your mouth.

- After the mask is correctly placed onto our mouth and nose and you are ready to speak, you will be asked to produce each speech task three times on one breath.

- To make sure that you don't forget the speech tasks, you will be asked to repeat after the principal investigator.

- It will take about 30 minutes to practice and record your speech sample.

- The mask will be cleaned and disinfected before and after each use.

\section{RISKS ASSOCIATED WITH PARTICIPATION:}

The procedures of recording oral and nasal airflow during speech production does not give rise to any physical, psychological, social, legal, or physiological risks. There may be unforeseen risks. The flow mask will be cleaned and disinfected before and after being placed on each participant. You may experience discomfort when you practice and record the speech task. If you appeal any discomfort during the procedure, you can stop participating in the study at any time. 
Some of the questions we will ask you as part of this study may make you feel uncomfortable. You may refuse to answer any of the questions and you may take a break at any time during the study.

Having your voice recorded may make your feel uncomfortable. You may take a break during any time of the study. There is also a potential risk of loss of confidentiality as someone who listens to your audio recording might identify you. Every effort will be made to keep your information confidential; however, this cannot be guaranteed. The investigator will keep you apprised of any new information that may affect your willingness to continue participation.

\section{BENEFITS ASSOCIATED WITH PARTICIPATION:}

There are no direct benefits to you. The study will contribute to our understanding about developmental patterns of speech motor control and coarticulation. The study may also provide a benefit of improved objective assessment of disordered speech resonance. The decision to participate in this study is strictly voluntary. You are free to withdraw from the study at any time for any reason. Your decision to participate, decline, or withdraw from participation will have no effect on your relationship with the University of Tennessee.

\section{ALTERNATIVES TO PARTICIPATION:}

You do not have to take part in this study if you do not want to. Your participation or non-participation in this project will in no way affect any future treatment or services you seek in any department at any time.

\section{CONFIDENTIALITY:}

All your paper research records will be stored in locked file cabinets and will be accessible only to research personnel. All your electronic research records will be computer password protected and accessible only to research personnel.

Your research records and computer files will be labeled with a code. A master key that links your name with the codes on your files will be maintained in a locked file cabinet at the local investigation site.

Under federal privacy regulations, you have the right to determine who has access to your personal health information (called "protected health information" or PHI). PHI collected in this study may include your speech airflow patterns. By signing this consent form, you are authorizing the researchers at the University of Tennessee to have access to your PHI collected in this study. Your PHI will not be used or disclosed to any other person or entity, except as required by law, or for authorized oversight of this research study by other regulatory agencies, or for other research for which the use and disclosure 
of your PHI has been approved by the IRB. Your PHI will be used only for the research purposes described in the Introduction of this consent form. Your PHI will be used until the study is completed.

You may cancel this authorization in writing at any time by contacting the principal investigator listed on the first page of the consent form. If you cancel the authorization, continued use of your PHI is permitted if it was obtained before the cancellation and its use is necessary in completing the research. However, PHI collected after your cancellation may not be used in the study. If you refuse to provide this authorization, you will not be able to participate in the research study. If you cancel the authorization, then you will be withdrawn from the study. Finally, the federal regulations allow you to obtain access to your PHI collected or used in this study.

You will not be identified in any presentations or publications based on the results of this research study.

\section{COMPENSATION AND TREATMENT FOR INJURY:}

You are not waiving any legal rights or releasing the University of Tennessee or its agents from liability for negligence. In the event of physical injury resulting from research procedures, the University of Tennessee does not have funds budgeted for compensation either for lost wages or for medical treatment. Therefore, the University of Tennessee does not provide for treatment or reimbursement for such injuries.

If you suffer a research related injury, your principal investigator will provide acute medical treatment and will provide you with a subsequent referral to appropriate healthcare facilities. You and/or your insurance carrier will be billed for the costs associated with the medical treatment of a research related injury. You and/or your insurance carrier will be billed for the costs associated with the medical treatment of a research related injury.

\section{QUESTIONS:}

If you have any questions about this research study you may contact Fadwa Khwaileh at fkhwaile@utk.edu or 865-228-1741 or Dr. Molly Erickson at merickso@utk.edu or 865-974-9895

In the event of a research related injury, contact Fadwa Khwaileh at 865-2281741 (cell phone).

You may contact Dr. Terrence F. Ackerman, Ph.D., UTHSC IRB Chairman at 901-448-4824 if you have any questions about your rights as a participant in this study or your rights as a research subject. 


\section{PAYMENT FOR PARTICIPATION:}

Adult subjects will not be paid for taking part in the study. However children will be paid $\$ 5$ for their participation.

\section{COSTS OF PARTICIPATION:}

There are no expected costs for taking part in the study. Also, you will be offered free parking on campus for the duration of the research study.

\section{PREMATURE TERMINATION:}

There are no expected safety reasons to end this study by the investigators without regard to your consent. However, should you feel discomfort or express the wish to end participation; you may withdraw from the study at any time.

You will also be notified if new information becomes available about the risks or benefits of this research. Then you can decide if you want to stay in this study. In addition, your participation in this study may be terminated by the investigator without regard to your consent if you do not meet all the inclusion criteria for participation.

\section{VOLUNTARY PARTICIPATION:}

Your participation in this research study is voluntary and your refusal to participate or your decision to withdraw will involve no penalty or loss of benefits to which you are otherwise entitled.

If you are a student, your participating or not participating in this study will in no way influence your grade in any course. If you are an employee of the university, your participating or not participating will not affect your employment status. In addition, any information that you have already provided will be kept in a confidential manner. 


\section{CONSENT OF SUBJECT:}

You have read a description of the research study as outlined above. The investigator or his/her representative has explained the study to you and has answered all the questions you have at this time. You knowingly and freely choose to participate in the study. A copy of this consent form will be given to you for your records.

Signature of Research Subject

Printed Name of Research Subject

\section{Date Time}

Signature of Person Obtaining Consent

Date Time

\section{Printed Name of Person Obtaining Consent}

In my judgment, the subject or the legally authorized representative has voluntarily and knowingly given informed consent and possesses the legal capacity to give informed consent to participate in this research study.

Signature of Investigator

Signature of Legally Authorized Representative

$\overline{\text { Relationship of Legally Authorized Representative }}$
Date Time

Date Time

Assent of Minor (Ages 14-17)

Date Time




\section{APPENDIX B. CHILD ASSENT}

To be used with children aged 8 years and older.

\section{Title: Temporal and Aerodynamic Aspects of Velopharyngeal Coarticulation: Effects of Age, Gender and Vowel Height}

\section{Examiner Script:}

I am a graduate student in the department of Audiology and Speech Pathology in the University of Tennessee. You are invited to take part in a study about sounds from your mouth and nose. The purpose of the study is to see whether your sounds and airflow from the mouth and nose are different from those of grownups. You will be asked to repeat speech sounds after me. You can practice the speech sounds before we record them. It will take about thirty minutes for you to practice and record the speech sounds.

There is nothing that will hurt you. We will place this special mask on your mouth and nose that you will talk into (show mask).

You will receive \$ 10 for your participation when you finish this study. questions?

You can ask me any questions before we start or at any time. Do you have any

Would you like to repeat the speech tasks and talk into this mask?

You can say "Yes, I'd like to do," or "No, I don't want to do." Although you say "yes," you can change your mind and decide to stop at any time. You only have to say, "I want to stop." We will stop immediately. 


\section{APPENDIX C. SUBJECT BACKGROUND FORM}

\section{Subject Personal Information (All information will remain Confidential)}

\section{Personal Identification}

Name

Date of Birth

Place of Birth

Address

Phone \# (

Which one of the following best describes your racial/ethnic background?
a. White
b. African American
c. Hispanic
d. Asian
e. Native-American
f. Pacific-Islander
g. Other (specify)

\section{Medical, Speech, Language and Hearing History}

Have you ever had a history of hearing loss?

Have you ever had speech problems (voice, stuttering)?

Have you ever had breathing problems (Asthma, COPD)?

Have you ever been treated by a Speech-Language Pathologist and/ or an ENT?

Have you ever had a throat, nose surgery, tonsillectomy, adenoidectomy?

Have you ever had a broken nose or jaw? 


\section{Current Health Status}

Do you currently have allergies, nasal congestion or sinus problems?

Do you currently have a cold or an upper respiratory infection?

Do you currently have breathing problems?

Do you have any other medical problems?

Printed Name

Signature 
APPENDIX D. LANGUAGE ITEMS

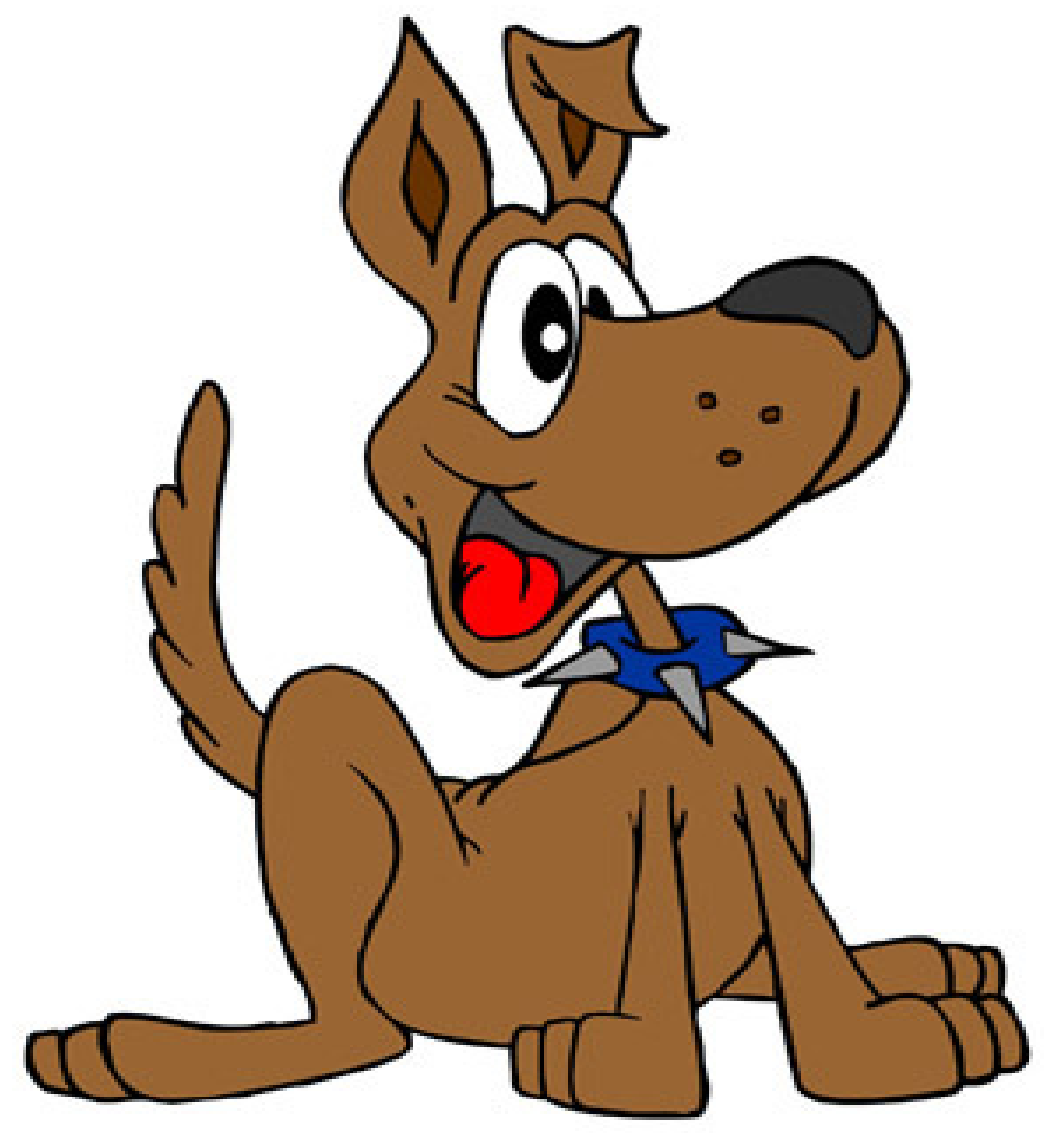

Meet our dog

His name is ini 


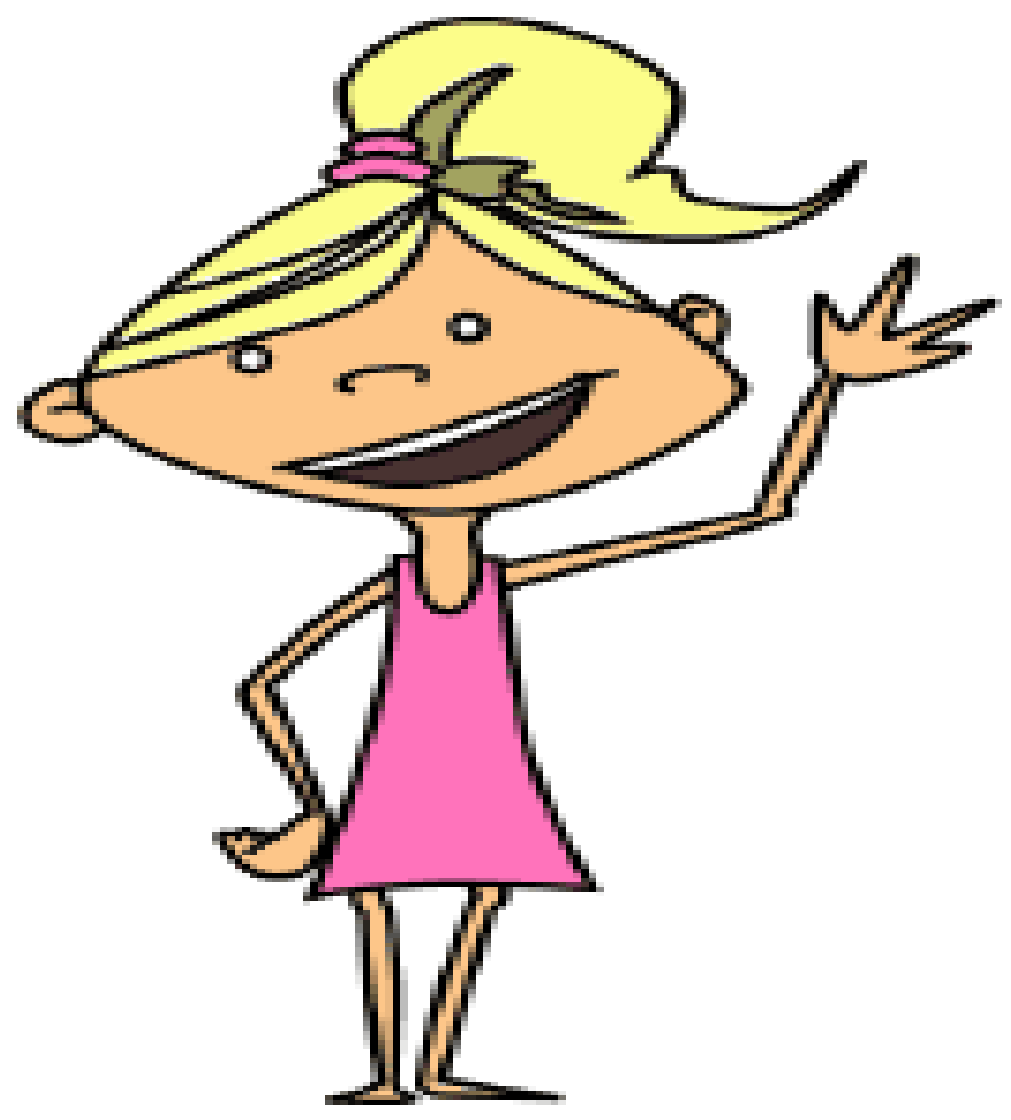

Hi, my name is

ana 


\section{VITA}

Fadwa Khwaileh was born in Jordan in 1978. She received her Bachelor in English Language and Literature from Yarmouk University, Jordan in 2000, and Master degree in Linguistics in 2005 from the same educational institution. She worked as a teacher of English as a second language at the Model School in Yarmouk University between 2002 and 2005. Fadwa Khwaileh enrolled at The University of Tennessee in August, 2006 to pursue a doctoral degree in Speech and Hearing Science. Her doctoral degree was received in May 2011. The author is a member of the American Speech and Hearing Association. The Author has one publication and six posters and presentations. She is married to Ali Al-Nadi and has two sons, Jawad and Abraham. 